\title{
Fair enough?
}

Central and East European migrants in low-wage employment in the UK Bridget Anderson, Martin Ruhs, Ben Rogaly and Sarah Spencer

This report explores the employment experiences of migrants from East and Central Europe, and reviews employer demand for their labour.

The research took advantage of the accession of ten new countries to the European Union on 1 May 2004 to explore the consequences of granting EU citizens' rights to migrants in the UK. It describes the perceptions and experiences of the employment of migrants from four new member states (the Czech Republic, Slovak Republic, Poland and Lithuania) working in low-wage occupations. Sectors of the UK economy selected were agriculture, construction, hospitality, and the au pair sector. It examines employers' recruitment practices and why they hire migrant labour; in particular, what the perceived advantages of migrant labour are. The report also discusses the Workers' Registration Scheme. The research surveyed and interviewed over a thousand workers and employers before and after EU enlargement.

\section{JOSEPH ROWNTREE FOUNDATION}




\section{Available}

in alternative formats

This publication can be provided in alternative formats, such as large print, Braille, audiotape and on disk. Please contact: Communications Department, Joseph Rowntree Foundation, The Homestead, 40 Water End, York YO30 6WP. Tel: 01904 615905. Email: info@jrf.org.uk 


\section{Fair enough?}

Central and East European migrants in low-wage employment in the UK

Bridget Anderson, Martin Ruhs, Ben Rogaly and Sarah Spencer 
The Joseph Rowntree Foundation has supported this project as part of its programme of research and innovative development projects, which it hopes will be of value to policy makers, practitioners and service users. The facts presented and views expressed in this report are, however, those of the authors and not necessarily those of the Foundation.

Joseph Rowntree Foundation, The Homestead, 40 Water End, York YO30 6WP Website: www.jrf.org.uk

\section{About the authors}

Bridget Anderson is Senior Researcher at the ESRC Centre on Migration, Policy and Society (COMPAS) at Oxford University.

Martin Ruhs is Senior Labour Market Economist at the ESRC Centre on Migration, Policy and Society (COMPAS) at Oxford University.

Ben Rogaly is Senior Lecturer in Human Geography and a member of the Sussex Centre for Migration Research, University of Sussex.

Sarah Spencer is Associate Director of the ESRC Centre on Migration, Policy and Society (COMPAS) at Oxford University.

(C) The Chancellor, Masters and Scholars of the University of Oxford 2006

First published 2006 by the Joseph Rowntree Foundation

All rights reserved. Reproduction of this report by photocopying or electronic means for noncommercial purposes is permitted. Otherwise, no part of this report may be reproduced, adapted, stored in a retrieval system or transmitted by any means, electronic, mechanical, photocopying, or otherwise without the prior written permission of the Joseph Rowntree Foundation.

ISBN-13: 9781859355152

ISBN-10: 1859355153

A CIP catalogue record for this report is available from the British Library.

Prepared by:

York Publishing Services Ltd

64 Hallfield Road

Layerthorpe

York YO31 7ZQ

Tel: 01904 430033; Fax: 01904 430868; Website: www.yps-publishing.co.uk

Further copies of this report can be obtained from the JRF website (www.jrf.org.uk/bookshop/). 


\section{Contents}

Preface vi

Acknowledgements vii

1 Introduction 1

Context 1

Research questions and structure of this report 6

Research methods and overview of data collected 7

Overview of sectors studied in this project 22

2 Migrants in low-wage jobs: experiences and perceptions of employment 25 $\begin{array}{ll}\text { Work, conditions and benefits } & 27\end{array}$

Perceptions and potential impacts of immigration status 40

Other key dimensions of employment 48

Employment after 1 May 2004: perceptions and experiences of change 54

Summary 64

3 Employers and host families: demand for migrants and recruitment $\begin{array}{ll}\text { practices } & 68\end{array}$

Recruitment challenges and perceived solutions 68

Nationality, immigration status and demand $\quad 79$

EU enlargement perceptions and impacts $\quad 87$

$\begin{array}{ll}\text { Summary } & 101\end{array}$

4 The Worker Registration Scheme 104

$\begin{array}{ll}\text { The scheme's rationale and mechanisms } & 104\end{array}$

The numbers registering and incentives to register 105

Migrant workers' perspectives on the Worker Registration Scheme 107

Employers' and agencies' perspectives on the Worker Registration Scheme 109

Summary 111

5 Conclusion 113

$\begin{array}{ll}\text { Notes } & 118\end{array}$

$\begin{array}{ll}\text { References } & 128\end{array}$

Appendix: Exploratory wage analysis $\quad 132$ 


\section{Preface}

This paper is the first report from a major research project: 'Changing status, changing lives? The socioeconomic impact of EU enlargement on low-wage migrant labour in the UK'. The lead researchers in this project are Bridget Anderson, Martin Ruhs and Sarah Spencer (all at the Centre on Migration, Policy and Society [COMPAS], University of Oxford) and Ben Rogaly (Sussex Centre for Migration Research, University of Sussex).

The research for 'Changing status, changing lives?' was motivated by the accession of ten new countries to the European Union (EU) on 1 May 2004. The ten accession states include the 'A8' countries - Czech Republic, Estonia, Hungary, Latvia, Lithuania, Poland, Slovakia and Slovenia - plus Cyprus and Malta. Among the member states of the pre-enlarged EU (EU15) only Sweden, Ireland and the UK granted A8 nationals free access to the labour market immediately upon EU enlargement.

EU enlargement enabled A8 workers to migrate and take up employment in the UK without restrictions (as long as they registered in the Worker Registration Scheme). It also meant that, overnight, A8 nationals who were already working in the UK before 1 May 2004 experienced a 'change of status', acquiring most of the rights of an EU national. This includes the right to live and work in the UK without restrictions, to remain permanently in the UK, and to be joined by dependants. For A8 nationals residing in the UK illegally, 1 May 2004 was, in effect, an amnesty. For those in the UK legally, but with restrictions on the work that they were permitted to do, acquiring EU rights has given them the freedom to change their employer and sector of employment.

'Changing status, changing lives?' aims to study the consequences of granting most of the economic and social rights of an EU national to A8 nationals who were already working in the UK before 1 May 2004 - with 'legal' or 'illegal' status. This paper, focusing on employment issues, is the first of a series of papers arising from the 'Changing status, changing lives?' project. It will be followed by a separate paper giving a detailed discussion of the methodology adopted in this research project. A third paper, analysing the lives of migrants outside of the workplace, will be published in autumn 2006. All papers arising from the 'Changing status, changing lives?' project will be made available at: www.compas.ox.ac.uk/changingstatus. 


\section{Acknowledgements}

The authors are grateful to the Joseph Rowntree Foundation (JRF) for its support for a substantial part of the study, and for the significant input and encouragement of its staff throughout the project. We are particularly grateful to Chris Goulden and Emma Stone. We are also grateful to the Economic and Social Research Council (ESRC) for providing financial support for the first wave of interviews just before EU enlargement.

A number of individuals and agencies played a key role in enabling us to reach employers and host families for the postal surveys (Work Permits UK, the British Hospitality Association and the British Association of Au Pair Agencies) and to reach employers, host families, au pairs and workers to be interviewed. We would like to thank in particular: Steve Lamb, Chris Jones, Mick Seals and Helen Pye at Work Permits UK; Martin Couchman at the British Hospitality Association; Christine Lumb of Concordia; Anna O'Sullivan and Terry Huggins of South Holland Borough Council; Sarah Glenn of King's Lynn Borough Council; Chris Brooks and colleagues at Wychavon District Council; Zad Padda; and the individual au pair agencies that facilitated surveys and interviews but who cannot be named for confidentiality reasons.

An advisory committee, including Professor John Salt (UCL), Danny Sriskandarajah (ippr), Don Flynn (JCWI), Nick Clark (TUC), Jeremy Kempton (Home Office) and Nicola Gilpin (Department of Work and Pensions), was brought together by JRF. They provided valued advice at each stage of the project and we are grateful to them for their contribution. For their helpful comments on the various research instruments designed for this project, we are grateful to Sue Conlan, Martin Couchman, Susi Dennison, Stefan Dercon, Mary Gregory, Nick van Hear, Lynda Joeman, Jacqui Jones, Jeremy Kempton, Elizabeth Lewis, Bevan Mottram, Rachel Prime, Jane Rushton and Susan Wilmott.

We want particularly to thank Juan Guataqui, Violetta Parutis and Leena Chauhan who did a fantastic job helping to manage a very large number of interviewers, data entryists and other research assistants in this project.

Needless to say, this research project could not have been carried out without the help and commitment of a very large number of research assistants who worked as interviewers, transcribers and/or data entryists. We are very grateful to: Tomas Andrisiunas, Dimitar Bechev, Zara Bielkos, Pavlina Binkova, Acala Boden, Magdalena Bogusiak, Dmytro Bondarenko, Kavita Brahmbhatt, Donna Crabtree, 
Julika Erfurt, Peter Gasparik, Esme Gaussen, Agnieszka Grodzinska, Shirin Hakimzadeh, Svatava Hanzikova, Eliska Janatova, Georgia Jettinger, Maria Karpouchina, Krys Kazmierczak, Aleksandra Kedzierska, Irina Khirivskaya, Galina Kostadinova, Nina Kozlova, Rachael Levene, Paula Lucci, Lubomir Lukac, Eugenia Markova, Nora Markova, Ana Maslenikova, Rosie McLeod, Raya Muttarak, Veneta Nikolova, Zuzanna Olszewska, Gintaras Parutis, Victor Pasisnychenko, Ganna Pavlenko, Peter Petkoff, Martin Petrik, Linda Pialek, Olga Pisarenko, Olga Podporinova, Elvina Quaison, Kirat Randhawa, leva Raubisko, Tomas Seminovas, Joanna Sephton, Sergei Shvedchikov, Gediminas Siminavicious, Taras Sobolev, Maria Sobolewska, Katerina Stanclova, Jolanta Stankeviciute, Marina Tzvetkova, Louise Waite, Hugo Whatley, Marissa Wilson, Ivana Witzova, Jing Yang, Roman Zaczkiewicz, Benjamin Zeitlyn, Adela Zilkova, Joanna Zmienko and Zuzana Zvirinska.

Seminars were held during the course of the project to discuss the issues investigated and later the emerging findings, and we thank the migrant representatives, employers, union and NGO representatives, national officials and police officers who gave their time to contribute in this way. Their suggestions and advice were invaluable to us. A number of senior representatives from local and central government, migrant community organisations, the police, employer representative bodies and unions, and embassies contributed their time to be interviewed on the policy relevance of the study and we thank them for their insights.

Special thanks are also due to our COMPAS colleagues. Alison Pomroy, Emma Newcombe and Zoe Davis-Heaney have been endlessly patient and supportive looking after the personnel, financial and other issues in this research project.

For their time and helpful comments on drafts of this report, we would like to thank: Nicola Gilpin, Chris Goulden, Mary Gregory, Jeremy Kempton, Emma Stone, Sonia McKay, Linda McDowell, Don Flynn and Alessio Cangiano.

Most of all we would like to thank the hundreds of migrant workers, employers, host families and recruitment agency staff who were willing to be interviewed or to complete our lengthy questionnaires. We are grateful to them and hope that all those who participated will find some reflection of their contribution in this report and the papers that follow.

All errors in this report are the responsibility of the authors alone. 


\section{Introduction}

This paper explores the employment experiences of migrants from East and Central Europe working in low-wage occupations in selected sectors of the UK economy (agriculture, construction, hospitality and the au pair sector); and the nature and determinants of employer demand for migrant labour in these sectors. We are particularly interested in investigating the role of immigration status - including 'illegal residence"1 - as a potential determinant of both employer demand and the conditions of migrants' employment. The paper is based on surveys of - and indepth interviews with - migrants and employers before and after EU enlargement on 1 May 2004. In total, more than 600 migrants and over 500 employers of migrants were surveyed and interviewed. The paper hopes to make a significant contribution to academic and policy debates on immigration in general, and on immigration status and employment in particular.

This introduction sets out the context of the project and the research questions, and summarises the methodology. It then gives an overview of the data collected and discusses the immigration status of the migrants surveyed and interviewed, using quantitative and qualitative instruments. It also includes an introductory discussion of the four sectors on which the project focused.

\section{Context}

Our analysis of the employment of Central and East European migrants in low-wage jobs needs to be set within the context of the:

1 rapid increase in labour migration to the UK since the mid-1990s, and especially since EU enlargement

2 Government's 'firm-but-fair' approach to 'managing migration'

3 relatively scant but increasing research evidence on the processes and impacts of migration on the UK economy and society. 


\section{Recent migration flows to the UK}

The number of migrants coming to work in the UK, both from outside and within the European Union, has significantly increased since the mid-1990s. ${ }^{2}$ In 2003, more than 80,000 work permits were issued to skilled and highly skilled migrant workers from outside the EU, up from less than 30,000 in the early 1990s. In addition, in 2003, about 30,000 non-EU workers entered the UK on permits for employment in selected low-skill occupations in agriculture, food processing and the hospitality sector. There are also a number of other immigration programmes, which are not explicitly labour immigration programmes but which still entail some permission to work. Non-EU nationals entering the UK under such schemes include: working holidaymakers (47,000 in 2003); au pairs (15,000 in 2003); students (319,000 in 2003); and dependants (about 87,000 in 2003). ${ }^{3}$ In spring 2004, just before EU enlargement, there were 2.8 million foreign nationals ${ }^{4}$ living in the UK. Of these, 1.44 million were working, accounting for approximately 5.2 per cent of all people in employment. ${ }^{5}$ Of course, these figures do not take account of the unknown, but probably not insignificant, number of workers who have entered and/or worked in the UK 'illegally'. ${ }^{6}$

Since early 2004, the UK has also seen a rapidly increasing inflow of workers from the new EU member states. ${ }^{7}$ Along with Ireland and Sweden, Britain was in a minority among the member states of the pre-enlarged EU (EU15) to grant workers from the A8 countries free access to the UK labour market immediately upon EU enlargement on 1 May 2004. Since that date, A8 workers have been free to migrate and take up employment in the UK without requiring work permits. This was part of the Government's strategy for migration management, expanding migration to fill vacancies in skilled and low-wage occupations. For all those A8 workers residing in the UK illegally, 1 May 2004 was, in effect, an amnesty.

In February 2004, a special Worker Registration Scheme was put into place for A8 workers taking up employment in the UK after 1 May 2004. Unless officially exempted from doing so, A8 workers are required to register their employment with the Home Office within one month of taking up employment in the UK. ${ }^{8}$ This was not intended to limit A8 nationals' access to the labour market. The stated policy objectives of the Worker Registration Scheme (WRS) are to control A8 workers' access to certain welfare benefits and services; to encourage participation in the formal economy; and to provide empirical data to facilitate monitoring of inflows and the formulation of evidence-based policy.

According to the Government's latest registration figures for A8 workers, about 345,000 workers from the new EU member states registered for employment during 
the period between May 2004 and December 2005. ${ }^{9}$ Up to 30 per cent of A8 workers who registered between May 2004 and September 2005 may have already been in the UK before 1 May 2004. Some of these workers may have used registration to 'regularise' their status. ${ }^{10}$ Although the number of workers registering suggests an inflow of workers that is significantly larger than predicted by the Government and academics before EU enlargement, ${ }^{11}$ it is important to note that registration figures are not a measure of the stock of A8 workers in the UK. The registration data do not record how long $A 8$ workers stay and it is not known how many have already left the UK. Data taken from the UK's Labour Force Survey suggest that the stock of A8 workers aged 16+ increased from 165,000 in the summer of 2004 to 245,000 in the summer of $2005 .{ }^{12}$

\section{Policies: the 'firm-but-fair' approach to managing migration}

Labour immigration - and indeed immigration more generally - is one of the most discussed and contested public policy issues in the UK. In an effort to manage migration, the Government has introduced a large number of pieces of immigration legislation and regulations. As of May 2004 there were more than 80 different routes of entry for non-EEA nationals ${ }^{13}$ to the UK, each governed by specific rules and regulations. ${ }^{14}$ In recent years, the Government also experimented with new types of labour migration policies such as the Highly Skilled Migrants Programme (HSMP, introduced in 2002) and the Sector-based Scheme (SBS, introduced in May 2003). The HSMP aimed to attract highly skilled migrants to the UK by offering them the opportunity to move to the UK without having a prior job offer. In contrast, the SBS aimed to facilitate the strictly limited and temporary employment of non-EU workers in selected low-skill occupations in the hospitality and food processing sectors.

On 1 May 2004, the Government opened the UK labour market to workers from the new EU member countries. At the same time, it introduced measures to strengthen the enforcement of section 8 of the Asylum and Immigration Act 1996 (as amended by section 147 of the Nationality, Immigration and Asylum Act 2002). Section 8 makes it a criminal offence to employ an individual over the age of 16 who does not have the entitlement to be in the UK or whose status precludes them from undertaking the employment in question. On the same date as the EU enlarged, the Government introduced the Immigration (Restrictions on Employment) Order 2004, which, among other things, revised the list of specified documents that may be taken to provide evidence of entitlement to work. Although enforcement efforts in relation to illegal migrant working increased - according to the Home Office the number of 'successful operations' increased from 390 in 2003 to 1,098 in 2004 - prosecution rates and fines imposed on employers following section 8 convictions remained very 
low. Between 1998 and 2004, 17 employers (including eight employers in 2004) were successfully prosecuted for illegally employing migrants under section 8 . More than half of section 8 convictions in 2004-05 resulted in fines of less than $£ 700$, with four employers fined the maximum of $£ 5,000 . .^{15}$

Following EU enlargement, the Government launched a public consultation ${ }^{16}$ about reforming the UK's overall immigration system and, in March 2006, gave details of a new 'points-system' framework for managing labour and other types of migration of non-EEA nationals to the UK. ${ }^{17}$ Among other things, the new points-based system aims to facilitate and simplify policies regulating the immigration and employment of skilled and highly skilled non-EEA workers, and to strictly limit low-skilled immigration from outside the EEA. This includes the termination of the existing Sector-based Scheme (SBS) and the proposed phasing out of the Seasonal Agricultural Workers Scheme (SAWS) by 2010. Any remaining low-skilled immigration programmes would be 'quota based, operator-led, and time-limited'. The restriction of low-skilled immigration of non-EEA workers is based on the Government's rationale that local employers should now be able to source all the workers required for low-skilled jobs from within the enlarged EU, especially from the A8 countries.

The recent plans for a points-based system continue to be founded on the 'firm but fair' approach that the Government has advocated since the publication of a major White Paper on immigration and asylum in the UK in the late 1990s. ${ }^{18}$ At the launch of the points-based system, the Home Secretary said that:

Managed migration is in the interest of the UK. Today's announcement sets out the Government's policy to deliver a firm but fair, simpler, more transparent and more rigorous system, which will benefit our economy and protect our borders.

(Home Secretary, Home Office press release, 10 March 2006)

\section{Research evidence}

It is now widely agreed that Britain's debate and policy making on migration requires an evidence base. ${ }^{19}$

The key thing that's missing is the evidence. There is a lot of emphasis on evidence and on being rational. We don't know enough about why people are coming and what their experiences are. We need the evidence to see what's working (Interview with senior official, Managed Migration Policy, Home Office) 
It is thus not surprising that the increase in migration, in terms both of numbers and of its importance as a policy issue, has triggered a growth in the academic and policy literature on the subject. Although still lagging behind countries such as the US, Canada and Australia, studies on labour immigration in the UK have recently been growing in number and scope of analysis. Examples of recent analyses include: studies of the impacts of labour immigration on the labour market; ${ }^{20}$ discussions of the fiscal impacts of immigration; ${ }^{21}$ and explorations of the labour market performance of non-British workers in the UK. ${ }^{22}$ Clearly, all of these studies are of paramount importance to advancing knowledge and debate on labour migration issues. At the same time, most of the existing studies rely on - and are therefore constrained by - official data taken from large-scale government surveys such as the Labour Force Survey (LFS) or the Census. Although obviously of critical importance in analysing generalisable trends and impacts, existing government surveys are likely to exclude or inadequately capture migrants who are residing and/or working in the UK without permission to do so. Such migrants have been given a variety of names including 'illegal', 'irregular' or 'unauthorised'. They remain a seriously underresearched group about whom policy makers and the public need to know more in order to engage in a comprehensive and informed debate on the employment of migrant workers in the UK. ${ }^{23}$

With notable exceptions, ${ }^{24}$ little research has been done on the experiences and perceptions of migrants working illegally - and mostly in low-wage occupations - in the UK. For example, concerns have been expressed at a policy level, and more generally in the media, about the relation between illegal immigration, working and grossly exploitative working conditions, ${ }^{25}$ although there is not yet sufficient empirical evidence to assess these claims. ${ }^{26}$ At the same time, little research has been conducted on the factors that determine employer demand for such workers within particular sectors of the labour market and the reasoning behind decisions on sources of labour, use of intermediaries, and pay and conditions. ${ }^{27}$ Importantly, in the context of the UK, the role of migrants' immigration status as a potential determinant of both employers' demand for migrant labour and migrants' labour market experiences has received very little attention in the existing research. Finally, little is known about the particular experiences of migrant workers from East and Central Europe, whether from countries that have recently joined the EU or from countries that have not done so.

This research project aims to help fill this important gap in the current research and evidence base on the employment of migrants in the UK. It sets out to explore: the key aspects and determinants of the employment of migrants working in low-wage occupations in selected sectors of the economy; and the nature and determinants of employer demand for such labour. We are particularly interested in exploring the role 
of immigration status in this context. To facilitate a discussion of the relationship between immigration status and migrants' labour market experiences and employer demand, we make use of a 'natural experiment' that the UK Government facilitated by granting A8 nationals free access to the UK labour market immediately upon EU enlargement on 1 May 2004. Overnight, workers from the EU accession countries became EU nationals and gained full rights to work in the UK without restrictions. This event offered an opportunity to explore how the change in legal status of A8 nationals already working in the UK before 1 May 2004 would affect their experiences in the labour market and employer demand for their labour. This is what this research project set out to do. ${ }^{28}$

\section{Research questions and structure of this report}

This paper aims to address two sets of research questions.

1 What are Central and East European migrants' experiences and perceptions of working in low-wage jobs in the UK? What is the role of immigration status including 'illegal residence' - in determining migrants' labour market outcomes?

2 What is the nature of employers' demand for migrant labour? How are employers meeting their demand for migrants? What is the role of migrants' immigration status in employers' recruitment decisions?

The report structure reflects these questions. The remainder of the introduction introduces our research methodology and gives an overview of the data collected. This includes a brief presentation of background information about the migrants, employers, agencies and policy makers interviewed.

Chapter 2 of this report uses the data obtained from survey and in-depth interviews with migrants to discuss their experiences and perceptions of working in low-wage jobs in the UK.

Chapter 3 draws on data obtained from our in-depth interviews with and postal surveys of employers, host families and agencies to discuss their demand for migrants, and the potential determinants of their recruitment and employment decisions.

Chapter 4 discusses migrants' and employers' perceptions of - and experiences with - the Worker Registration Scheme (WRS). 
Chapter 5 concludes with a discussion of the key findings that emerge from our analysis. This is based on a synthesis of the findings from the analysis of migrants' and employers' data in the previous chapters.

\section{Research methods and overview of data collected}

This section gives a brief overview of the methods and participants of this research project. A more detailed discussion can be found in a separate paper to be made available on the project website www.compas.ox.ac.uk/changingstatus.

The project made use of a range of methods (see below). Overall, we have attempted to formulate a truly interactive methodology, drawing on quantitative (survey) and qualitative (in-depth interviews and diaries) methods. Both survey and in-depth interviews ${ }^{29}$ are exploratory and contemporaneous, and we have chosen a flexible, issue-led model, in which we selected our method depending on whether it was the most appropriate for the questions we were exploring. So quantitative and qualitative approaches have been combined, not only in the fieldwork, but also during the conceptual design and analysis.

\section{A general health warning}

Most of the people included in our sample, providing data analysed in this project, were purposely selected rather than randomly chosen. This means that the samples are not representative of the wider populations of migrants, employers, host families and agencies under consideration. The results of any analysis based on these data are thus not generalisable, but serve as an indication of potential patterns and relationships. Despite this important caveat, the data are still extremely useful in carrying out exploratory analysis of many issues - such as the employment experiences of 'irregular' migrants - that have so far remained greatly underresearched in existing studies of labour migration in the UK.

\section{Survey and in-depth interviews with migrants}

Research design and sampling strategy

The 'Changing status, changing lives?' project comprises two waves of quantitative and qualitative research. Wave 1 was conducted between March and May 2004, and 
funded by the Economic and Social Research Council (ESRC); ${ }^{30}$ Wave 2 was conducted between November 2004 and February 2005, and funded by the Joseph Rowntree Foundation (JRF). We selected four sectors of employment in April 2004:31 agriculture, construction, hospitality and the au pair sector, though relations between au pairs and host families are governed not by employment contracts but by being 'part of the family'. We did not aim to study the whole agriculture sector, but focused our in-depth and survey interviews on the labour-intensive sub-sectors of fresh fruit, vegetable and salad production, where migrant workers are employed in large numbers in fields and co-located packhouses (see Precision Prospecting, 2005). The postal survey was of employers who had applied for Seasonal Agricultural Workers Scheme visa holders, and therefore included the food-processing sector. For ease of reference, we refer in this paper to 'agricultural employers', when strictly speaking we should refer to them as agriculture and food processing employers.

We selected four accession nationalities on the basis of their prominence in the SAWS, Au Pair and SBS schemes: Czech, Slovak, Lithuanian and Polish. As a comparison group of people whose immigration status would not change with EU enlargement, we selected two further nationalities: Ukrainian and Bulgarian. Both survey and in-depth interviews with workers and au pairs were conducted face to face and in the migrant's first language. Surveys were designed to be completed by an interviewer and to take approximately one hour. In-depth interviews were semistructured and designed to be tape-recorded, with the possibility of detailed notes if interviewees did not consent to being taped. Wave 2 comprised two sets of participants: reinterviews of those who had been interviewed in Wave 1, and new respondents/ interviewees whom we could ask retrospective questions about their experiences both before and after EU enlargement. We attempted to match the latter group on the basis of the gender, age range and nationality of the Wave 1 respondents who could not be reinterviewed. As shown in Tables 1 and 2, of the 333 survey respondents in Wave 1, 109 could be reinterviewed in Wave 2. Of the 51 indepth interviewees in Wave 1, 20 were reinterviewed in Wave 2. The numbers of retrospective survey and in-depth interviews taking place in Wave 2 were 243 and 42 , respectively. 
Table 1 Survey interviews with migrants (576 respondents)

\begin{tabular}{lrrrrrrrrr}
\hline & \multicolumn{1}{c}{ Czech } & Lithuanian Polish & \multicolumn{2}{c}{ Slovak } & Bulgarian Ukrainian & Total & A8 & NA8 \\
\hline Wave 1 & 48 & 81 & 59 & 53 & 46 & 46 & 333 & 241 & 92 \\
Wave 2: reinterviews & 14 & 36 & 18 & 19 & 14 & 8 & 109 & 87 & 22 \\
Wave 2: retrospective & 29 & 33 & 35 & 33 & 42 & 71 & 243 & 130 & 113 \\
Total respondents & 77 & 114 & 94 & 86 & 88 & 117 & 576 & 371 & 205 \\
'Panel' & 43 & 69 & 53 & 52 & 56 & 79 & 352 & 217 & 135 \\
\hline
\end{tabular}

Notes:

Wave 1 took place in March-April 2004; and Wave 2 in November 2004-February 2005.

'A8' indicates nationals of A8 countries;' 'NA8' indicates workers from non-A8 countries.

Panel indicates the number of respondents/interviewees for whom we have information about their situation in both Wave 1 and Wave 2.

Table 2 In-depth interviews with migrants (93 interviewees)

\begin{tabular}{lrrrrrrrrr}
\hline & \multicolumn{2}{c}{ Czech } & Lithuanian Polish & \multicolumn{2}{c}{ Slovak } & Bulgarian Ukrainian & Total & A8 & NA8 \\
\hline Wave 1 & 2 & 17 & 22 & 2 & 6 & 2 & 51 & 43 & 8 \\
Wave 2: reinterviews & & 7 & 10 & 1 & 2 & & 20 & 18 & 2 \\
Wave 2: retrospective & 11 & 4 & 5 & 11 & 4 & 7 & 42 & 31 & 11 \\
Total interviewees & 13 & 21 & 27 & 13 & 10 & 9 & 93 & 74 & 19 \\
'Panel' & 11 & 11 & 15 & 12 & 6 & 7 & 62 & 49 & 13 \\
\hline
\end{tabular}

Notes:

Wave 1 took place in March-April 2004; and Wave 2 in November 2004-February 2005. 'A8' indicates nationals of A8 countries; 'NA8' indicates workers from non-A8 countries.

Panel indicates the number of respondents/interviewees for whom we have information about their situation in both Wave 1 and Wave 2.

\section{Characteristics of migrants surveyed and interviewed}

This section provides background information about the migrants surveyed and interviewed. All the data presented in this section refer to respondents' and interviewees' situation before EU enlargement, i.e. either at the time of the survey or in-depth interview (April 2004) or, where specified, at the time of respondents' last entry to the UK for employment purposes (always before 1 May 2004).

We must re-emphasise that the respondents and interviewees for both the survey and in-depth interviews were purposively selected rather than randomly chosen. In some cases, there were 'interviewer effects', e.g. older interviewers tended to find and interview older respondents; 'sector effects', e.g. in agriculture most respondents were legally employed under the SAWS scheme, which meant that most of them were students in their home countries; ${ }^{32}$ and/or other 'sampling effects', e.g. respondents working as au pairs were selected on the basis that they had legally entered, and were legally residing, on an au pair visa. The data are thus not representative of the wider population of migrants under consideration. 
The overall gender distribution of the survey sample is reasonably even: 54 per cent of all respondents were male. Among Czech and Slovak respondents, women outnumbered men (see Table 3). In construction all respondents were male, and among au pairs the majority were female.

Most respondents were young and single. Their average age - at the time of the Wave 1 interview - was 27. Ukrainians (30 years on average) and Bulgarians (28 years) were older than the respondents from the accession states whose average age was 26 .

On average, respondents had completed 13 years of formal schooling (which may include vocational training) with little difference between the various nationalities. A fairly high share (42 per cent) of all migrants surveyed had received vocational training. Bulgarians and Ukrainians reported a higher incidence of vocational training than A8 nationals ( 50 per cent compared to 37 per cent, respectively). Furthermore, among those respondents who received vocational training, Ukrainians and Bulgarians also reported the highest average years of vocational training (3.6 and 4.2 years, respectively, compared to an overall average of 3.4 years for all migrants interviewed).

A8 workers reported significantly fewer months of total work experience (64 months on average) than Bulgarians (89 months) and especially Ukrainians (110 months). ${ }^{33}$ Bulgarian and Ukrainian respondents' higher average age is likely to be an important factor explaining this difference. Importantly, there was almost no difference between respondents from A8 states and non-A8 states in terms of work experience in the $U K$, which is 21 months, on average, for both groups.

More than two-thirds of respondents described their English-speaking proficiency as 'fluent' or 'adequate'. ${ }^{34}$ The lowest levels of English-speaking proficiency were reported by Bulgarians (52 per cent fluent or adequate) and Poles (57 per cent fluent or adequate).

Table 3 Survey respondents by citizenship and gender, April 2004

\begin{tabular}{lccccccccc}
\hline & Czech & Lithuanian Polish & \multicolumn{2}{c}{ Slovak } & Bulgarian Ukrainian & Total & A8 & NA8 \\
\hline Male & 33 & 65 & 58 & 40 & 56 & 63 & 315 & 196 & 119 \\
Female & 44 & 49 & 36 & 46 & 32 & 54 & 261 & 175 & 86 \\
Total & 77 & 114 & 94 & 86 & 88 & 117 & 576 & 371 & 205 \\
\hline
\end{tabular}

Source: survey interviews with migrant workers and au pairs.

Notes: 'A8' indicates nationals of A8 countries; 'NA8' indicates workers from NA8 countries. 
Almost half of Bulgarian respondents - and almost a third of Ukrainian respondents - said that they spoke basic English only. The corresponding average figure for all respondents from the accession countries was 22 per cent.

In April 2004, just over a third of survey respondents were working in hospitality, just under a third in construction and the remainder in agriculture, in the au pair sector or in another sector. ${ }^{35}$ As shown in Table 4, respondents in hospitality and the au pair sector were predominantly female (67 per cent and 86 per cent, respectively). In contrast, almost two-thirds of respondents working in agriculture and all of the respondents working in construction were men. In terms of respondents' citizenship, we obtained a fairly good spread within the four sectors of interest to this study. The exception is the au pair sector, where Czechs and Slovaks (who are all A8 nationals) made up more than three-quarters of respondents. A8 workers constituted just over half of all respondents in hospitality and construction, and three-quarters of respondents in agriculture.

Almost three-quarters of all survey respondents were working in London. This share was highest for those working in construction (92 per cent) and hospitality (82 per cent). Three-quarters of the au pairs interviewed were working in London and most of the remainder in Oxfordshire or Hertfordshire. The majority of respondents employed in agriculture were working in Cambridgeshire (28 per cent), Kent (28 per cent) or Linconshire (17 per cent). This was a result of our purposive sampling strategy and should not be taken as indicating any general trend.

Table 4 Survey respondents by nationality, gender and sector of employment in April 2004

\begin{tabular}{|c|c|c|c|c|c|c|}
\hline & Hospitality & Construction & Au pair & Agriculture & Other & Total \\
\hline A8 respondents & 114 & 101 & 81 & 61 & 14 & 371 \\
\hline Czech Republic & 21 & 15 & 31 & 6 & 4 & 77 \\
\hline Lithuania & 32 & 45 & 11 & 20 & 6 & 114 \\
\hline Poland & 34 & 32 & 2 & 23 & 3 & 94 \\
\hline Slovakia & 27 & 9 & 37 & 12 & 1 & 86 \\
\hline NA8 respondents & 91 & 77 & 4 & 21 & 12 & 205 \\
\hline Bulgaria & 35 & 40 & 4 & 9 & 0 & 88 \\
\hline Ukraine & 56 & 37 & $0^{*}$ & 12 & 12 & 117 \\
\hline Total & 205 & 178 & 85 & 82 & 26 & 576 \\
\hline$\%$ female & 67 & 0 & 86 & 37 & 81 & 45 \\
\hline
\end{tabular}

Source: survey interviews with migrants.

* In the au pair sector, we interviewed only those respondents who were working legally on au pair visas. Ukrainians are not eligible to apply for au pair visas. 
Finally, the great majority of respondents were very recent migrants. As of April 2004, respondents reported an average of 17 months since their last entry for employment to the UK. This figure was lowest for Bulgarians (nine months) and highest for Ukrainians (21 months). A quarter of all respondents had last entered the UK in the first four months of 2004; another half entered during 2002-03; and the remaining quarter in or before 2001. In total, 39 respondents last entered the UK to work before 2000.

The personal characteristics of in-depth interviewees were broadly similar to those of survey respondents. Slightly more than half of the interviewees were men (the share was two-thirds among NA8 interviewees). The average age of interviewees was 27. NA8 interviewees were slightly older (30 years, on average) than A8 interviewees (27 years). On average, interviewees had 14 years of schooling. As was the case with survey respondents, the great majority of in-depth interviewees were recent migrants: three-quarters last entered the UK for employment purposes between January 2003 and April 2004.

\section{Migrants' immigration status}

One of the key questions of interest to this research project is how migrants' immigration status relates to employment conditions and employer demand for migrant labour. This section begins this analysis by offering a description of the selfreported immigration status of survey respondents by sector of employment in April 2004.

There was great diversity in the self-reported immigration statuses of respondents in April 2004, prior to EU enlargement (see Table 5). The four major statuses reported by respondents were self-employed, au pair, visa expired or student. There was, however, significant variation across sectors. For example, 'student' was a major immigration status in hospitality (31 per cent in that sector) but less so in other sectors. 'Self-employed' was the status most commonly reported by respondents in construction (58 per cent), less so in hospitality ( 15 per cent) and not at all by respondents in agriculture. A little less than a quarter of respondents in hospitality and construction described their status as 'visa expired'. 
Table 5 Respondents' self-reported immigration status by sector, April 2004

\begin{tabular}{lccccc}
\hline & Hospitality & Construction & $\begin{array}{c}\boldsymbol{N} \\
\text { Au pair }\end{array}$ & Agriculture & Total \\
\hline SBS permit & 5 & 2 & - & 1 & 8 \\
SAWS permit & 1 & - & - & 48 & 49 \\
Self-employed & 28 & 98 & - & - & 126 \\
Au pair & 9 & 2 & 84 & - & 95 \\
Student & 59 & 11 & - & 11 & 81 \\
Dependant & 13 & 2 & - & 1 & 16 \\
Asylum seeker & 3 & 1 & - & 1 & 5 \\
Visa expired & 46 & 36 & - & 7 & 89 \\
Illegal & 1 & 1 & - & - & 2 \\
Don't know & 18 & 15 & 1 & 8 & 42 \\
Other & 21 & 10 & - & 4 & 35 \\
Total & 204 & 178 & 85 & 81 & 548 \\
\hline Source: surej & 178 & & &
\end{tabular}

Source: survey interviews with migrants.

We have used the survey data - which include the information on self-reported immigration status above and answers to various other questions pertaining to respondents' immigration status - to construct an indicator of whether a respondent is 'illegally resident' (i.e. without valid leave to remain) in the UK or not. Of the 548 respondents working in hospitality, construction, agriculture and the au pair sector in April 2004, at least 123 were illegally resident. This includes 91 respondents who described their immigration status as either 'visa expired' or 'illegal'; and another 32 respondents whom we classified as 'illegally resident' because the interview data clearly suggested that they had either overstayed their visas or their reported immigration status was simply impossible (e.g. respondents suggesting that they had entered and been working in the UK on SBS permits since before May 2003, when the SBS scheme was introduced). It should also be noted that we deliberately set out not to interview 'illegally resident' au pairs. This was because of the complex methodological issues that would arise in attempting to differentiate between 'au pairs' and 'domestic workers', when those entering on au pair visas fall out of status. Nevertheless, we did come across 11 migrants on au pair visas who were working in other sectors (see Table 5).

It is worth repeating at this point that our data are not representative and can thus not be used to assess the incidence of a certain immigration status - such as 'visa expired' - among migrant workers employed in a particular sector. It is also clear that the diversity of immigration statuses identified in Table 5 is, in part, a natural implication of the UK's immigration system, which accords a great number of 
different immigration statuses to migrants depending, in some cases, on the migrant's sector of employment.

Each of the immigration statuses of our migrant respondents is associated with a different set of rights and responsibilities. Table 6 examines these differences with reference to three sets of rights: the right to remain on the territory; rights of access to the labour market; and rights to be joined by spouse and dependants ('family reunion'). The table is indicative only and generalised. Not included are differential rights to access welfare benefits and to political participation. It is important to note that most of those deemed 'subject to immigration control' under the 1999 Immigration and Asylum Act cannot obtain 'public funds' including welfare support or social housing if homeless. 'Public funds' do not include NHS medical treatment. Migrants legally resident for the purposes of employment, unlike visitors, have a right to such treatment.

To understand what the ramifications of different immigration statuses are, it is necessary to briefly introduce the schemes that are of relevance for this paper. For employers and host families wishing to recruit from abroad there are three major schemes (i.e. official immigration programmes) available for employing migrants in low-wage occupations in the sectors we are considering: the Sector-based Scheme (SBS) for hospitality; the Seasonal Agricultural Workers Scheme (SAWS) for agriculture and food processing; and the au pair scheme. It is worth noting that au pairs usually come under the rubric of 'cultural exchange' rather than low-skilled labour.

The Sector-based Scheme (SBS) was introduced in May 2003. It allowed UK-based employers to recruit workers from outside the European Economic Area to fill selected low-skill jobs in the hospitality and food manufacturing sectors. The SBS is a temporary migration policy, as it strictly limits the employment of migrants to a maximum period of 12 months. The SBS was introduced as a pilot programme and was strictly limited by quotas (20,000 in its first year of operation). One of the major rationales of the SBS has been to reduce, through the opening up of legal channels of employment, the number of migrant workers who are illegally employed in the hospitality and food manufacturing sectors. The SBS was reviewed in early 2005 and subsequently closed for the hospitality sector but kept going for the food processing sector. ${ }^{36}$ As mentioned before, the recently announced points-based system for managing immigration in the UK entails, among other things, the termination of SBS for the food processing sector by the end of 2006 . 
Table 6 'Immigration status' and associated rights, 2004

\begin{tabular}{|c|c|c|c|c|c|}
\hline $\begin{array}{l}\text { Immigration } \\
\text { status }\end{array}$ & $\begin{array}{l}\text { Maximum } \\
\text { duration of stay* }\end{array}$ & $\begin{array}{l}\text { Lead to } \\
\text { settle- } \\
\text { ment? }\end{array}$ & Switch & $\begin{array}{l}\text { Labour market: } \\
\text { rights and } \\
\text { restrictions }\end{array}$ & $\begin{array}{l}\text { Family } \\
\text { reunion }\end{array}$ \\
\hline $\begin{array}{l}\text { Seasonal } \\
\text { Agricultural } \\
\text { Workers (SAWS) }\end{array}$ & Six months & No & No & $\begin{array}{l}\text { Can only work for } \\
\text { approved agricultural } \\
\text { employers }\end{array}$ & No \\
\hline $\begin{array}{l}\text { Sector-based } \\
\text { Scheme (SBS) }\end{array}$ & 12 months & No & No & $\begin{array}{l}\text { Can only work for } \\
\text { named employers in } \\
\text { particular sectors } \\
\text { (hospitality, food } \\
\text { processing) }\end{array}$ & No \\
\hline Au pair & 24 months & No & $\begin{array}{l}\text { To dependant } \\
\text { only }\end{array}$ & $\begin{array}{l}\text { Can only 'help' in } \\
\text { private homes. } \\
\text { Subject to minimum } \\
\text { wage exemption. Can } \\
\text { switch host family }\end{array}$ & No \\
\hline Visitor ('tourist') & Six months & No & $\begin{array}{l}\text { To familial } \\
\text { categories only. } \\
\text { CEEC citizens may } \\
\text { switch to business/ } \\
\text { self-employment }\end{array}$ & $\begin{array}{l}\text { No right to work } \\
\text { (other than 'special } \\
\text { classes of visitors') }\end{array}$ & No \\
\hline $\begin{array}{l}\text { Persons intending } \\
\text { to establish } \\
\text { themselves in } \\
\text { business }\end{array}$ & $\begin{array}{l}\text { One year initially, } \\
\text { but may be } \\
\text { extended }\end{array}$ & Yes & $\begin{array}{l}\text { To certain } \\
\text { categories }\end{array}$ & $\begin{array}{l}\text { Must have } £ 200,000 \\
\text { to invest and create } \\
\text { employment for at } \\
\text { least two UK residents } \\
\text { (plus some other } \\
\text { requirements) }\end{array}$ & Yes \\
\hline $\begin{array}{l}\text { European } \\
\text { Community } \\
\text { Association } \\
\text { Agreement (ECAA) }\end{array}$ & $\begin{array}{l}\text { One year initially, } \\
\text { but may be } \\
\text { extended }\end{array}$ & Yes & $\begin{array}{l}\text { To certain } \\
\text { categories }\end{array}$ & $\begin{array}{l}\text { CEEC nationals*: } \\
\text { Must have business } \\
\text { plan. Does not have } \\
\text { to have } £ 200,000\end{array}$ & Yes \\
\hline Student & $\begin{array}{l}\text { Normally until four } \\
\text { months after the } \\
\text { end of a course or } \\
\text { one year initially }\end{array}$ & No & $\begin{array}{l}\text { To dependant and } \\
\text { some employment } \\
\text { categories only }\end{array}$ & $\begin{array}{l}\text { Usually } 20 \text { hours } \\
\text { per week in } \\
\text { term-time. More than } \\
20 \text { hours permitted in } \\
\text { holidays }\end{array}$ & Yes \\
\hline $\begin{array}{l}\text { Spouse/partner } \\
\text { (not fiancé/fiancée) }\end{array}$ & $\begin{array}{l}\text { Initially two years, } \\
\text { could be extended } \\
\text { depending on case }\end{array}$ & Yes & Limited categories & $\begin{array}{l}\text { Permitted to work } \\
\text { once entry clearance } \\
\text { or leave to remain has } \\
\text { been granted }\end{array}$ & $\mathrm{N} / \mathrm{A}$ \\
\hline $\begin{array}{l}\text { 'A8' citizen (post } \\
\text { May 2004) }\end{array}$ & $\begin{array}{l}\text { No formal time } \\
\text { limit on stay. No } \\
\text { conditions of entry }\end{array}$ & Yes & $N / A$ & $\begin{array}{l}\text { Once work is } \\
\text { obtained must 'register' } \\
\text { with Work Permits UK, } \\
\text { unless self-employed } \\
\text { or other specified } \\
\text { categories exempted } \\
\text { from registration }\end{array}$ & Yes \\
\hline
\end{tabular}

Sources: JCWI (2002); www.ind. homeoffice.gov.uk.

* In some categories it is possible to obtain limited extension (e.g. au pair can obtain a six-month extension as a visitor). This is not included in the stated maximum duration.

** The group of countries known as the 'Central and Eastern Europe Countries' (CEEC) include Bulgaria, Czech Republic, Estonia, Hungary, Latvia, Lithuania, Poland, Romania, Slovakia and Slovenia. 
Like SBS, the Seasonal Agricultural Workers Scheme (SAWS) is a temporary labour migration programme that aims to help local employers in agriculture to fill seasonal labour shortages with migrant workers. SAWS permits are valid for up to six months. Migrants on SAWS permits must be registered as students in their home countries. There is an annual quota of SAWS workers (25,000 in 2004, declining to 16,250 in 2005 ) and it is run by nine operators who recruit and place workers. The operators are registered with Work Permits UK, which inspects both operators and farmers. Two operators provide workers for farmers in specific geographical areas, two provide workers for farmers throughout the UK and five recruit for their own labour only.

The au pair scheme is an agreement between certain European countries to facilitate cultural exchange for young people at the same time as providing help to families with young children. There is no annual quota for au pairs and they are not categorised as workers for the purposes of immigration control. The rules stipulate that they must be coming 'for the purpose of learning English and not to work as a full-time childminder'. ${ }^{37}$ They can help in the home for a maximum of 25 hours a week plus two babysittings, and receive 'pocket money' rather than a wage. They are not subject to the minimum wage. The au pair must live 'as a member of an Englishspeaking family' and that family do not constitute employers. Au pair visas are valid for up to two years and are held by the au pair who is free to stay with any host family. Au pairs are not required to register in the Worker Registration Scheme.

Self-employed people in general may apply to enter the UK as a business person. They must usually have at least $£ 200,000$ to invest in their UK business. However, a group of countries known as the Central and Eastern European Countries (CEEC) are governed by 'Association Agreements'. This means that, among other advantages, they do not have to have $£ 200,000$ capital, including for those who are intending to set themselves up as self-employed. They must also have a business plan. In April 2004, nationals of Poland, Czech Republic, Slovakia, Lithuania and Bulgaria all fell under these arrangements, but Ukrainians did not.

\section{Postal survey and in-depth interviews with employers and agencies}

The postal survey of employers was carried out during May-July 2005. It was distributed for COMPAS by Work Permits UK and the British Hospitality Association. Five-and-a-half-thousand questionnaires were distributed and they drew a total of 365 responses (equivalent to a relatively low response rate of 6.6 per cent). ${ }^{38} \mathrm{Here}$, too, the data obtained are not necessarily representative of the wider population of employers in hospitality and agriculture/food processing. 
Of the 365 businesses that completed and returned survey questionnaires, 245 were in the hospitality sector and 120 in agriculture and food processing. Almost two-thirds of the hospitality respondents filled in the questionnaires on behalf of hotels, ${ }^{39}$ while the remainder were divided between restaurants (33 per cent), and canteens and catering ( 5 per cent). Of the respondents in agriculture/food processing, the majority were producers and packers of agricultural (mainly horticultural) goods (89 per cent). Eleven per cent were food or beverage manufacturers.

In both hospitality and agriculture/food processing, more than three-quarters of respondents described their firm as an individual business rather than as a branch of a bigger company or as company headquarters with several branches. Almost threequarters of the businesses surveyed ${ }^{40}$ can be classified as small businesses with fewer than 50 workers. The remainder are mainly made up of medium firms (50-249 workers) and very few large firms (more than 249 workers). Just over half of all businesses surveyed reported a turnover of less than £1 million in 2004.

As shown in Figures 1 and 2, the postal survey drew responses from across the United Kingdom. It is notable that only 4 per cent of all businesses ( 6 per cent in hospitality and, less surprisingly, none in agriculture and food processing) were in London. This is in contrast with the survey of workers, much of which, in the hospitality and construction sectors, was carried out in London.

Figure 1 Location of the businesses surveyed in the hospitality sector $(N=245)$

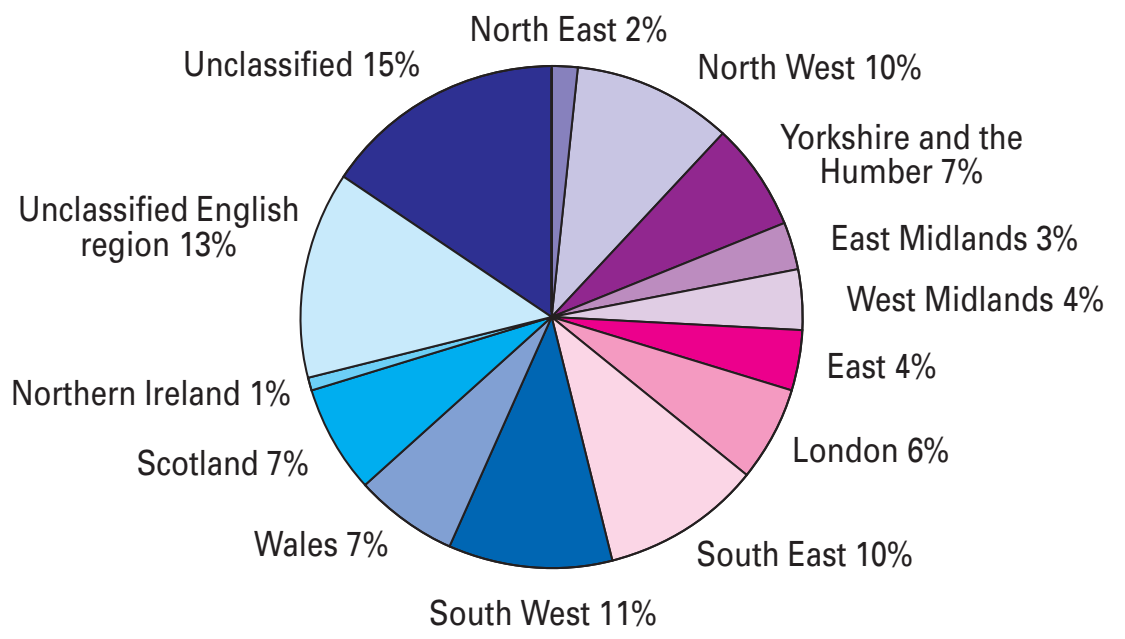

Source: postal survey of employers, May-July 2005. 
Fair enough?

Figure 2 Location of the businesses surveyed in agriculture and food processing $(N=120)$

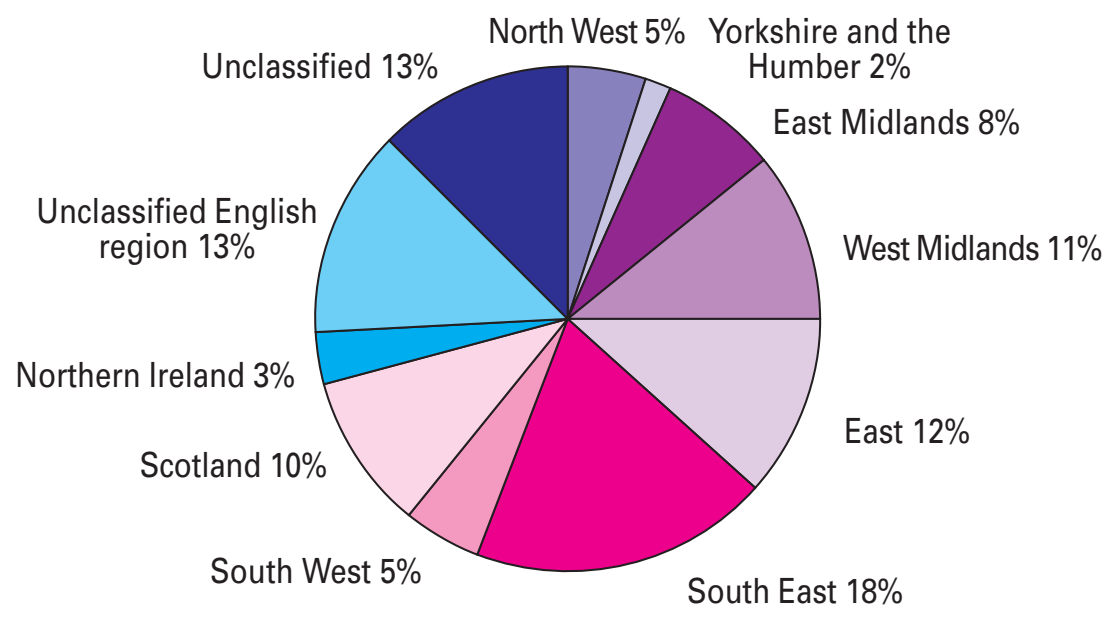

Source: postal survey of employers, May-July 2005.

Figure 3 shows the composition of the company workforce of employers surveyed in hospitality and agriculture/food processing. It can be seen that respondents in agriculture/food processing reported significantly higher shares of both A8 workers and non-EU workers in the total business workforce than respondents in the hospitality sector.

\section{Figure 3 Composition of business workforce by broad nationality group}

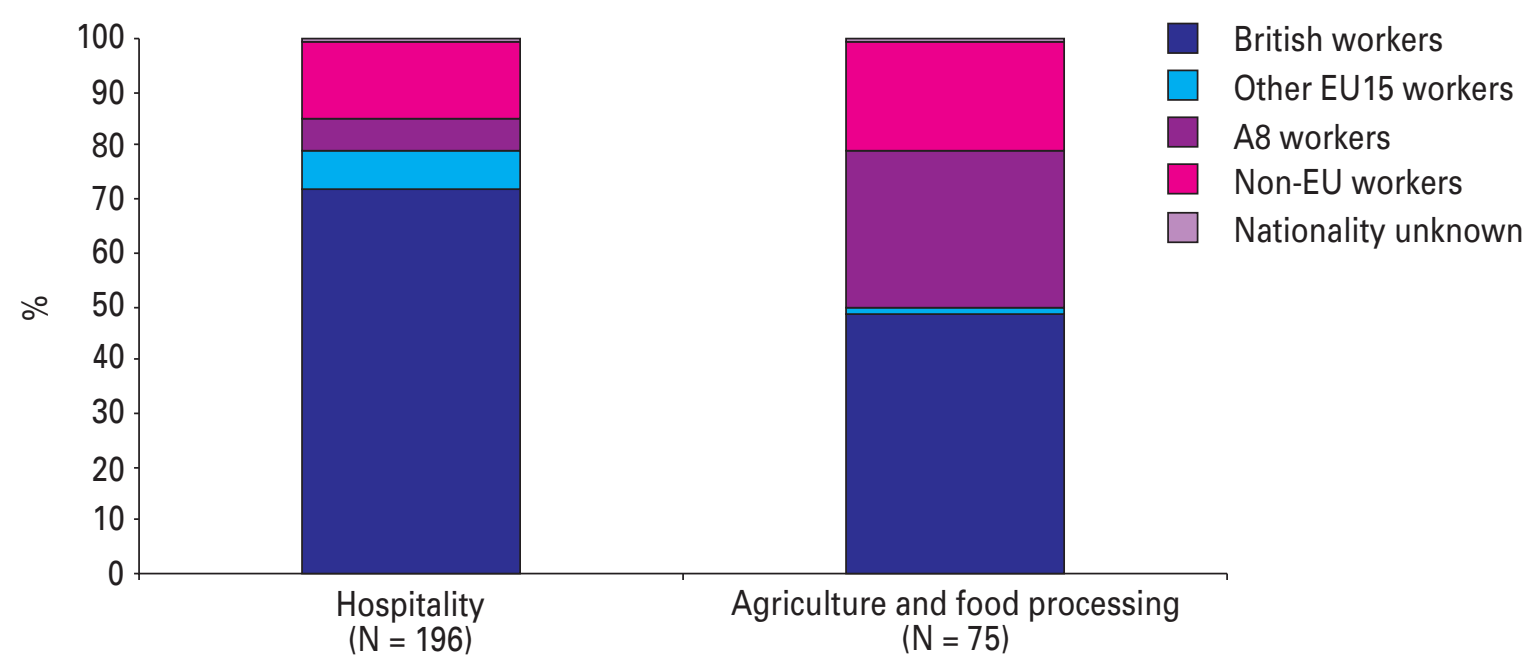

Source: postal survey of employers, May-July 2005. 
In addition to the postal survey, we also conducted in-depth interviews with 34 employers, including ten employment agencies, in: agriculture (nine employers, three agencies); construction (five employers, three agencies); and hospitality (ten employers, four agencies). In contrast to the postal survey, which was carried out only after EU enlargement, the in-depth interview data were collected in two waves, one at the time of EU enlargement (April/May 2004) and the second approximately seven months later. In Wave 1, we interviewed 32 employers (March-May 2004), of which 23 were reinterviewed in Wave 2 (November 2004-January 2005, with one interview in May 2005). Two additional employers were interviewed in the hospitality sector in Wave 2.

Unlike in the postal survey, only agricultural producers and packers, not food processors, were included in the sample of agricultural employers ${ }^{41}$ selected for indepth interviews. However, the three agencies interviewed in this sector between them provided labour across the UK food supply sector as a whole. Interviewees included soft fruit, salad, field vegetable and top fruit suppliers. Annual turnovers in 2003 ranged from under $£ 100,000$ to $£ 190$ million. The companies were all based in England in the following regions: East Midlands, West Midlands and South East. Of the labour providers in this sector, only one had more than one office. Each operated in a particular region corresponding to three of the regions where we interviewed employers.

The turnover of the five construction sector employers ${ }^{42}$ we interviewed ranged from $£ 100,000$ to $£ 4.5$ million. All were London-based, so the findings on construction from this dataset are specific to that region. The construction industry in London and the South East uses a high proportion of migrants, but it is structured very differently in other parts of the United Kingdom. Of the agencies providing construction workers, two were medium-sized with six and seven offices respectively, and one was very large with over 50 offices and some 9,000 workers on its books.

Almost all of the 14 hospitality sector in-depth interviews were based in London. The exceptions were one agency interviewed near Gatwick and one restaurant in each of Oxford and Bristol. Labour users ranged from small family-owned businesses to large chain hotels and restaurants. One conference centre manager was also interviewed. Two small labour-provider agencies were interviewed and one very large agency. 


\section{Postal survey and in-depth interviews with host families}

The postal survey of host families of au pairs was carried out during JanuaryFebruary 2005. It was sent to 800 host families and drew a total of 268 responses (equivalent to a response rate of 33 per cent). We also carried out an additional ten in-depth interviews with six different host families (four of whom were interviewed before and after EU enlargement).

Access to host families, both for the survey and for in-depth interviews, was obtained through au pair agencies. This is therefore not a random sample of host families, particularly since the agencies in turn had been contacted through the British Association of Au Pair Agencies (BAAPA), which represents the self-regulated section of the industry.

As shown in Table 7, the majority of postal survey respondents were female ( 88 per cent), aged 30-50 (93 per cent) and living with their partners (81 per cent). More than half of our 12 per cent of male respondents were single parents. All of our respondents had children living with them. Over 80 per cent of respondents had more than one child living with them and over one-third (38 per cent) had at least one child aged five or under.

Over 90 per cent of our respondents were British; the remainder were nationals of other European countries or of the USA, Australia or New Zealand. Ninety-seven per cent of our respondents described themselves as white. Most worked outside the home (more than 80 per cent), usually full-time, though 12 per cent described their occupation as 'housewives' or 'mothers'.

The sample was conspicuously highly educated, with 72 per cent of host family respondents holding a degree and 44 per cent having a postgraduate qualification. Accordingly, more than three-quarters of respondents were working in jobs requiring a high level of skill and qualifications. A similarly high share (74 per cent) of respondents were living in households whose total annual income exceeded $£ 50,000$.

Table 7 Respondents' living arrangements by gender

\begin{tabular}{lcccccc}
\hline Living arrangements & \multicolumn{2}{c}{ Male respondents } & \multicolumn{2}{c}{ Female respondents } & \multicolumn{2}{c}{ Total } \\
& $\boldsymbol{N}$ & $\%$ & $\boldsymbol{N}$ & $\%$ & $\boldsymbol{N}$ & $\%$ \\
\hline Living with partner & 19 & 59 & 196 & 84 & 215 & 81 \\
Living with no partner & 13 & 41 & 37 & 16 & 50 & 19 \\
Total & 32 & 100 & 233 & 100 & 265 & 100 \\
\hline
\end{tabular}

Source: postal survey of host families, January-February 2005. 
In addition to the postal survey, we also carried out five in-depth interviews with host families before EU enlargement. Four out of five in-depth interviewees were female. All interviewees were white British aged 31-40 and had children. The respondents' occupations included architect, housewife, lecturer, recruitment manager and researcher. Four interviewees had a degree or postgraduate qualifications. Two respondents' annual household incomes were in excess of $£ 50,000$. Of the five au pair agencies we interviewed, two were based in London and two in towns in the South and East of England. The fifth, larger, agency had offices in different English towns. Two dealt with au pairs only and three with a range of childcare provision, focused principally on provision in private households. Numbers of au pairs dealt with ranged from 300 to 700, and host family numbers were between 240 and 1,000 per year.

\section{Migrant diaries}

In order to capture the 'felt impacts' of immigration status, we requested some migrants to keep diaries from October 2004 for six months. These were designed to give diarists space to record their thoughts and experiences in a semi-structured way in their own language, every two weeks. The selection of diarists was made with the intention of involving an approximately equal number of each of the six nationalities of worker being studied and of workers/au pairs who had recent work experience in each of the sectors. It was also intended that the ratio of men to women would approximately reflect their proportions in the sector. Although we had initially aimed at 50 diarists, the number of people open to contributing was nearer to 30 . In the end, a total of 12 diarists wrote fortnightly entries, which were supplemented in May 2005 with a final essay written at the workshop for diarists and worker and employer interviewers. Table 8 shows how the diarists were distributed by nationality.

Table 8 Migrant diaries (November 2004-May 2005)

\begin{tabular}{lcccccc}
\hline Czech & Lithuanian & Polish & Slovak & Bulgarian & Ukrainian & Total \\
\hline 2 & 0 & 2 & 3 & 3 & 2 & 12 \\
\hline
\end{tabular}




\section{Policy interviews}

In order to explore the historical and policy context of the research questions, 16 interviews were conducted in June 2005 with representatives of organisations with responsibilities relating to migrant workers in the public, private and voluntary sectors. These were with officials in the Home Office, Department of Work and Pensions, and Work Permits UK; in a local authority in whose area a significant number of migrant agricultural workers are living (involving two officials and a representative of the local diocese); with two senior police representatives in the same region; with the TUC and two trades unions representing workers in the sectors covered by the project; with the $\mathrm{CBI}$, three bodies representing employers and one agency responsible for placing SAWS workers; with the head of a migrant association; and with representatives from two embassies from among the six Eastern and Central European countries covered by the research. The interviews established the nature of the organisation's responsibility for migrant workers before exploring the anticipated impact of EU enlargement on 1 May 2004 and the actual impact experienced by the organisation and/or its members.

\section{Overview of sectors studied in this project}

It is well known that migrant labour is an important component in all of the sectors in which we are interested: agriculture, construction, hospitality and the au pair sector. ${ }^{43}$ Rather than providing a comprehensive overview, this section briefly outlines some of what, for our purposes, are the key features of each of the four sectors under consideration.

\section{Agriculture}

There is a high demand for workers in jobs designated 'low skill', for planting and harvesting crops, on farm processing and packing. ${ }^{44}$ The agriculture sector as a whole has long relied on the labour of contingent workers, often women, children or migrants, to fulfil its requirement for large numbers for short periods. ${ }^{45}$ Temporary workers are required in the sector at particular times and businesses cannot afford to keep them on across the year. Since at least the nineteenth century, these seasonal fluctuations have been managed in the UK through the use of labour-supplying intermediaries, often referred to as gangmasters. A recent survey for the Department of Environment, Food and Rural Affairs estimated the number of temporary workers in UK agriculture and horticulture in the year to spring 2004 to be between 420,000 
and $611,000 .{ }^{46}$ In this report, we focus on the labour-intensive subsectors of fresh fruit, vegetable and salad production, which require large numbers of temporary workers for manual harvesting and other work. Recent research suggests, that wherever in the UK they are located, horticultural businesses across the country have greatly increased their use of foreign nationals over the last decade, through use of both the Seasonal Agricultural Workers Scheme and labour-providing agencies ('gangmasters'). ${ }^{47}$

\section{Construction}

Construction work is generally carried out on a project basis. Contractors bring together teams of workers, many of whom are self-employed, who work together for a period of time and then disperse. As of late 2003, about 37 per cent of the construction workforce was self-employed. ${ }^{48}$ The historical reliance on subcontracting has recently increased. ${ }^{49}$ There are critical shortages in skilled trades, as well as in elementary occupations. The data on migrants in the sector are limited, but migrant labour is acknowledged to be an important component of the skilled and low-skilled workforce. A survey conducted by the Considerate Constructors Scheme (2004) suggests that there are up to 100,000 workers on UK building sites for whom English is a second language. There is no legal scheme for migrants to enter to work in construction, but it is possible for certain nationalities to obtain a self-employed visa enabling them to take on work in this sector and many migrants have taken this option.

\section{Hospitality}

The hospitality sector can be divided into both public and commercial sectors and, within the latter, it can be further divided into both hotel and catering sectors. In this research project we focused on the commercial sector within hospitality, concentrating (but not exclusively so) on hotels and restaurants. Difficulties of retention and recruitment, particularly at the lower end of the skills level, have long plagued the industry. It has previously relied on recruitment of young and female workers to fill bottom-end, low-wage jobs, but is increasingly looking to recruit older and migrant labour. ${ }^{50}$ There are a number of schemes to facilitate migration into the sector, most notably the Sector-based Scheme for low-skilled workers, and work permits for the highly skilled. However, international students and working holidaymakers with permission to engage in paid employment as an incidental activity during their stay in the UK also work in the sector - as do British students. 
Migrant workers tend to work as cooks, waiting and bar staff, and in room service, in housekeeping and as cleaners. Certain groups may also work in 'front-of-house' jobs such as receptionists. The numbers of migrants in the sector is unknown but, according to the TUC, in 2003, 70 per cent of catering jobs in London were carried out by migrants. ${ }^{51}$

\section{The au pair sector}

Little is known about this diverse sector. Data and analysis are particularly challenging because the sector straddles both paid and unpaid work. It is known, though, that domestic work in private households is an important employment sector for migrants, particularly migrant women. It is also thought that domiciliary care services are increasingly dominated by migrants. ${ }^{52}$ While there is a domestic workers' visa available, this is only for workers accompanying employers and the only legal means of applying for household help from abroad otherwise is the au pair scheme. Au pairs are not designated as workers - though there have recently been some successful legal challenges on this matter. While originally designed as a cultural exchange programme, it has grown in size and is increasingly used by families to access live-in domestic help. ${ }^{53}$ While the majority of au pairs are female, there are also increasing numbers of young male au pairs. 


\section{Migrants in low-wage jobs: experiences and perceptions of employment}

This chapter draws on data obtained from survey and in-depth interviews with migrants to discuss their experiences and perceptions of employment in the UK. Although we discuss various aspects of migrants' employment, we are particularly interested in exploring the role that immigration status may have on migrants' labour market outcomes.

Most of the discussion refers to migrants' experiences as of April 2004, i.e. just before EU enlargement. This enables us to draw on the full sample of 550 survey respondents and 93 in-depth interviewees who provided information about their employment in April 2004. The discussion of changes in migrants' employment following EU enlargement at the end of this chapter makes use of the information provided by 352 respondents and 62 interviewees about their employment before and six to eight months after 1 May 2004.

Before proceeding with the analysis, it is necessary to introduce the concept of the 'primary job'. This is needed because some 12 per cent of our survey respondents were working in multiple jobs in April 2004 (see Table 9). The share of respondents

Table 9 Respondents' total number of jobs and type of primary job, April 2004

\begin{tabular}{lrrrrr}
\hline & Hospitality & Construction & Au pair & Agriculture & Total \\
\hline Number of jobs held in April 2004 & 181 & 174 & 51 & 80 & 486 \\
1 & 22 & 3 & 24 & 2 & 51 \\
2 & 2 & 1 & 9 & 0 & 12 \\
3 & - & - & 1 & 0 & 1 \\
4 & & & & & \\
Primary job is & 46 & 8 & 57 & 3 & 114 \\
Part-time & 159 & 170 & 28 & 79 & 436 \\
Full-time & 184 & 89 & - & 79 & 352 \\
Employment status in primary job* & 21 & 85 & - & - & 106 \\
Employee & - & - & 85 & - & 85 \\
Self-employed & 205 & 178 & 85 & 82 & 550 \\
Au pair & & & & & \\
Total & & & &
\end{tabular}

Source: survey interviews with migrants.

* Four missing observations in construction; and three missing observations in agriculture. 
with multiple jobs was highest in hospitality (12 per cent) and the au pair sector (40 per cent). In contrast, almost all respondents working in agriculture and construction reported to be working in only one job in April 2004.

The job reported by respondents with only one job is naturally also their 'primary job'. For all those respondents with more than one job in April 2004, the 'primary job' has been defined as the job that respondents would 'least like to lose'. The majority of respondents doing more than one job said that they would least like to lose their primary job because it was their 'most stable job' or the 'best paid job'.

Given the data about number of jobs held, it is not surprising that almost all primary jobs in construction and agriculture were full-time jobs. In contrast, a quarter of the primary jobs reported in the hospitality sector - and two-thirds of the primary jobs of au pairs ${ }^{1}$ - were part-time jobs (i.e. jobs with less than 30 working hours per week).

There are some differences by gender. Only 3 per cent of male respondents, but 22 per cent of female respondents, had more than one job in April 2004. Accordingly, part-time working was more common among female respondents (36 per cent reported their primary jobs to be part-time jobs) than male respondents ( 9 per cent). ${ }^{2}$

It should also be noted that a significant number of respondents described their employment status in their primary job as 'self-employed' (48 per cent in construction and 10 per cent in hospitality). As will be shown later in this chapter, a self-reported employment status of 'self-employed' does not necessarily imply a corresponding immigration status of 'self-employed', or vice-versa.

Unless indicated otherwise, the following analysis of the experiences and perceptions of respondents' and interviewees' employment refers to their primary jobs in April 2004. The discussion explores various aspects of migrants' (self-) employment ${ }^{3}$ including:

- migrants' employment conditions including pay, working hours and non-wage benefits

- the (mis)match between migrants' qualifications and the skills required in their jobs in the UK

- migrants' perceptions of immigration status, and the potential relationship between immigration status and migrants' experiences in the labour market

- contracts, agency working and informal working 
the changes perceived and experienced by migrants following EU enlargement.

At this stage of our analysis, some of our findings are still exploratory rather than comprehensive. Our main contribution at this stage is to highlight a number of important but significantly under-researched dimensions of migrants' employment in the UK, including aspects and potential implications of 'illegality' and 'illegal working'.

\section{Work, conditions and benefits}

As shown in Table 10, a significant share - but not all - of the respondents were working in occupations defined as requiring a relatively low level of skill. ${ }^{4}$ In hospitality, two-thirds of respondents were working in elementary occupations and about 12 per cent in skilled trades occupations including especially kitchen chefs. ${ }^{5}$ In agriculture, the corresponding shares were 62 per cent and 23 per cent, respectively. The highest proportion of skilled trades respondents was in construction where almost two-thirds were employed in skilled trades occupations (including carpenters as the biggest group), and a quarter of the respondents worked in elementary occupations.

Table 10 Respondents' occupation by sector of employment, primary job in April 2004

\begin{tabular}{|c|c|c|c|c|c|}
\hline & Hospitality & Construction & Au pair & Agriculture & Total \\
\hline $\begin{array}{l}\text { Managerial, professional, } \\
\text { administration and secretarial } \\
\text { occupations }{ }^{\star}\end{array}$ & al & 2 & - & 2 & 30 \\
\hline Skilled trades occupations & 24 & 114 & - & 19 & 157 \\
\hline Personal service occupations & 4 & - & 85 & - & 89 \\
\hline $\begin{array}{l}\text { Sales and customer service } \\
\text { occupations }\end{array}$ & 11 & - & - & 1 & 12 \\
\hline $\begin{array}{l}\text { Process, plant and machine } \\
\text { operatives }\end{array}$ & 4 & 7 & - & 6 & 17 \\
\hline Elementary occupations & 136 & 47 & - & 51 & 234 \\
\hline Unknown & 1 & 8 & - & 3 & 11 \\
\hline Total & 205 & 178 & 85 & 82 & 550 \\
\hline Of whom self-employed & 21 & 85 & - & - & 106 \\
\hline $\begin{array}{l}\text { Of whom self-employed in } \\
\text { skilled trades occupations }\end{array}$ & 10 & 66 & - & - & 76 \\
\hline $\begin{array}{l}\text { Of whom self-employed in } \\
\text { elementary occupations }\end{array}$ & 8 & 14 & - & - & 22 \\
\hline
\end{tabular}

Source: survey interviews with migrants.

* This occupational category includes: managers and senior officials; professional occupations; associate professional and technical occupations; and administrative and secretarial occupations. 
Note that self-reported self-employment was particularly prevalent among - but not strictly limited to - respondents working in skilled trades occupations (58 per cent in construction and 41 per cent in hospitality).

\section{Workers: conditions and benefits}

For the purposes of the discussion of respondents' employment conditions we consider workers and au pairs separately, as the latter are not defined as 'workers' or 'employees'. Whenever necessary, we also distinguish between respondents who describe themselves as employees and self-employed. The discussion below focuses on migrants' pay, working hours and non-wage benefits. It is worth noting at the outset that none of our respondents was a member of a trade union.

\section{Pay}

Respondents in hospitality, construction and agriculture (i.e. 'workers') were asked a number of questions about their pay - including questions about their gross pay and weekly working hours ('including overtime') - for each of the jobs held in April 2004. Respondents were given the option of reporting gross pay per hour, per week or per month. Only 193 workers (45 per cent of respondents who provided information about their gross pay) chose to report hourly figures. For the remainder, hourly gross pay had to be computed based on weekly working hours and weekly or monthly gross pay reported. ${ }^{6}$

As shown in Table 11, the computed gross hourly pay for respondents working as employees in elementary occupations ranged from $£ 5.00$ in hospitality to $£ 5.71$ in construction. As might be expected, gross hourly pay rates in skilled trades occupations were higher, ranging from $£ 5.46$ in agriculture to $£ 8.29$ in construction. Respondents describing their employment status as self-employed reported higher average pay than respondents who worked as employees.

It is important to emphasise that the earnings data obtained from our survey need to be interpreted with care. The most important caveat is that our data are based on a relatively small and non-randomly selected sample of migrant workers. There may also be a number of other complicating factors including, for example, inconsistent treatment of overtime hours across respondents. Qualitative data from interviewees working in hospitality also suggest that tips, which may or may not be included in respondents' gross pay calculations, are an important component of workers' pay: 
Table 11 Hourly gross pay of respondents, April 2004

\begin{tabular}{lcccc}
\hline & Hospitality & Construction & Agriculture & Total \\
\hline Employees in skilled trades occupations & 6.30 & & & \\
Mean £ & 1.32 & 2.29 & 5.46 & 7.34 \\
SD & 13 & 45 & 1.8 & 2.67 \\
$N$ & & 16 & 74 \\
Employees in elementary occupations & 5.00 & 5.71 & 5.35 & 5.19 \\
Mean £ & 1.26 & 1.40 & 1.29 & 1.31 \\
SD & 118 & 32 & 41 & 191 \\
N & & & & \\
Total employees (all occupations) & 5.41 & 7.38 & 5.41 & 5.94 \\
Mean £ & 1.57 & 2.75 & 1.44 & 2.12 \\
SD & 167 & 85 & 66 & 318 \\
N & & & & \\
Total self-employed & 6.69 & 11.15 & - & 10.31 \\
Mean £ & 1.76 & 4.47 & - & 4.45 \\
SD & 16 & 70 & - & 85 \\
N & & & & 6.86 \\
Total respondents & 5.52 & 9.09 & 5.43 & 3.29 \\
Mean £ & 1.62 & 4.07 & 1.43 & 407 \\
SD & 183 & 155 & 69 & \\
$N$ & & &
\end{tabular}

Source: survey interviews with migrants.

I get paid per hour but apart from that, since I work in a restaurant, I get tips. There are two kinds of tips: tips in cash I get for myself, and tips by credit cards go through my account and I pay taxes on them ${ }^{7} \ldots$ the fixed rate is $£ 3.50$ per hour, but if I don't get any tips on credit cards, our employer has to add for us to the minimum rate of $£ 4.50$. But this never happens because simply tips from credit cards are added to the $£ 3.50$. (Polish female hospitality worker aged $30[\mathrm{~W} 1])^{8}$

Table 12 contains data taken from the Annual Survey of Hours and Earnings 2004 (ASHE 2004) (ONS, 2004) on the average gross hourly pay for all employees in the United Kingdom, by the occupations relevant to our project. A comparison of these official data with our survey data suggests that the earnings of a significant number but not all - of our survey respondents were relatively low compared to the national average for all employees within the relevant occupational category. 
Table 12 Hourly gross pay for all employee jobs, United Kingdom, 2004

\begin{tabular}{|c|c|c|c|c|c|c|}
\hline Occupation & $\begin{array}{l}\text { Mean gross } \\
\text { hourly pay }\end{array}$ & 10 & 20 & $\begin{array}{l}\text { Percentiles* } \\
30\end{array}$ & 40 & 60 \\
\hline Skilled trades & 9.87 & 5.76 & 6.85 & 7.72 & 8.49 & 10.10 \\
\hline Skilled agricultural trades & 7.50 & 5.21 & 5.68 & 6.20 & 6.72 & 7.62 \\
\hline $\begin{array}{l}\text { Skilled construction and } \\
\text { building trades }\end{array}$ & 9.77 & 6.51 & 7.50 & 8.10 & 8.61 & 9.96 \\
\hline Chefs, cooks & 6.87 & 4.70 & 5.10 & 5.49 & 5.78 & 6.60 \\
\hline Elementary occupations & 6.96 & 4.52 & 4.90 & 5.17 & 5.49 & 6.45 \\
\hline $\begin{array}{l}\text { Elementary agricultural } \\
\text { occupations }\end{array}$ & 6.79 & 5.00 & 5.27 & 5.69 & 6.09 & 6.76 \\
\hline $\begin{array}{l}\text { Elementary construction } \\
\text { occupations }\end{array}$ & 7.89 & 5.14 & 5.84 & 6.29 & 6.84 & 7.87 \\
\hline $\begin{array}{l}\text { Elementary personal } \\
\text { services occupations }\end{array}$ & 5.63 & - & 4.50 & 4.67 & 4.90 & 5.31 \\
\hline
\end{tabular}

Source: Annual Survey of Hours and Earnings 2004 (ONS, 2004).

* The xxth percentile is that value that is greater or equal to xx per cent of the observations. For example, in elementary personal service occupations, 30 per cent of employees are earning $£ 4.67$ per hour or less.

** Includes hotel porters, kitchen and catering assistants, waiters and waitresses, bar staff, hospital porters, leisure and theme park attendants and elementary personal services occupations n.e.c. (not elsewhere classified).

To further explore the issue of low pay among our survey respondents in the context of minimum wages, Table 13 gives a breakdown of the various ranges of gross hourly pay reported by respondents who described themselves as employees. Given the various complexities of minimum wage regulations (especially with respect to agriculture), the survey data collected are not detailed enough for an accurate assessment of the share of respondents receiving earnings below the minimum wage. Nevertheless, the survey data do suggest that a significant number of respondents were working at gross hourly pay rates that were close to - but not necessarily below - the national minimum wage (NMW), especially in hospitality and agriculture (where the majority of respondents were working in elementary occupations).

In April 2004, the NMW in construction and hospitality was $£ 4.50$ per hour for workers aged 22 years and older; and £3.80 per hour for workers aged $18-21 .{ }^{9} \mathrm{In}$ agriculture, wages are set by the Agricultural Wages Board. A number of minimum wages are set depending, among other things, on the worker's age and whether the work consists of manual harvest work. In April 2004, the minimum wage for a 'standard' worker in agriculture was $£ 5.15$ per hour for workers aged 19 and over, and $£ 4.38$ for 18 year olds. The rate for 'manual harvest workers' aged 19 or over was $£ 4.50$ per hour. Where a worker is paid a piece rate, the worker's wages must not be less than the appropriate minimum for the actual hours worked. 
Table 13 Respondents' gross hourly pay by range, April 2004 (employees only)

\begin{tabular}{lrrrrrrrr}
\hline Gross hourly & \multicolumn{2}{c}{ Hospitality } & \multicolumn{2}{c}{ Construction } & \multicolumn{2}{c}{ Agriculture } & \multicolumn{2}{c}{ Total } \\
pay $(£)$ & $\boldsymbol{N}$ & $\%$ & $\boldsymbol{N}$ & $\%$ & $\boldsymbol{N}$ & $\%$ & $\boldsymbol{N}$ & $\%$ \\
\hline$<3.00$ & 7 & 4 & 1 & 1 & 1 & 2 & 9 & 3 \\
$3.00-3.49$ & 7 & 4 & 1 & 1 & 1 & 2 & 9 & 3 \\
$3.50-3.99$ & 9 & 5 & 3 & 4 & 4 & 6 & 16 & 5 \\
$4.00-4.49$ & 12 & 7 & 4 & 5 & 4 & 6 & 20 & 6 \\
$4.50-4.99$ & 24 & 14 & 2 & 2 & 12 & 18 & 38 & 12 \\
$5.00-5.49$ & 32 & 19 & 8 & 9 & 25 & 38 & 65 & 20 \\
$5.50-5.99$ & 22 & 13 & 7 & 8 & 6 & 9 & 35 & 11 \\
$6.00-6.49$ & 21 & 13 & 17 & 20 & 3 & 5 & 41 & 13 \\
$6.50-6.99$ & 5 & 3 & 5 & 6 & 1 & 2 & 11 & 3 \\
$>7.00$ & 28 & 17 & 37 & 44 & 9 & 14 & 74 & 23 \\
Total & 167 & 100 & 85 & 100 & 66 & 100 & 318 & 100 \\
\hline
\end{tabular}

Source: survey interviews with migrants.

\section{Working hours}

Average weekly working hours of respondents who were working as full-time employees in their primary jobs were: 45.3 in hospitality; 45.6 in construction; and 47.9 in agriculture. Figure 4 shows respondents' total weekly working hours by occupational category and compares them with the total weekly working hours reported for comparable occupations in the ASHE 2004. Across all occupational categories, survey respondents were on average working longer hours than the average hours reported in the ASHE 2004.

Among full-time employees, the proportion of respondents reporting overtime work was just over 40 per cent in hospitality and construction, and almost 50 per cent in agriculture. Figure 5 compares the average number of weekly overtime hours by fulltime employees, as reported by our survey respondents and in the ASHE 2004. It is interesting to note that the difference between the average weekly overtime hours reported by our survey respondents and the average weekly overtime hours for all employees (as given in the ASHE 2004) was positive in some sectors but negative in others.

Comparing Figures 4 and 5 , it is clear that the overall difference between the average weekly working hours reported by survey respondents and the corresponding average for all employees found in the ASHE 2004 cannot be adequately explained by corresponding differences in overtime hours. In fact, in some sectors, our survey respondents worked overtime hours that were below the national average for all employees. The bulk of the difference in overall working hours must therefore be due to differences in basic hours worked. 
Figure 4 Total working hours per week of full-time employees, ASHE 2004 and Compas survey respondents (April 2004)

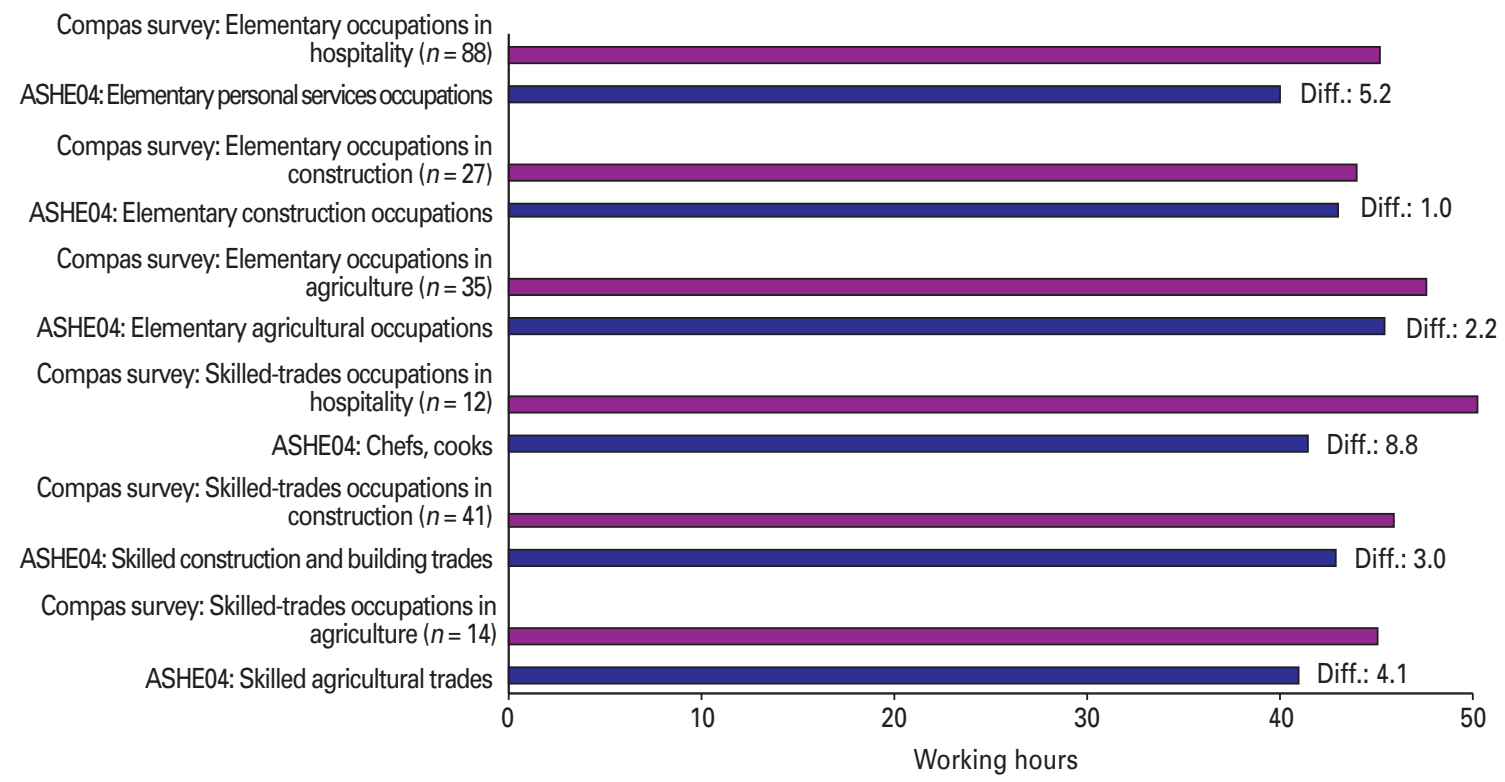

Source: ASHE 2004 and Compas survey interviews with migrants.

\section{Figure 5 Overtime hours per week of full-time employees, ASHE 2004 and Compas survey respondents (April 2004)}

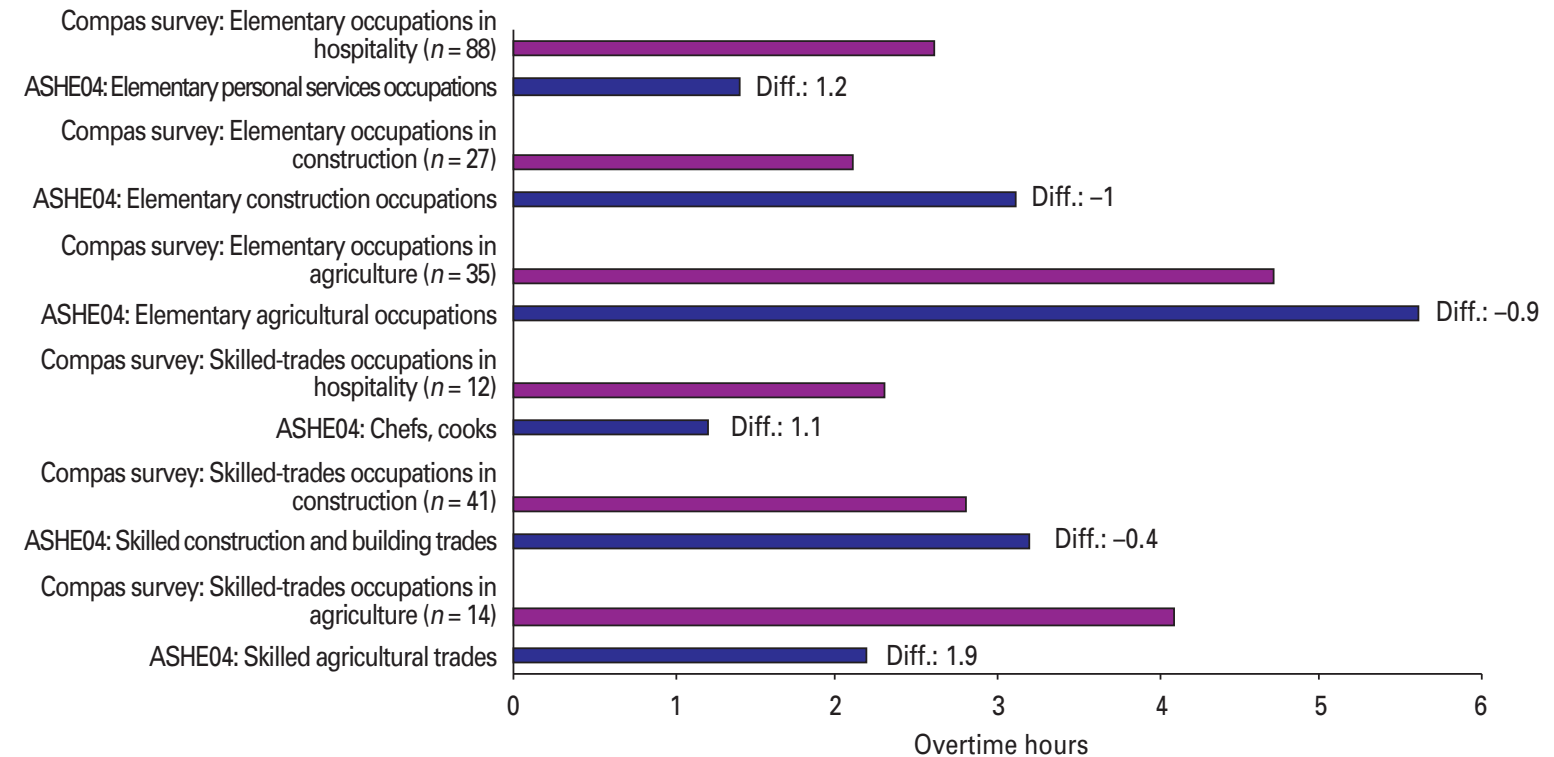

Source: ASHE 2004 and Compas survey interviews with migrants. 
The survey data from full-time employees doing overtime work further suggest that, in construction and agriculture, most overtime was paid (but not necessarily at higher 'overtime' rates). In contrast, respondents working in hospitality suggested that just over a third of their overtime work was 'unpaid' (in the sense that, according to respondents, no payments were received for the overtime hours worked). Hospitality was also the only sector where a significant share of respondents (45 per cent) suggested that most of their regular working hours were not during 8.00 a.m. to 6.00 p.m.

\section{Non-wage benefits}

Survey respondents were also asked about non-wage benefits which, as may be expected, were found to vary with sector of employment. For example, only 10 per cent of employee respondents in agriculture reported they were receiving free food. In contrast, in hospitality, more than 70 per cent of respondents said they benefited from free food. In-depth interviewees in low-paid hospitality confirmed that free food, or very cheap meals, were significant benefits in terms of supplementing both their income and how they felt about work - 'your every wish comes true, you can take everything' (Ukrainian female hospitality worker aged 25 [W2ret]). Just under half of respondents working in hospitality and agriculture reported they were benefiting from paid holidays. The shares receiving sick leave were even smaller: 29 per cent in hospitality; and 17 per cent in agriculture.

Very few employees were offered free accommodation - only 3 per cent in total. Free accommodation was reported by agricultural workers (10.3 per cent). This should not be taken as representative since the agricultural workers were interviewed at relatively few sites. ${ }^{10}$ Respondents working in construction who were not self-employed reported a very low level of benefits received: less than 15 per cent of employees received paid holidays and/or paid sick leave and none received free accommodation.

\section{Au pairs: conditions and benefits}

The au pairs interviewed in Wave 1 spent about half of their working time looking after children. The other two major activities were cleaning (19 per cent of working time) and ironing (7 per cent). ${ }^{11}$ 
The average weekly'pocket money' for au pairs was £68. Au pairs reported an average of 30 working hours per week, five hours above the guideline maximum of 25 working hours per week. The great majority ( 94 per cent) of au pairs interviewed said that their regular working hours were during the day. Fifty per cent said that they were working an average of eight hours of 'overtime' per week, most of which was 'unpaid'. One au pair who had become a nanny observed that, in her new situation:

All overtime hours are paid, sometimes even double the rate depending whether it is during weekends or in the evening. With an au pair it is more a matter of 'Can you do me a favour?' and it is always unpaid.

(Slovak female au pair aged 28 [W2ret])

Generally the work was felt to be 'hard and stressful' (Slovak female hospitality worker aged 34 [W2ret]). Seventy-eight per cent did not have a written contract with their host family. Au pairs must live as part of the family, so the provision of certain 'benefits' including accommodation and food is a requirement of host families. In addition, some au pairs received paid holidays (60 per cent); and paid visits to au pairs' home countries (16 per cent).

The au pair scheme rests on notions of 'cultural exchange', but over one-third of the respondents did not participate in any cultural activities, while 44 per cent were offered such opportunities less than once a month. ${ }^{12}$ The purpose of the au pairs' visit must be to learn English and 27 per cent said that they were offered free English classes. Seventy-one per cent of our respondents working as au pairs in April 2004 were attending English classes for at least two hours a week. Eighteen of the 25 respondents who did not attend classes described their spoken English as 'adequate' or 'basic'.

\section{High-quality migrants in low-skill jobs?}

For some respondents working in elementary occupations, there appears to be a significant mismatch between their (self-reported) qualifications/skills and the skills required to competently carry out their primary jobs in April 2004. Table 14 gives an indication of some of the qualifications and skills of the survey respondents. 
Table 14 Indicators of qualifications and skills of respondents working in elementary/personal service occupations in April 2004

\begin{tabular}{|c|c|c|c|c|}
\hline & Hospitality & Construction & Agriculture & Au pairs \\
\hline $\begin{array}{l}\text { Age in April } 2004 \text { (mean years, } \\
\text { Nw = 224; Nau-p }=85)^{\star}\end{array}$ & 27 & 31 & 25 & 23 \\
\hline \multicolumn{5}{|c|}{ Highest level of schooling completed $(\%, \mathrm{Nw}=233 ; \mathrm{Nau}-\mathrm{p}=85)$} \\
\hline Lower secondary & 2 & 11 & 4 & 6 \\
\hline Upper secondary & 39 & 32 & 63 & 61 \\
\hline Post-secondary & 59 & 57 & 33 & 33 \\
\hline \multicolumn{5}{|c|}{ Months of work experience (mean, Nw = 224; Nau-p = 72) } \\
\hline Total & 75 & 107 & 41 & 31 \\
\hline In UK & 20 & 16 & 6 & 9 \\
\hline \multicolumn{5}{|c|}{ English-speaking proficiency $(\%, \mathrm{Nw}=234 ; \mathrm{Nau}-\mathrm{p}=85)$} \\
\hline Fluent or adequate & 76 & 51 & 55 & 88 \\
\hline Basic & 21 & 38 & 43 & 12 \\
\hline None & 2 & 11 & 2 & - \\
\hline $\begin{array}{l}\text { Average months since last entry to } \\
\text { the UK, as of April 2004 } \\
(\mathrm{Nw}=224 ; \mathrm{Nau}-\mathrm{p}=85)\end{array}$ & 20 & 18 & 4 & 13 \\
\hline \multicolumn{5}{|c|}{ Employment status and occupation before last entry to the UK } \\
\hline Not working and not looking for work & 40 & 11 & 30 & 30 \\
\hline Not working but looking for work & 32 & 11 & 8 & 16 \\
\hline Working & 64 & 25 & 13 & 39 \\
\hline $\begin{array}{l}\text { Managerial, professional, } \\
\text { admininstration and secretarial } \\
\text { occupations }\end{array}$ & 33 & 8 & 6 & 19 \\
\hline \multicolumn{2}{|c|}{ Other including elementary occupations 29} & 15 & 7 & 18 \\
\hline
\end{tabular}

Source: survey interviews with migrants.

* 'Nw' indicates number of respondents working in hospitality, construction and agriculture. 'Nau-p' indicates number of respondents working as au pairs.

Elementary occupations 'will usually require a minimum general level of education'. ${ }^{13}$ Our interview data suggest that the qualifications and skills of some of our respondents working in elementary occupations - especially those working in hospitality - significantly exceeded these minimum requirements. More than half of the respondents doing elementary jobs in hospitality had post-secondary education (including 42 per cent with tertiary education). Seventy-six per cent described their spoken English as fluent or adequate. Only 3 per cent of au pairs were working in personal services before coming to the UK, and more than half were working in more formally skilled occupations, most of them in administrative and secretarial occupations (30 per cent). Au pairs had the highest proportion of fluent or adequate English speakers. 
There was some unhappiness expressed at the mismatch between their qualifications and their work. This diary entryist explained:

I am more and more nervous because of the fact that I am not able to get a job according to my education and skills and I still work manually which brings me down pretty much. Every day my mind is occupied by money! What is the fastest way to earn? I have no problem with manual work but I would like to use my brains and skills to earn money.

(Slovak male former au pair)

In-depth interviewees included an experienced accountant working as a waitress, a machinist working as an agricultural labourer and a philosopher working as a labourer on a building site. Some felt isolated - the philosopher complained, for example, about the 'low intellectual level' on construction sites, and there were often complaints about the lack of potential for intellectual development and the physical demands of their work. The following speaker had come to the UK after completing her masters degree:

It is a big physical effort, which definitely is not proportional to the payment. And in general this job is very dulling on a long-term basis burning one out intellectually I would say.

(Polish female hospitality worker aged 28 [W1])

Some felt that they lacked experience in physical labour and consequently found that it was particularly hard and required a change in attitude:

I hadn't had a hammer in my hand since high school. And it was difficult because my friend was paid piece work and you know I didn't have experience and I couldn't keep up with him ... it was hard physical work. I will show you photos what I looked like.

(Polish male construction worker aged 28 [W1])

In Poland I never did this kind of work. Because in Poland I would be an intellectual worker, and here I'm a physical worker in some sense. So first of all I had to change my attitude.

(Polish female hospitality worker aged 30 [W1])

However, the work performed was not viewed purely negatively. Some interviewees, while finding the work hard, also felt they were learning new skills, particularly communication, language and organisational. The 30-year-old graduate cited above explained how she had changed: 
I noticed that I count more on experience than on knowledge. Once I had a greater respect for knowledge and was a more intellectual person.

(Polish female hospitality worker aged 30 [4W1])

Interviewees sometimes responded in manners that indicated different ways of maintaining self-respect. Some people took pride in their rising to the physical demands of their jobs. One interviewee explained how he was called 'The Beast' by co-workers because of his immense physical strength, which he deployed carrying $27 \mathrm{~kg}$ concrete blocks up to the appropriate construction level. Another, who had previously worked in computer design and was working in construction in the UK, was positive about the change in employment:

Because it's something new. Something that I never did in my life and in Poland I could never imagine earning enough money in this job to live on ... I like the way I work not maybe the actual work. I like that nobody stands above me and looks onto my hands, and that I don't have to ask if I can have coffee now and smoke or chat on the phone because this is my private business.

(Polish male construction worker, age unknown [W1])

The mismatch between some respondents' qualifications and the skills required to carry out their jobs in the UK is, at least in part, likely to be a reflection of their immigration status. In hospitality, for example, 29 per cent of respondents reported being students in the UK. Similarly, more than half of the respondents working in agriculture had SAWS visas, which are restricted to migrants who are students in their home countries. This is not, however, the only explanation and the picture that emerges from the in-depth material is complex. Some interviewees talked about a clear economic trade-off - working hard in lower-status jobs that pay more than 'better' jobs in their country of origin:

Clearly it is not something to fulfil one's ambitions. It is the type of work that one does exclusively for the purpose of earning money.

(Polish female au pair aged 29 [W2ret])

Several in-depth interviewees also mentioned 'money' as a reason why people might want to forfeit holidays and other benefits: 'we give up certain things for the sake of income' (Polish female hospitality worker aged 30 [W1]).

However, some interviewees claimed to be earning less than they were in their countries of origin but to be getting general experience and, in particular, improving their English. English language was an important non-monetary benefit, sometimes related to the work that they did and sometimes incidental to it: 
But then I decided to go abroad to get some experience and to improve my language ... I imagined as it is: I see only work and home, work and home. In financial terms I had a better life in Lithuania. I could afford more because the living standard and prices are different here.

(Lithuanian female hospitality worker aged 39 [W2ret])

Catering is such ungrateful and tiresome work ... advantage is undoubtedly contact with people, which helps to develop your language skills.

(Polish female hospitality worker aged 28 [W1])

Considering the position of au pairs adds another interesting dimension to the discussion of migrants' trade-offs and poor work. People who entered as au pairs did not necessarily want to work in private households and frequently made comments like 'it was the cheapest and the easiest way to get here' (Czech female au pair aged 30 [W2 ret]), 'there was no other legal way to get here' (Czech female au pair aged 25 [W2ret]). While au pairing is not 'work', it is a legal way of entering and staying in the UK and, as demonstrated above, many au pairs do additional work as well as au pairing. Poor money, long hours and dependence on a family, generally considered very negatively, are often explicitly traded for security, food and accommodation. The 'calculation', while explicit, is not straightforward:

When you live with a family you actually never leave your job, which is horrible .... you don't have your own life. When you work in a pub, I think you have to find some very cheap room for yourself, maybe even a shared room, so you too don't have privacy, but then, you have your life; it's your choice. However, you don't save so much money ... As an au pair, you have your own room secured, as well as you have a certain standard secured, you don't have to share a bathroom and so on. And when you have some casual jobs, you can save something ... I have seen it more as an advantage that I didn't have to pay rent even in spite of the fact that I have lost my freedom partly.

(Czech female au pair aged 25 [W2ret])

Moreover, as shown in Table 14 earlier in this chapter, a significant proportion of survey respondents were not working before their last entry to the UK. This is confirmed by in-depth interviewees, some of whom reported being highly skilled and experienced, but who had been made redundant or fired and had looked for work in the UK as a consequence. Others were students, usually just finishing their studies (though not in the case of agriculture because of the SAWS scheme, which requires them to come before they have finished their course) and wanting to learn English, have fun and see the world. 
Personal circumstances can also be important in motivating a person with skills and experience to uproot and work elsewhere. This construction labourer for example, is a mechanical engineer with his own business. He was on a short-term work permit in the UK when he discovered his wife was having an affair and had gone to live with a neighbour:

I understood that I did not have a home any more to return to ... I thought I had nowhere to go to back home. They biased my son against me. Then I decided to make some money here.

(Ukrainian male construction worker aged 28 [W2ret])

Others were motivated simply by a desire for change. This person too is a construction labourer:

I worked as an IT specialist in a German-Polish company. And simply it started to be boring. I had a cousin who left a nice job as well and went to England, and that's it. It was such a kick that you can leave everything you have in Poland and leave and have fun. And I do have a lot of fun here.

(Polish male construction worker aged 25 [W1])

Trade-offs, then, may not simply be economic, but may involve ideas of selfdevelopment, and emotional and other circumstances. Key too is the idea, intimated in the last quotation, of temporariness. The work may be transient in that the stay in the UK is envisaged as only for a limited period, but it may also be temporary in the sense that migrants plan to move to better things in the UK, perhaps when their English has improved, and/or when they have better contacts or accommodation possibilities. This leaves open the question of course as to whether this will be possible in practice:

I gather experience and then I will get a better job.

(Czech female au pair aged 30 [W2ret])

I can work for a minimum salary about a year and then try to get a

promotion. For the moment I cannot have high requirements due to my

level of English and lack of experience.

(Lithuanian female au pair aged 26 [W1]) 


\section{Perceptions and potential impacts of immigration status}

This section begins to discuss how immigration status - including 'illegal residence' is perceived and experienced by migrants. Given the inherent difficulties associated with identifying a worker's immigration status, our discussion aims to be exploratory rather than comprehensive. We focus specifically on the four types of immigration status most commonly found among our survey respondents and in-depthinterviewees: self-employed, au pair, student and 'illegal residence'. For each status, we use our survey and in-depth interview data to discuss briefly how the status is perceived and experienced by migrants in practice.

\section{Self-employment as an immigration status}

The generic term 'self employment' can describe three different kinds of status: immigration status; employment status; and taxation status. Harvey (2001) suggests that:

... it is possible for one and the same person to be classified as an employee for tax purposes, as self-employed for some employment protection purposes, and as a worker for other employment protection purposes. ${ }^{14}$

UK employment case law divides people into two categories: the employed, and the self-employed (a contract of services and a contract for services). However, this simple distinction is proving increasingly inadequate as a categorisation, as there are growing numbers of workers who are neither clearly employees nor self-employed. Moreover, the separate concept of a 'worker' has been introduced and extended in legislation ${ }^{15}$ and includes many people who would be counted as self-employed. A further confusion results from a difference between self-employment under employment law (covering mainly matters of employment protection and rights) and self-employment for taxation purposes (concerning the relationship between the taxpayer and the State).

Onto this already confused situation maps the immigration status of self-employed. This further complicates the concept of self-employment in practice. In particular, it means that a worker with self-employed immigration status is not necessarily in a self-employed contractual relation at work. As shown in table 15, 30 per cent of all respondents reporting to be on self-employed visas in April 2004 described their employment status in their primary job as 'employee'. 
Table 15 Self-reported employment status of respondents reporting to be on selfemployed permits/visas

\begin{tabular}{lccc}
\hline & Hospitality & Construction & Total \\
\hline Employee (\%) & 39 & 27 & 30 \\
Self-employed (\%) & 61 & 73 & 70 \\
Total (\%) & 100 & 100 & 100 \\
$N$ & 28 & 95 & 123 \\
\hline
\end{tabular}

Source: survey interviews with migrants.

It is interesting to note that 39 per cent of the survey respondents on self-employed visas in April 2004 had switched to self-employed status after initially entering the UK on tourist visas. Some in-depth interviewees in fact described themselves as entering on visitors' visas with the intention of applying for a visa as self-employed once in the UK. Most seem to view it as in effect a relatively easy means of 'selflegalisation', rather than a distinctive career choice:

I had to have the possibility to come back to Poland ... and to be able to come back here. Because my father is very ill ... Another thing, I wanted to feel relatively safe, even though this involves costs, etc. ... I was left only with a business visa option.

(Polish male construction worker aged 28 [W1])

The proportion of respondents claiming to be in self-employed relationships in the hospitality sector is somewhat surprising (though the numbers are small). The possibilities for low-wage self-employment work in hospitality are very limited, as self-employment in hospitality is more associated with entrepreneurs setting up small businesses. However, in construction, the situation is somewhat different, as 'false self-employment' is rife. ${ }^{16}$

In construction, the phenomenon of self-employment as a way of gaining legal employment is a particularly complex issue that requires some unpacking. The construction industry is subject to a peculiar taxation regime, whereby the selfemployed have a Construction Industry Scheme (CIS) registration card, and have their tax and national insurance deducted at source by the people who pay them. These are calculated by 'employers' with reference to price of labour rather than by the 'self-employed' with reference to profits. Possession of a CIS card does not serve as proof that the holder has the employment as opposed to taxation status of selfemployed. Neither does it prove that they have the immigration status of selfemployed. However, in practice, it can result in considerable confusion. Harvey (2001, p. 18) suggests that: 
$\ldots$ in the absence of other tangible indicators, [CIS cards] are the only manifest sign or indicator of status. No hoops have to be jumped to obtain them ... irrespective of whether or not ... individuals are employed or self-employed, they hold registration cards and pay tax and insurance as if they were self-employed. It is like issuing passports whilst at the same time insisting they are not proof of citizenship.

Although we did not interview any worker who said that they had a fraudulent CIS card, some of our migrant interviewees who were working in construction and who were residing illegally had obtained CIS cards but, to do so, had had to present false documents or documents that belonged to other people. Those with false documents did not seem to find it difficult to obtain CIS cards, i.e. to be recognised for taxation purposes as self-employed, although of course their immigration status was not selfemployed.

In construction, several of the interviewees with self-employed permits/visas complained about not having sick pay or holiday pay in particular, though interestingly this was often blamed on the employer rather than on the fact of being self-employed (in terms of immigration and taxation status). Having to pay for one's own equipment and other costs as a consequence of the legal employment relationship, and the limitations attaching to the immigration status of being selfemployed, were also referred to by some interviewees:

Self-employed [people] pay for everything except for the Christmas sweets in the banks. Even for language classes there are limited places for self-employed.

(Bulgarian male construction worker aged 23 [W2ret])

\section{Au pairs}

Migrants may work as housekeepers and carers in private households on a range of different visas including students, working holidaymaker visas, domestic worker visas, etc. In this research project, we set out to interview only those migrants working in private households who were currently au pair visa holders. Au pairs are not categorised as workers for the purposes of immigration controls. The rules stipulate that they must be coming 'for the purpose of learning English and not to work as a fulltime childminder'. The au pair visa, unlike a work permit, is held by the migrant rather than by the employer/host family, and au pairs are able to change host families without implications for their immigration status. However, the au pair must live 'as a member of an English-speaking family', and that family does not constitute an employer. The 
nature of relation between au pairs and host families is, then, crucial to what it is to be an au pair, and it is, as will be seen, somewhat contentious.

What it is to live as part of a family is not defined in the immigration rules, but, under minimum wage legislation, those who live as part of the family are exempted from the minimum wage. The Immigration Directorate Instructions guidelines also indicate that, if the au pair earns more than the 'reasonable allowance', this might suggest that the person is filling the position of domestic servant, or similar, which would require a work permit'. ${ }^{17}$ Data on working hours and earnings from our survey of au pairs detailed above indicate that, on this criterion, many au pairs are more 'like' domestic workers than au pairs.

Lack of clarity, conflicting expectations and fuzzy boundaries were experienced as real problems by au pairs and host families (the perceptions and experiences of host families will be discussed in Chapter 3 of this paper). Unlike SAWS visa holders, for example, au pairs were very clear that 'living in' meant that they had to be available for their host families, and that this was a considerable disadvantage to them, from the point of view of both their personal lives and their availability:

Besides, being an au pair means little freedom - I have to stay with the family almost 24 hours, to live with them. Sometimes it feels like living in a 'golden cage'.

(Lithuanian female au pair aged 25 [W2reint])

Issues of space and establishing boundaries were also raised by au pairs (and, as will be discussed in Chapter 3, also by host families). Indeed, interestingly, it was clear that 'being part of the family' was not necessarily the positive experience that such a term indicates. Almost all au pairs, even those for whom au pairing was a successful experience, spoke of difficulties around being dependent, lack of privacy and 'freedom':

While being an au pair I had to live with the host family. I didn't like it very much because I was dependent on the family, i.e. had to follow their rules ... In a 'normal' job you finish your work and you are free, while being an au pair means lack of clear boundaries: host family can ask you to help them at any time since you are living there.

(Lithuanian female au pair aged 28 [W2reint])

This might be contrasted with having a 'job' - as one Slovak au pair put it: 'if you are an employee you have all the rights, like a British citizen' (Slovak female au pair aged 25 [W1]). Another woman, who became a self-employed nanny though on an au pair visa, contrasted being a nanny and being an au pair: 
I don't think you can really compare it because, when my work finishes, my mind switches off and I go home and get on with my personal life. As an au pair, on the other hand, the work never finishes. When I was an au pair I was even sharing a room with a small boy, so it is like you are with the child 24 hours a day, which means you can't really talk about a personal life.

(Slovak female au pair aged 28 [W2ret])

The personal difficulties of being an au pair were emphasised often more than the relatively low money by in-depth interviewees. One Czech au pair described her nightmarish feeling:

When you live with a family you actually never leave your job, which is horrible. Even when you close the door, they are there always and you can't go to the kitchen, or you can, but you disturb them. It's as if you were living the life of someone else.

(Czech female au pair aged 25 [W2ret])

Relationships did not have to be conflictual to be onerous for either side. Some au pairs described host families causing them some difficulties, but staying with them because they personally liked them:

She clearly couldn't afford the three kids, let alone an au pair. And I am perhaps a good-hearted person - we became good friends together and I believed in our friendship and trusted her, and till now ... she owes me approximately £3,000.

(Slovak female au pair aged 28 [W2ret])

As described earlier in this paper, more than half of the au pairs interviewed were working more than the legally allowed 30 hours per week. Some au pairs were also working outside the au pair sector doing, for example, cash-in-hand cleaning work or working in the hospitality sector. In-depth interviewees who would violate the conditions attached to their immigration status in this way did not seem unduly concerned about being detected as an 'illegal worker'. There seems to be a sense that what they were doing was not really 'illegal', that it was tolerated:

In Germany it is impossible to place an ad as a cleaner somewhere, you are there simply as an au pair and there's nothing else you are allowed to do there at all. Here I think it's slightly illegal but tolerated.

(Czech female au pair aged 25 [W2ret]) 


\section{Students}

Migrants on student visas are allowed to work 20 hours a week during term-time and full-time during the holidays. As described above, the interview data suggest that a significant number of students work for more than 20 hours a week during term-time. In fact, just under two-thirds of the 81 students surveyed reported to be working for more than 30 hours a week, often in multiple jobs.

Similarly to au pairs working in violation of the conditions attached to their immigration status, some of our in-depth interviewees revealed that students who were working in excess of the permitted hours per week felt that they were bending, rather than breaking, the rules. A Polish waitress working 47 hours a week described herself as:

... employed legally - maybe for a little bit more hours than the law on students' employment allows.

(Polish female hospitality worker aged 25 [W1])

Others felt able to claim that the rules were not clear. As one Ukrainian waitress on a student visa said:

They said you could work at one work 20 hours; nobody said that you could not have two or three job places ... but I had finished my college within two weeks and then I had a break for five months; I have not been studying. (Ukrainian female hospitality worker aged 25 [W2ret])

Our in-depth findings suggest that some people may be using student visas effectively as a means of working legally rather than coming specifically to study:

I was under a great pressure from my cousin's side who decided that I won't cope with work unless I had a student visa. Thus only because of this I came here on a student visa, because ... it's easy to enter, the entrance was easier than on tourist visas.

(Polish male construction worker aged 25 [W1])

It is interesting to note that working on an unexpired visitors' visa was regarded by some with greater discomfort than working full-time on a student visa. This interviewee entered with a visitor's visa, together with her husband. At the time of the interview she was working full-time on a student visa: 
We came here in September, so by December we actually earned enough money for studies. We bought a 'school', we got visas and in January we went home. From February we were students. In the beginning while we didn't have visa [i.e. when they were on a visitor's visa] we worked through this agency which employed people illegally. Then when we already got the [student] visa we registered at different agencies.

(Polish female hospitality worker aged 28 [W2ret])

In contrast, others on student visas seem to have found themselves slipping further and further into the labour market almost by default. One Ukrainian worker, who we interviewed as a construction worker, was an economics student who seems to have been highly committed to his studies. He came to the UK on the understanding that those with British qualifications are 'held in respect', but worked temporarily as a construction labourer to support himself, and found he had to invest in tools and other instruments:

Of course, if you want to work well you have to graduate college ... But it is almost impossible here. My father is not poor, but he is not Abramovich, he cannot give that amount of money away.

(Ukrainian male construction worker aged 25 [W2ret])

\section{Illegal residence}

In theory, being illegally resident may lead to a situation where employers gain excessive powers over migrants who work in constant fear of deportation. The Home Office suggests that 'people who are in this country illegally' find themselves vulnerable to:

... employers or gangmasters who take advantage of their status by making them work in poor or dangerous conditions, often for unacceptably low wages. People in this situation can be too afraid to challenge their treatment yet powerless to escape their exploiters. ${ }^{18}$

While the term 'illegal' is regarded by many as problematic when applied to migrants, it is used by both employer and worker in-depth interviewees. ${ }^{19}$ This term is not only contested but also vague. For example, while some individuals might describe students working over the legal number of hours as 'illegal', others might not. It was clear from some of our interviews that certain types of breaches of immigration law (in particular overstaying) were regarded as more serious than others. We believe 
that most of our speakers, whether employers or workers, would agree, however, that the term 'illegal' does cover those resident illegally (without valid leave to remain). We therefore restrict our comments in this section to illegal residence.

In practice, insecurity and fear were common themes among in-depth interviewees and national insurance numbers were a concern with reference to employment:
But the employer there demanded national insurance number and I got scared because I wasn't working legally. I didn't show up there any more, giving up £300. Before 1 May, I always worked under a false name and with a fake Home Office permit after my student visa expired ... I think British government was intelligent enough to know what was going on. If they wanted they would have caught all illegally working people. But perhaps everything is about money - somebody is getting multi-billion income from immigration. (Lithuanian male construction worker aged 27 [W2ret])

It should be noted that, in this case, the worker's employer/labour user was unlikely to be aware of his immigration status. In contrast to most other nationalities, Ukrainian interviewees tended to have entered or worked in the UK using fake documentation. This does not mean they felt safe. Some of those interviewed had clearly endured some distressing experiences. One young woman had trained as a primary school teacher in Ukraine, but had come to the UK because of unemployment. She first collected glasses in a pub for $£ 1$ an hour and, at the time of interviewing, was doing similar work for £2 an hour, working up to 12 hours a day depending on how business was. She was given free chips and crisps at work. She described her situation as one of intense vulnerability and she had experienced two serious sexual assaults and sexual harassment at work, but felt unable to take any action because of her legal status.

Other interviewees of varying nationalities reported fear if employers demanded legal documents or national insurance numbers, anxiety about what would happen if they fell sick, or they were simply feeling stressed on the street. However, there were also people of the opinion that 'immigration status means nothing' (Slovak male construction worker aged 20 [W2ret]), the speaker had worked on au pair, visitors' and self-employed visas, or that the difficulties of being 'illegal' can be met with 'strength of mind and personality' (Polish male hospitality worker aged 25 [W1]).

Generally, those with legal status were not particularly hostile to others who were 'illegal' and did not express concern about them undercutting wages. Indeed, one illegally resident Ukrainian complained about post-enlargement A8 nationals: 
They are legal and they agree to any salary. We are illegal, but we want good money.

(Ukrainian female hospitality worker aged 25 [W2ret])

Some interviewees did remark, however, that employers might prefer illegal workers:

If it is just a small cafe on the corner they want better illegal because they can do to that person everything they want ... they want to get as much as it is possible from people, but to pay as little as they can. (Ukrainian female hospitality worker aged 21 [W2ret])

Such comments point to an interesting but - at least in the context of the UK - much under-researched empirical research question, namely, whether illegal residence has a significant impact on migrant workers' earnings. Some preliminary analysis of this important and complex issue is given in the Appendix to this report. ${ }^{20}$

It is also important to keep in mind that the impact of illegal residence is not only confined to employment, but also has a more general affect on some of our interviewees' lives - a dimension to be explored more fully in a subsequent report:

Sometimes you try to look into the future and you see something, but sometimes you see only darkness. I do not know what will be tomorrow or a day after tomorrow.

(Ukrainian male construction worker, aged 25 [W2ret])

Overall, the perceived impact of illegal residence appears to be mixed. Interviewees indicated that immigration status is not static, but shifts and changes over time: some interviewees had been working on tourist visas, for instance, but had switched to self-employed; some had entered and worked legally but overstayed their permits; and some 'illegally resident' respondents - especially A8 respondents before May 2004 - were expecting their situation to change. As with the trade-offs for low-waged jobs, the extent to which people feel their 'illegal residence' might be temporary might affect how tolerable it is.

\section{Other key dimensions of employment}

Immigration status may be expected to be an important but certainly not the only important aspect or determinant of migrants' employment experiences in the UK. This section briefly discusses three other key dimensions of employment: contracts; agencies; and informal working. These additional dimensions are not necessarily 
specific to migrants but could equally apply to British workers, though they may well interact with certain immigration statuses.

\section{Contracts}

Just under half of the survey respondents reported to be working without a written employment contract. However, this varied significantly by sector (see Table 16). ${ }^{21} \mathrm{Au}$ pairs were the least likely to have contracts ( 21 per cent of the au pair respondents described themselves as having a contract 'or written agreement' with their host families), and agricultural workers the most likely (87 per cent). Interestingly, 'illegally resident' respondents were not significantly more likely to be working without written employment contracts than other respondents. Fifty-five per cent of 'illegally resident' respondents did not have a written employment contract (compared to 51 per cent of other respondents).

It is again important to emphasise that the figures in Table 16 stem, at least in part, from our non-random sampling of respondents and should therefore be read with some caution. For example, the agricultural workers we interviewed were predominantly SAWS scheme members (96 per cent of respondents on SAWS permits had a written employment contract), and au pairs are not constructed as employed, so a written agreement in both these instances might be considered not standard. Furthermore, respondents working part-time reported a higher incidence of employment without a written contract (65 per cent) than those working full-time (44 per cent). As previously discussed, part-time working was much more prominent among respondents in hospitality than in construction or agriculture.

Interestingly, the qualitative data suggest that the absence of a written employment contract is not necessarily regarded by workers as without benefits. Some interviewees argued that, while a written contract does guarantee you work and payment, 'on the other hand if there is no contract you can leave whenever you want' (Polish male construction worker aged 25 [w1]). Another interviewee felt similarly about the potential benefits of not having a contract:

Table 16 Written employment contracts in respondents' primary job, April 2004

\begin{tabular}{lrcccc}
\hline & Hospitality & Construction & Au pair & Agriculture & Total \\
\hline Has written contract (\%) & 56 & 45 & 21 & 87 & 51 \\
Does not have written contract (\%) & 44 & 55 & 79 & 13 & 49 \\
Total (\%) & 100 & 100 & 100 & 100 & 100 \\
$N$ & 201 & 175 & 84 & 82 & 542 \\
\hline
\end{tabular}

Source: survey interviews with migrants. 
A written contract protects you from losing the job, but you can leave the job for a better one if there is no written contract.

(Lithuanian male construction worker aged 39 [W1])

The freedom to move and to change employer was valued as an important consideration by interviewees, and the insecurity of not having a contract could be traded off against greater possibilities of leaving an employer. Given that many of our interviewees, as discussed above, felt that the temporary duration of their job made the type of employment and working conditions tolerable, perhaps this is to be expected. It is noticeable that very few of our in-depth interviewees who did not have a contract actually saw this as a problem, with the exception of the au pairs who, while not calling for a contract, often stated that they would like something 'written' on either the tasks they were expected to perform, or hours, or both.

\section{Agencies}

The question remains, contract with whom? Contracts may be held, not only with direct employers (i.e. businesses producing goods or providing services), but also with 'employment businesses'. Employment businesses are a type of employment agency that employs workers directly but then hires workers out to 'labour users' (e.g. businesses producing goods or providing services). For linguistic convenience, in the discussion below, we use the term 'agency' (or 'agency working') to refer specifically to employment businesses rather than to all types of agencies. ${ }^{22}$

In April 2004, 18 per cent of the survey respondents were directly employed by an agency rather than by a business producing goods or providing services. As shown in Table 17, the incidence of agency working was highest in construction (24 per cent of respondents) and lowest in hospitality (11 per cent).

Table 17 Respondents' employment by businesses or agencies (employment businesses)

\begin{tabular}{lcccc}
\hline & Hospitality & Construction & Agriculture & Total \\
\hline Employed by business (\%) & 89 & 76 & 79 & 82 \\
Employed by agency (employment & & & & \\
$\quad$ business) (\%) & 11 & 24 & 21 & 18 \\
Total (\%) & 100 & 100 & 100 & 100 \\
$N$ & 200 & 174 & 82 & 456 \\
\hline
\end{tabular}

Source: survey interviews with migrants. 
The data do not suggest that those who were employed by an agency were less or more likely to have a written employment contract than those directly employed by an employer. Agency working also appears to cut across occupations and immigration statuses. Twenty-three per cent of respondents working in skilled trades occupations, and 16 per cent of respondents in elementary occupations, were directly employed by agencies.

In terms of respondents' immigration status, agency working was most common among students (32 per cent) and among respondents reporting to be working on self-employed permits/visas (19 per cent). ${ }^{23}$ Importantly, there does not seem to be any obvious relationship between illegal residence and the incidence of agency working. Fifteen per cent of illegally resident respondents were reporting to be directly employed by an agency.

While agencies differ in whether or not they check documents, some of our interviewees felt that it was easier to work for an agency than directly for an employer when documents were not in order:

Agencies register you, but they do not check your documents, whether you have renewed your visa. You can go there with fake documents. Almost all people there are with fake documents. They pay very little. I do not like that they send you every time to a different place.

(Ukrainian female hospitality worker aged 25 [W2ret])

Some agencies seem to be known to be 'good' to go to for those who are working illegally or in breach of conditions, while others are known to demand documentation. Thus one interviewee described how she and her husband went to one agency when they were working on visitors' visas, but were able to go on the books of many more once they had obtained student visas. Some workers felt that agencies preferred 'illegal workers':

Agencies value illegal workers more as they are more confident that illegal workers will be loyal to the agency and won't leave them. Legal workers can leave the agency and go on easily.

(Polish female hospitality worker aged 30 [W1])

Most in-depth interviewees viewed agency working less positively than being directly and permanently employed by a business. For example, interviewees who were working in construction were often scathing about agencies: 
I work through a mediator, a thief ... I have to go to him for money. I have to know which pub he's in ... this English company pays him as if for the work done, and he divides the money. That is I asked the guy from the company, I went to him and asked him whether I could, whether there was a possibility that I could get employed by them on normal conditions, because I have papers. He said that unfortunately he was sorry, but $S$ takes care of these things.

(Polish male construction worker aged 28 [W1])

Other disadvantages cited by in-depth interviewees working for agencies included the temporary and casual nature of the work, commission charged and a broad range of financial disadvantages including no pension, sick pay and lower wages. There were also more indirect financial implications, such as agency workers having to pay for their own tools or protective clothing. Insecurity was consistently referred to, not being guaranteed a job and, when there was work, not knowing how long it would last for or how many hours it would be for. It brought 'stresses', whereas working as a direct employee brought 'a peace of mind'. Interviewees working for agencies also referred to a sense that they were somehow different from permanent employees of businesses:

You come to a hotel, but they have their own staff there. We are from a lower status for them. Maybe I know the job better, but a hotel takes us for nothing ... It is better [to work for] an employer. You are working all the time with the same people; you know all the context, what is going on around you at your work. You know all pluses and minuses, managers, all people.

(Ukrainian female hospitality worker aged 25 [W2ret])

There were, however, also some advantages to agency working that were recognised by some interviewees - though many claimed that it was very hard to think of any advantages to it. Some interviewees felt that agencies were useful for new arrivals or 'the best way out if you don't know the language' (Lithuanian male construction worker aged 39 [W1]). Some also considered agencies to be more flexible; people can leave work places they don't like relatively easily - the flip side, as it were, to insecurity. This interviewee neatly summed up the advantages and disadvantages of agency working:

Working for an agency means no guarantees whether you will work next week, or you may have to work where you don't want ... but the advantages of the agency are it's fun; you work at places where you wouldn't be let into under normal circumstances, you don't get bored. 
There are new people and new places ... Disadvantages: no sick pay, no pension scheme, less money.

(Lithuanian male hospitality worker aged 25 [W1])

\section{Informal working}

In 2000, the Treasury published a report by Lord Grabiner QC into the informal economy. It defined the informal or hidden economy as covering a wide variety of abuses of the tax and benefits systems, from work paid cash in hand to organised crime:

Being in the hidden economy means not complying with the basic legal requirements to declare and pay tax, to register for VAT, or, for benefit recipients, to be available for work and to declare earnings. ${ }^{24}$

According to Grabiner, businesses in the informal economy are typically low-wage and labour-intensive. Grabiner cites eight sectors where such businesses may operate, including three of the four sectors examined in our research..$^{25}$ Indeed, if one equates au pairs with 'domestic service', it includes all four sectors. Our evidence of informal working is, however, limited to not making the required tax payments.

A quarter of all respondents working in hospitality and construction said that they - or their employers - were not paying national insurance. ${ }^{26}$ As may be expected, respondents with written employment contracts are more likely to be paying national insurance than those without. Seventy per cent of respondents who paid national insurance also had a written employment contract; and 87 per cent of the respondents who did not pay national insurance did not have a written employment contract.

Initial analysis of our data therefore suggests some evidence of informal working not having contracts and non-payment of national insurance. However, there does not appear to be a straightforward relationship between immigration status and informal working. For example, almost half of respondents in hospitality and construction who were violating some or all of the conditions attached to their immigration status reported to be paying national insurance. In some cases, workers have bought documents from other people who were working legally and then returned home:

I work with Ukrainian documents from that girl who used to work here legally. She lived here legally, and then went home to Ukraine, but her 
documents she sold me. I work under other name and surname. All documents are hers.

(Ukrainian female hospitality worker, aged 25 [W2ret])

At the same time, some of the hospitality and construction respondents who were legally resident and employed in full compliance with the conditions attached to their immigration status were not paying national insurance.

\section{Employment after 1 May 2004: perceptions and experiences of change}

This section explores migrants' pre-enlargement expectations and plans with regard to their employment in the UK after 1 May 2004. It also discusses whether and how survey respondents and in-depth interviewees perceived and experienced changes in their employment following EU enlargement.

\section{Expectations and plans}

Before EU enlargement, Wave 1 survey respondents were asked if they thought that EU enlargement would make a difference to their employment or their lives in the UK. Three-quarters of A8 nationals felt that it would make a difference and half of non-A8 nationals (NA8) did. This does not tell us of course whether the difference is positive or negative and there are some differences, as one might expect, between A8 and NA8 respondents.

Over three-quarters of the $\mathrm{A} 8$ respondents identified changing immigration status and right to work as factors that would make a difference to them. The key improvements anticipated were not with reference to employment, however, but in accessing education services ( 75 per cent felt this would be easier) and the right to bring family to the UK (81 per cent). ${ }^{27}$ In terms of employment, expectations were rather lower with about three-quarters expecting wages and conditions of employment to remain the same. Almost all of the remaining 25 per cent expected wages and conditions to improve (see Figure 6). 
Figure 6 Wave 1 survey respondents' expectations about EU enlargement

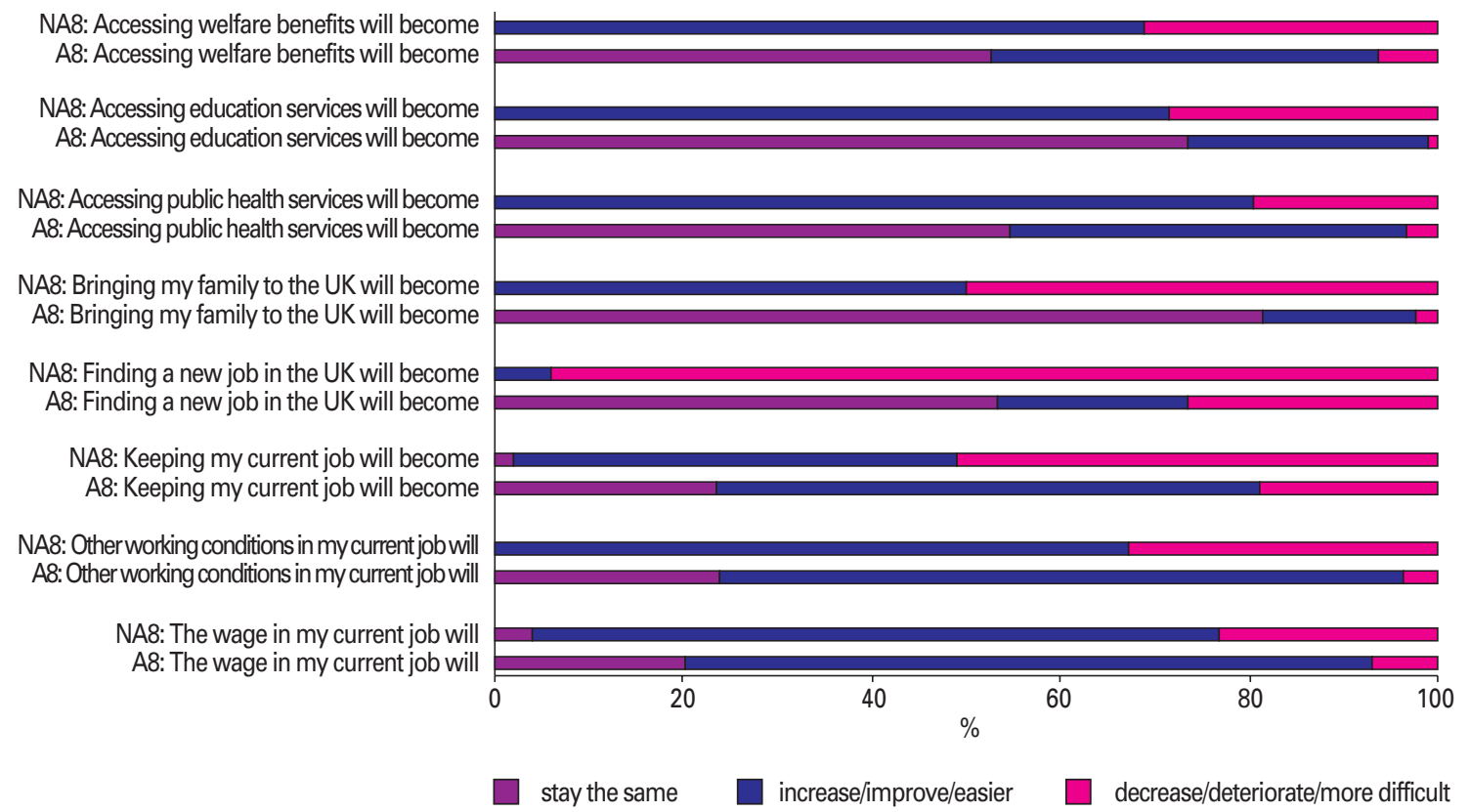

Source: survey interviews with migrants, April 2004 (A8 $N=185$; NA8 $N=53$ ).

As one may expect, A8 nationals who were illegally resident ( $N=44$, including mainly acknowledged overstayers) were particularly positive about anticipated changes. Eighty-eight per cent of illegally resident A8 respondents said that accessing education services would become easier. All of them except one were expecting their immigration status and right to work to change, nearly 30 per cent were expecting wages to improve and 32 per cent expected conditions at work to improve. In total, 13 A8 respondents thought that wages would decrease and only two of these described themselves as illegally resident.

Thus A8 respondents' expectations around conditions of employment were generally either neutral or positive. However, they were rather more negative around labour market conditions in general, with 19 per cent thinking that it would be harder to keep their current job and 26 per cent anticipating that it would be more difficult to find a new job in the UK. There were no significant differences between illegally resident and other A8 respondents in this regard. It appears, then, that some A8 nationals were anticipating increased competition in the labour market because of the expected inflow of workers ('newcomers') from the A8 countries.

The picture for the NA8 nationals surveyed is rather different. While roughly similar proportions of NA8 respondents to A8 respondents felt that wages and conditions would remain the same, 23 per cent of NA8 respondents expected their wage to decrease and 33 per cent expected that their conditions of employment would 
deteriorate after EU enlargement. No NA8 respondent thought conditions of employment would improve. A significantly larger proportion of NA8 nationals were concerned about labour market competition, with 51 per cent believing it would become more difficult to keep their current job after EU enlargement and 94 per cent believing it would be more difficult to find a job in the UK. The sample size of illegally resident respondents from NA8 countries is too small $(N=12)$ to be able to say anything about the effect of illegal residence on expectations.

As for the specific personal plans of our respondents, 39 per cent of A8 workers (not including au pairs) surveyed in Wave 1 planned to find a new job after EU enlargement and 15 per cent (mainly construction workers) planned to set up their own business. Fifty-eight per cent of A8 au pairs surveyed said that they planned to find a new kind of job. This contrasts with 15 per cent of NA8 nationals who planned to find a new job and 8 per cent who were considering starting up their own business. $^{28}$

Qualitative data suggest that planning on staying in the same job does not necessarily mean that changes relating to employment are not anticipated. There were also A8 interviewees who clearly expected to change their job, but were not in a hurry to do so:

I hope this will change for good. I mean we will not be accepted straight away in any company, because I know that even Brits, Scots and Irishmen have problems regarding getting employed in London. I don't know what it is like outside the city. But also because of the possibility to change jobs, I decided to take on a manager's assistant position. Then I don't know, I decided that I will get the training during the coming two months and then, if I see that this doesn't suit me, I will start sending my $\mathrm{CV}$ to other places.

(Polish female hospitality worker aged 30 [W1])

After 1st of May the biggest change will be that I will get a legal contract without an agency as an intermediary. It's more convenient for the college - they'll get to determine my shifts. So it's strange - my employer will change, but not my workplace, and I will definitely earn more. (Polish male hospitality worker aged 24 [W1]) 


\section{Perceptions of change}

Some six to eight months after EU enlargement, survey respondents were asked if they felt that their situation in relation to their employment - and more generally their lives in the UK - had changed since EU enlargement. ${ }^{29}$ Seventy-one per cent of A8 nationals and 18 per cent of NA8 nationals said that they thought it had. It is worth noting that seven A8 respondents said that they had never heard of EU enlargement.

As shown in Figure 7, the change for A8 nationals was generally experienced as positive, with 28 per cent saying that conditions at work had improved (only 2 per cent said they had deteriorated compared with 30 per cent of NA8 nationals). Some in-depth interviewees reported an improvement in contractual arrangements and getting overtime rates. However instability at work and problematic contracts were still commented on at some length by some of our interviewees:

Now I am a supervisor ... but I am not feeling very secure ... This firm has many hidden tricks. Although we are all actually working full-time, our contracts have only been signed for 20 hours a week ... if it is less busy they are obliged then to guarantee us only 20 hours of work. If I tried to ask for more hours they would give me even less.

(Polish female hospitality worker aged 30 [W2reint])

Earnings are definitely much too small in relation to the number of hours ... But 1.5 hours she was supposed to spend with me talking shrank to 20 minutes ... three weeks later she called to tell me that in secret she awarded me a bonus and that I am not to tell anyone else about it. Bonus is bonus, but I want a rise.

(Polish female hospitality worker aged 31 [W2reint])

What about perceptions of labour market competition? Again there seems to be some difference between A8 and NA8 nationals. Twenty-six per cent of those A8 nationals either reinterviewed or interviewed retrospectively felt it was easier to keep their job after enlargement. At the same time, 10 per cent of A8 nationals felt it was now more difficult to keep their current job.

A much higher proportion of NA8 respondents (64 per cent) felt it was more difficult to keep their job and none of them said that it was easier. The contrast between the groups is even more marked with reference to perceptions of how easy or difficult it was to find new jobs in the UK. Fifty-nine per cent of A8 nationals surveyed postenlargement felt that it was easier to find work, while 85 per cent of NA8 nationals felt it was more difficult. 
Figure 7 Respondents' perceptions of change following EU enlargement

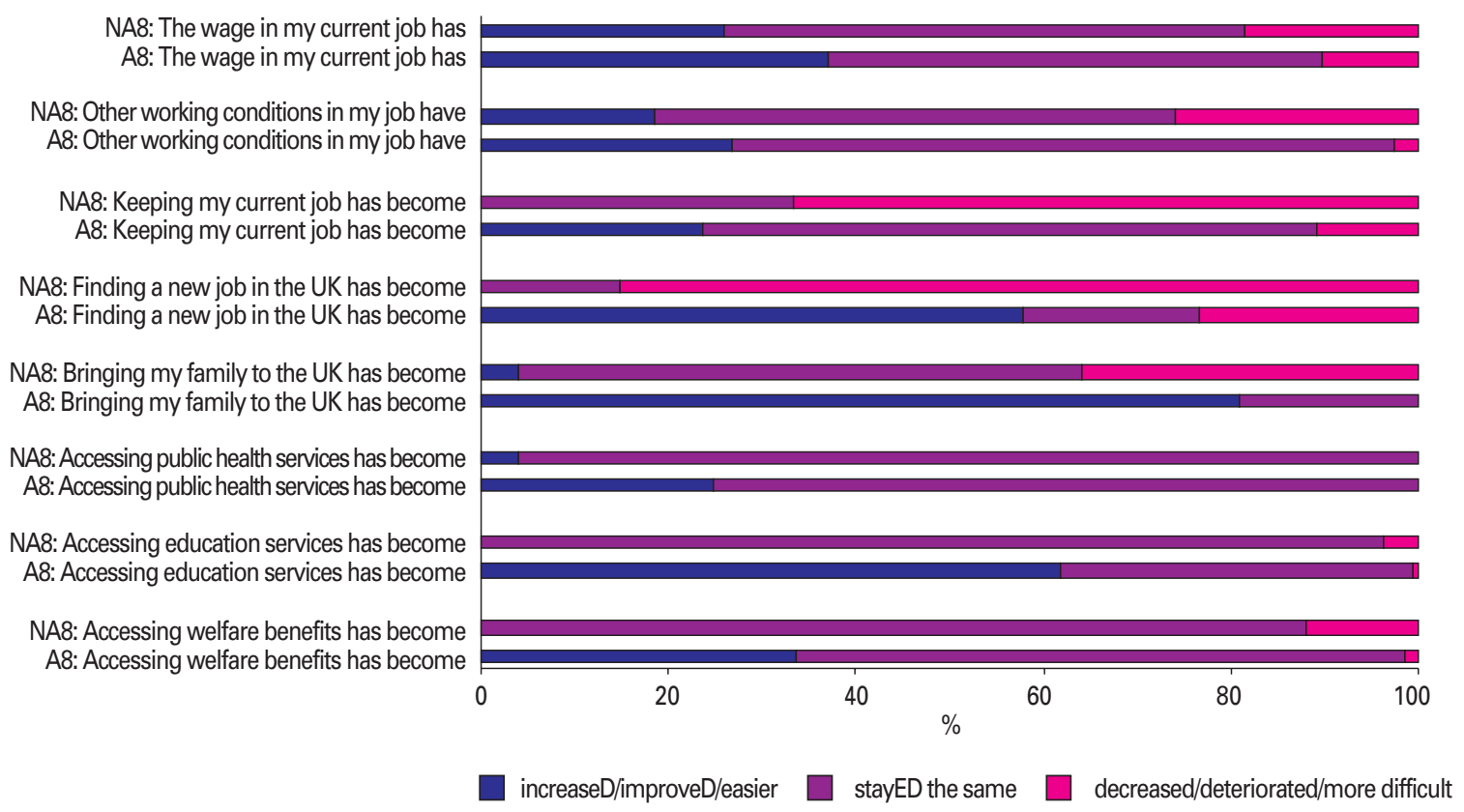

Source: survey interviews with migrants (A8 $N=148$; NA8 $N=27$ ).

In-depth interviews painted a slightly different picture, with many interviewees expressing concern about competition for jobs with newcomers, though interestingly there are very few concrete examples of this given. The number of Polish newcomers was a particular source of comment for Polish and non-Polish respondents alike. Box 1 gives a sample of some comments made by interviewees. A small minority felt that it was easier to find work with increased numbers of fellow nationals because of improvements in networks.

\section{Box 1 Examples of in-depth interviewees' comments on labour market competition following EU enlargement}

I think it decreased my chances because more people from Poland are coming.

(Polish male construction worker aged 26 [W2reint])

Competition for jobs increased.

(Polish female hospitality worker, age unknown [W2reint])

Lots of people from Poland came and this made it more difficult to look for something new.

(Polish female hospitality worker aged 30)

(Continued) 
I know that those Lithuanians, Polish who had worked in our banqueting before that are still working there. Nothing has changed. They maybe can work more hours and that is it ... It is about newcomers and those who were here before that.

(Ukrainian female hospitality worker aged 25 [W2ret])

I think EU enlargement opened the doors to students and newly arriving workers, which made it more difficult for us, who are here for a few years already. Two to three coaches of Poles are coming every day, although not all of them stay in London of course ... Actually there is lack of order in England in this respect. For example, the immigration infrastructure is much more efficient in Germany.

(Lithuanian construction worker aged 22[W2ret])

It is harder to find a job after we joined the EU ... The job market is the same but competition got bigger and bigger.

(Polish female hospitality worker aged 31 [W2reint])

Many people came looking for work, which increased competition on the market.

(Polish female hospitality worker aged 28 [W2ret])

It became harder because of a large number of immigrants from Eastern Europe.

(Lithuanian male construction worker aged 27[W2ret])

It made it more difficult. Huge numbers of people came from the new EU countries. As a result the wages decreased due to higher supply. Especially Polish people.

(Lithuanian male construction worker aged 43 [W2reint])

[There are tensions with Poles] because lots of them came here with illusions and no knowledge of English so they end up working illegally being paid £2-3 an hour. That lowers the work rates in low-paid jobs and creates the tension. (Slovak female hospitality worker aged 34 [W2ret])

It has become easier to find work through the agencies because they hire legal workers. On the other hand, the competition increased because, for example, Poles agree to work for lower wages.

(Slovak female au pair aged 28 [W2ret])

Source: in-depth interviews with workers, Wave 2. 


\section{Experiences of change}

This section begins to explore whether and how respondents' actual employment experiences changed after EU enlargement. Of course, these may change over time for a number of reasons. ${ }^{30}$ We are particularly interested in discussing whether A8 nationals' change in legal status on 1 May 2004 had any impact on their experiences in the UK labour market. This section will begin this discussion but it needs to be stated at the outset that the relationship between changing immigration status and labour market experiences can be adequately addressed only by detailed statistical analysis, which we plan to carry out at a later stage of this research project.

The discussion of change below draws on data obtained from survey and in-depth interviews with respondents and interviewees for whom we have information about their employment experiences both before and after EU enlargement (352 survey respondents and 62 in-depth interviewees).

\section{Changing primary jobs}

Table 18 shows the number and percentage shares of respondents whose primary job changed between April 2004 and the time of the Wave 2 interview (six to eight months after EU enlargement). Overall, about 30 per cent of respondents for whom we have Wave 1 and Wave 2 data changed their primary jobs. This figure is highest among respondents who were working in agriculture in April 2004 and lowest among respondents in construction.

Table 18 Number of survey respondents who changed primary jobs between the Wave 1 interview (April 2004) and the Wave 2 interview (six to eight months after 1 May 2004) - by sector of employment in April 2004

\begin{tabular}{lccccc}
\hline & \multicolumn{5}{c}{ Sector of employment in April 2004 } \\
& Hospitality & Construction & Au pair & Agriculture & Total \\
\hline Changed primary job & 36 & 27 & 20 & 12 & 95 \\
$\%$ & 27.91 & 24.55 & 40.82 & 41.38 & 29.97 \\
Did not change primary job & 93 & 83 & 29 & 17 & 222 \\
$\%$ & 72.09 & 75.45 & 59.18 & 58.62 & 70.03 \\
Total & 129 & 110 & 49 & 29 & 317 \\
$\%$ & 100 & 100 & 100 & 100 & 100 \\
\hline
\end{tabular}

Source: survey interviews with migrants, Wave 1 and Wave 2. 
It is again important to emphasise that the figures in Table 18 are not representative, as they are likely to be heavily influenced by 'sampling effects'. For example, we know that the pooling of retrospective and reinterview survey respondents in the analysis may give a misleading overall picture. This is because the sampling was done in a way that would tend to result in lower job-change rates among retrospective survey respondents (26 per cent of whom we found to have changed primary jobs) than among reinterview survey respondents (38 per cent were found to have done so). This is because 'retrospective survey interviewers' were asked to interview only those migrants who had been employed in one of our four sectors in April 2004 (but who could have been working in any sector at the time of the Wave 2 interview). Most interviewers naturally looked for appropriate respondents by searching within the four sectors specified for Wave 1 and, as a result, tended to interview migrants who had not changed sector of employment.

Self-employment - as a workplace relation rather than immigration status ${ }^{31}$ - is another complicating factor that primarily affects construction. Fifteen per cent of the 57 respondents who were working in construction in April 2004, and who described themselves as self-employed in both Wave 1 and Wave 2, reported that they had 'changed primary jobs'. The remainder (84 per cent) said that they had not. It is unclear what the notion of 'changing jobs' means in the context of self-employment.

Table 19 contains data on changes in primary jobs for respondents from A8 and NA8 countries. Because of the potential distortion of the data due to the issue of selfemployment, separate figures are given for all respondents and for respondents who were not self-employed in either Wave 1 or in Wave $2 .{ }^{32}$ In both sub-tables, the share of respondents changing primary jobs is higher among A8 nationals than among NA8 nationals.

Table 19 Number of survey respondents who changed primary jobs between the Wave 1 interview (April 2004) and the Wave 2 interview (six to eight months after 1 May 2004) - by broad nationality group

\begin{tabular}{|c|c|c|c|c|c|c|}
\hline & \multicolumn{3}{|c|}{ All respondents } & \multicolumn{3}{|c|}{$\begin{array}{l}\text { Excluding respondents who } \\
\text { were self-employed in both } \\
\text { Wave } 1 \text { and Wave } 2\end{array}$} \\
\hline & A8 & NA8 & Total & A8 & NA8 & Tota \\
\hline Changed primary job & 74 & 21 & 95 & 66 & 18 & 84 \\
\hline$\%$ & 37 & 18 & 30 & 38 & 24 & 34 \\
\hline Did not change primary job & 127 & 95 & 222 & 109 & 57 & 166 \\
\hline$\%$ & 63 & 82 & 70 & 62 & 76 & 66 \\
\hline Total & 201 & 116 & 317 & 175 & 75 & 250 \\
\hline$\%$ & 100 & 100 & 100 & 100 & 100 & 100 \\
\hline
\end{tabular}

Source: survey interviews with migrants, Wave 1 and Wave 2. 
Respondents who were reinterviewed and had changed jobs were asked about their reasons for changing jobs. As may be expected, better pay and better conditions were among the reasons given most often. However, some respondents also changed jobs for other reasons, including the wish to 'try something different' or to 'move to another part of the UK'.

Three-quarters of respondents (excluding those who were self-employed in both Wave 1 and Wave 2) who changed primary jobs between Wave 1 and Wave 2 remained in the county that they were employed in as of April 2004. The remainder moved to other counties of the UK.

Table 20 shows that, for just under half of the respondents who changed primary jobs, the job change also involved a change in the sector of employment (and the sample as noted above is likely to be biased towards those who did not change sector of employment). Although the numbers are very small, there appear to be some sectoral differences. Most respondents who were employed in construction in April 2004 and had changed jobs following EU enlargement remained working in the construction sector. In contrast, almost half of job changes by respondents who were employed in hospitality in April $\mathbf{2 0 0 4}$ - and the great majority of those working as au pairs before EU enlargement - involved changes to different sectors.

Some, but not all, respondents who changed primary jobs changed to jobs whose skill requirements were greater than those of the jobs they were working in as of April 2004. For example, the majority of job changers working in skilled trade occupations in 2004 were still working in such occupations at the time of their Wave 2 interview. In contrast, only six of the 20 job changers working in personal service occupations (mostly au pairs) in April 2004 were still working in such occupations after EU enlargement. Some had taken up managerial positions or skilled trades occupations, others elementary occupations. Almost half of all job changers working in elementary

Table 20 Sector of primary job in Wave 1 and Wave 2 of respondents who changed primary jobs, excluding respondents who were self-employed in both Wave 1 and Wave 2

\begin{tabular}{lccccccc}
\hline $\begin{array}{l}\text { Sector of primary } \\
\text { job in Wave }\end{array}$ & Hospitality & Construction & Au pair & Agriculture & Other & Total \\
\hline Hospitality & 19 & 0 & 0 & 0 & 15 & 34 \\
Construction & 2 & 14 & 0 & 0 & 1 & 17 \\
Au pair & 6 & 2 & 4 & 0 & 8 & 20 \\
Agriculture & 0 & 1 & 0 & 7 & 4 & 12 \\
Total & 27 & 17 & 4 & 7 & 28 & 83 \\
\hline
\end{tabular}

Source: survey interviews with migrants, Wave 1 and Wave 2. 
occupations in April 2004 had changed to jobs that can be classified as skilled trades occupations or above in terms of the skills required.

\section{Changing conditions of employment?}

Table 21 compares survey respondents' gross hourly earnings just before and six to eight months after EU enlargement. We focus our discussion on respondents who described themselves as 'employees' in both Wave 1 and Wave 2, and who were working in hospitality and construction in April 2004. This gives us a sample of 135 respondents including 78 A8 workers and 57 NA8 workers. We report separate figures for respondents who did not change jobs. We also provide separate figures for respondents whose reported gross hourly earnings in Wave 1 and Wave 2 were consistent with their answers about perceived changes in earnings in their current job since EU enlargement. ${ }^{33}$

Table 21 Respondents' gross hourly earnings in Wave 1 and Wave 2, respondents who were employees in both Wave 1 and Wave 2 only

\begin{tabular}{|c|c|c|c|c|c|c|}
\hline & \multicolumn{3}{|c|}{ All employees } & \multicolumn{3}{|c|}{ Employees who did not change jobs } \\
\hline & A8 & NA8 & Total & A8 & NA8 & Total \\
\hline \multicolumn{7}{|c|}{ Respondents working in hospitality or construction in Wave 1} \\
\hline Gross hourly rate Wave $1(£)$ & 6.43 & 6.08 & 6.28 & 6.75 & 6.12 & 6.43 \\
\hline Gross hourly rate Wave $2(£)$ & 7.34 & 6.41 & 6.95 & 7.38 & 6.22 & 6.80 \\
\hline$\%$ change & 14.1 & 5.4 & 10.7 & 9.33 & 1.6 & 5.7 \\
\hline$N$ & 78 & 57 & 135 & 49 & 49 & 98 \\
\hline \multicolumn{7}{|c|}{ Respondents working in hospitality or construction in Wave 1, excluding inconsistent answers* } \\
\hline Gross hourly rate Wave $1(£)$ & 6.36 & 6.11 & 6.24 & 6.74 & 6.20 & 6.45 \\
\hline Gross hourly rate Wave $2(£)$ & 7.25 & 6.47 & 6.87 & 7.07 & 6.31 & 6.66 \\
\hline$\%$ change & 14.0 & 5.9 & 10.1 & 4.9 & 1.8 & 3.3 \\
\hline$N$ & 54 & 51 & 105 & 38 & 44 & 82 \\
\hline \multicolumn{7}{|c|}{ Respondents working in hospitality in Wave 1, excluding inconsistent answers* } \\
\hline Gross hourly rate Wave $1(£)$ & 5.51 & 5.38 & 5.44 & 5.66 & 5.43 & 5.53 \\
\hline Gross hourly rate Wave $2(£)$ & 6.18 & 5.77 & 5.98 & 5.92 & 5.51 & 5.69 \\
\hline$\%$ change & 12.2 & 7.2 & 9.9 & 4.6 & 1.5 & 2.9 \\
\hline$N$ & 37 & 38 & 75 & 26 & 33 & 59 \\
\hline \multicolumn{7}{|c|}{ Respondents working in construction in Wave 1, excluding inconsistent answers * } \\
\hline Gross hourly rate Wave $1(£)$ & 8.19 & 8.27 & 8.23 & 9.06 & 8.52 & 8.80 \\
\hline Gross hourly rate Wave $2(£)$ & 9.56 & 8.50 & 9.10 & 9.55 & 8.70 & 9.14 \\
\hline$\%$ change & 16.7 & 2.8 & 10.6 & 5.4 & 2.1 & 3.8 \\
\hline$N$ & 17 & 13 & 30 & 12 & 11 & 23 \\
\hline
\end{tabular}

Source: survey interview with migrants, Wave 1 and Wave 2.

* Respondents whose reported gross hourly earnings in Wave 1 and Wave 2 were consistent with their answers about perceived changes in earnings in their current job since EU enlargement. 
Based on a small and non-random sample of workers, the wage figures presented in Table 21 should not be taken as representative. Nevertheless, the figures do suggest what appears to be a fairly robust finding: average gross hourly earnings increased for both A8 and NA8 respondents in the six to eight months following EU enlargement $(+3.3$ per cent for employees who had not changed jobs and gave consistent answers), but the increase was greater for A8 workers (+4.9 per cent) than for NA8 workers (+1.8 per cent). As may be expected, including job changers in the analysis generates greater increases in average earnings for both groups but the increase of earnings for A8 workers remains significantly greater than that for NA8 workers.

It is clear that at least part of the increases in respondents' average earnings can be explained by an increase in the legal minimum wage. On 1 October 2004 the main minimum rate increased by 7.7 per cent from $£ 4.50$ to $£ 4.85$ an hour for workers aged 22 and over. In our postal survey of employers (discussed in Chapter 3 of this paper), three-quarters of employers surveyed (in early/mid 2005) said that their workers' pay had risen since EU enlargement. Importantly, almost all employers suggested that pay had risen for al/non-British workers rather than for specific groups such as A8 workers. The primary reason employers gave for the pay increases was the increase in the national minimum wage on 1 August 2004.

Although the increase in the national minimum wage undoubtedly contributed to the earnings increases reported by our respondents, the question remains why the wage increases differed for A8 and NA8 workers. One potential explanation that needs to be explored is that NA8 respondents were employed in occupations and at wages that are less affected by increases in the national minimum wage than those of $A 8$ workers. At the same time, the difference in wage increases shown in Table 21 is also consistent with the idea that A8 workers' change in legal status on 1 May 2004 may have impacted positively on their earnings, at least relative to those of NA8 workers. This hypothesis will be explored in future analysis.

\section{Summary}

This chapter was concerned with migrants' experiences and perceptions of employment, particularly the role of immigration status. It draws on data obtained from survey and in-depth interviews with migrants to discuss their experiences and perceptions of employment in the UK. Most of the discussion refers to migrants' experiences as of April 2004, i.e. just before EU enlargement. This enables us to draw on the full sample of 550 survey respondents and 93 in-depth interviewees who provided information about their employment in April 2004. The discussion of 
changes in migrants' employment following EU enlargement at the end of this chapter makes use of the information provided by 352 respondents and 62 interviewees about their employment before and six to eight months after 1 May 2004.

The majority of respondents were employed in elementary occupations, but 28 per cent were working in skilled trades occupations, especially in construction. Whereas almost all workers in construction and agriculture worked full-time in their primary jobs, 12 per cent of hospitality sector workers and 40 per cent of au pairs held multiple part-time jobs. In construction, self-employment was very common, having been reported by two-fifths of those surveyed in April 2004.

For those who were working as employees (rather than as self-employed persons), earnings were relatively low compared to the national average for all employees and average hours worked were longer. The longer hours appear to be mainly due to longer basic hours rather than more overtime hours. Au pairs worked an average of 30 hours per week for £68 pocket money, but overtime work, which was common, was mostly unpaid. The latter was also true for many migrants working in hospitality, in contrast to construction and agriculture where hours of overtime work were paid, though not necessarily at higher 'overtime' rates. Non-wage benefits - including paid holidays, sick leave and free accommodation - were reported by a minority of workers, although more than two-thirds of hospitality sector workers received free food as part of their jobs.

It was also found that a significant share of respondents and interviewees were in low-wage jobs, which often did not match their qualifications and skills. Migrants' reasons (and in some cases compulsions) for taking their jobs varied. Some migrants saw a trade-off between working below their skill level on the one hand and earning more money than they would have had they been in a job matching their skills in their home country. In addition to financial gains, learning English was seen as a significant benefit from interviewees working in the UK. Many tolerated poor work because it was seen as temporary.

There was great diversity in the self-reported immigration statuses of respondents in April 2004. The four major statuses reported by respondents were self-employed, au pair, visa expired or student. There was, however, significant variation across sectors. For example, student was a major immigration status in hospitality (31 per cent in that sector) but less so in other sectors. Self-employed was the status most commonly reported by respondents in construction (58 per cent), less so in hospitality (15 per cent) and not at all by respondents in agriculture. A little less than a quarter of respondents in hospitality and construction described their status as visa 
expired. Immigration status did not stand still. For example, almost two-fifths of respondents who described their immigration status in April 2004 as self-employed had switched from tourist status after entering the UK.

Migrants' perceptions of immigration status and its consequences varied. Au pair status exempted au pairs from minimum wage legislation. Although it also limited weekly hours of work to 25 , the majority of survey respondents worked for longer. Interviewees found the unclear boundaries between themselves and the host families with whom they had to live were a source of difficulty. Students, also restricted to 20 hours by their immigration status, mostly worked more than 30 . For some students, this status was more a means of working legally than a programme of study, while others, trying hard to study, found themselves slipping further into the labour market. More respondents were working in violation of their immigration conditions than were illegally resident. Three-quarters of those on student visas and more than half of the au pairs were legally resident but working in breach of their conditions. The immigration status of self-employment - which maps onto an already confused picture of self-employment in terms of employment and taxation status was sometimes perceived as a way of 'self-regularisation' rather than as a distinctive career choice. Almost a third of survey respondents reporting their immigration status as self-employed described themselves as 'employees' in the workplace.

Finally, those workers who were 'illegally' resident often experienced vulnerability, fear and anxiety. Further research and comprehensive statistical modelling are needed to explore the relationship between illegal residence and earnings. First, exploratory analysis has found no statistically significant relationship between the two variables, but this cannot be considered a reliable finding at this stage of the analysis. In addition to caveats pertaining to methodology, there are two more fundamental issues that are likely to complicate and potentially distort the analysis of the impact of illegal residence on respondents' wages. First, the usefulness of the discussion of respondents' earnings by immigration status obviously depends on the correct assessment of whether respondents are legally or illegally resident in the UK. Second, the idea that illegal residence may have an impact on migrants' wages rests largely on the assumption that employers know about their workers' immigration status. This may not always be the case in practice if, for example, the worker is using false documents, which certainly seems to have been the case for some of our in-depth interviewees.

Just under half of all survey respondents reported they were working without a written contract and a quarter without national insurance payments. With the exception of au pairs, very few in-depth interviewees considered the absence of a written employment contract as a problem. In fact, the absence of a written contract 
was sometimes perceived as advantageous to the worker because of greater possibilities of leaving an employer. There was no relation found between working without a contract and agency working, nor between agency working and 'illegal' residence status. Agency working was seen by most migrants as disadvantageous compared to being directly employed. However, as with the common experience of working without a contract, there were also advantages expressed.

Some important differences were found between the A8 and NA8 nationals in their expectations of the effect of EU enlargement and in their experience of it. Most A8 respondents had expected either neutral or positive change in employment conditions, in spite of an anticipated increase in competition for jobs. NA8 nationals were also concerned about labour market competition and a considerably higher proportion (than A8 nationals) expected wages and employment conditions to decline. Most A8 nationals perceived actual changes to have been positive, as against under a third of NA8 nationals. Strikingly, almost three-fifths of A8 nationals said they now found it easier to find work, as against over four-fifths of NA8 nationals who said it had become more difficult.

Among survey respondents who described themselves as employees, well over a third of A8 workers but under a quarter of NA8 workers had changed primary jobs during the six to eight months following EU enlargement, mostly in order to get better pay and conditions. Almost half of all job changers working in elementary occupations in April 2004 had changed to jobs that can be classified as skilled trades occupations or above in terms of the skills required. Average gross hourly earnings increased for both A8 and NA8 respondents in the six to eight months following EU enlargement, but the increase was more significant for A8 workers than for NA8 workers. This result holds when job changes are controlled for. The overall increase in average earnings of respondents who had not changed jobs is likely to have been at least partly due to the increase in the minimum wage in November 2004. However, the differential earnings increases of $A 8$ and other respondents suggest that there is scope for further analysis of the role that the change in A8 workers' legal status on 1 May 2004 has played in increasing their earnings faster relative to the earnings of NA8 respondents. 


\section{Employers and host families: demand for migrants and recruitment practices}

This chapter explores how employers and host families understand the demand for migrant labour, what they perceive the determinants of this demand to be, and how they go about finding and recruiting migrants in practice. We also discuss the impacts and employers' perceptions of EU enlargement. Throughout the analysis, we are particularly interested in exploring the role of migrants' immigration status as a potential determinant of employer demand and recruitment practices.

The analysis draws primarily on data obtained from our postal surveys and in-depth interviews with employers and host families. As before, we use the term 'respondent' to refer to employers and host families who responded to our postal surveys, which were conducted in 2005 after EU enlargement. 'Interviewees' refer to employers, host families and agencies with whom we conducted in-depth interviews before and after EU enlargement.

\section{Recruitment challenges and perceived solutions}

In considering the nature of the demand for migrant workers, one must first consider the question of whether there is in fact a demand for migrant labour per se. There may be a demand for a certain type of worker (for example, with particular skills or qualities, 'flexible', low-waged, etc.), who in practice is a migrant, but who in theory could equally be a UK citizen. This is not to be equated with a demand for people of a particular immigration status (including those we have described as illegally resident), though the two may also be related. We will thus first consider the nature of the recruitment difficulties experienced by the employers of our sample, and then explore why and how migrants offer possible solutions.

\section{Recruitment challenges}

Almost all employers surveyed reported difficulties in recruitment. This is not surprising since our sampling meant that those who had applied for work permits (including SAWS and SBS) were disproportionately represented. When asked to 
describe what kind of vacancy is most difficult to fill with applicants from the UK workforce, agricultural employers emphasised seasonal and manual work, lowskilled work, and field and packing work, summarised by one respondent as 'lowskilled, long working hours, low wages'. In contrast, hospitality employers, while saying that low-skilled positions and junior or entry-level posts were difficult to fill, also described a range of skilled vacancies including chefs, head waiting staff and receptionists. Construction employers and agencies interviewed also described both skills shortages and a shortage of labour for low-skilled jobs.

Data obtained from the postal survey of employers suggest that the recruitment difficulties described above persisted despite employers' efforts to attract UK workers. Eighty-five per cent of agricultural employers and 91 per cent of hospitality employers claimed to have raised salaries in an attempt to make jobs more attractive to the UK workforce. ${ }^{1}$ Almost two-thirds of employers in hospitality, and over onethird of employers in agriculture, also said that they had increased non-wage benefits and changed shift patterns to attract British workers.

While recruitment difficulties were widespread among our sample of respondents and interviewees, the reasons underlying such difficulties need to be understood within the broader context of the workforce profile and the kinds of jobs available in each sector. Issues such as geographical location, the prevalence of selfemployment in construction, the complexity of public/private relations for au pairs, the prevalence of informality in the hospitality sector are important in setting the parameters of the demand for labour, both migrant and non-migrant. ${ }^{2}$

The postal survey of employers in hospitality and agriculture/food processing asked employers to indicate the reasons for their recruitment challenges in certain occupations. Figure 8 summarises respondents' answers.

In both sectors, employers estimated that labour costs represented approximately 30 per cent of the total costs of the business making them key to profitability. Both sets of employers - in hospitality and agriculture - felt that salaries might not be attractive to UK workers.

Issues of recruitment and demand for au pairs are different from those of other sectors, not least because, to choose an au pair, is perceived as opting for a certain style of childcare rather than as employing a migrant as a childcarer. Nevertheless, cost was an important consideration for almost two-thirds of host families surveyed: 
Figure 8 Employers' reasons why certain positions are difficult to fill with British workers

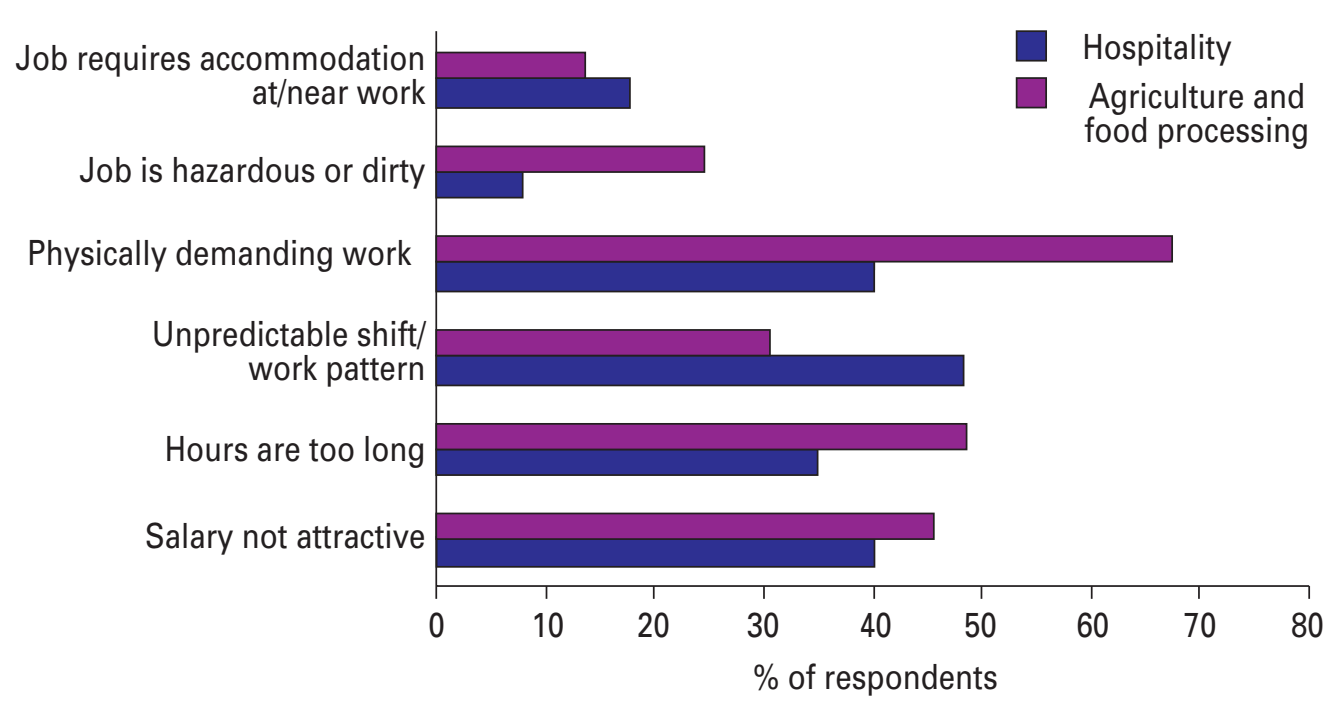

Source: postal survey of employers, May-July $2005(N=325)$.

You have to pay, nowadays, if you get an English person to clean your house, I know people who are paying 10,12, 15 pounds an hour, it's just a joke ... that's probably why I started having au pairs in the first place ... it is really exploitation if you think about it, because ... they don't earn very much, they come for the money and you make them do the jobs that we British people don't want ... I'm not particularly proud of it, but that is really why a lot of people do it because it's actually much more financially viable.

$(2 \mathrm{P} 9)^{3}$

Another reason that employers gave for recruitment difficulties was to do with the nature of the work. The aspects stressed depended on the sector. Two-thirds of respondents in agriculture and food processing and 40 per cent of respondents in hospitality suggested that UK workers were difficult to recruit because of the physically demanding nature of the work. Furthermore, nearly one-quarter of the agricultural and food processing respondents felt that the hazardous or dirty nature of the work made it difficult to recruit for the sector. While relatively low numbers of hospitality employers expressed this as a problem, what does come out very strongly from the in-depth interviews is the issue of job status. All in-depth interviewees working in hospitality felt that the lack of status accorded jobs in the sector - that it is not 'glamorous' and is associated with servility - was a factor in recruitment difficulties. This was generally felt to be a particular issue in the UK, and some contrasted British attitudes with a continental European approach in which staff are 
accorded a more professional status. Construction employers referred both to their sector being accorded a low status and to the physical nature of this work as factors in recruitment difficulties:

Young UK-born nationals do not want to go into the building industry. They see it as dirty. It's not low paid, but they see it as dirty, unhygienic, hard work.

The question of status was also recognised by host families as making it less likely for young people in Britain to want to work in private households. Interestingly, host families indicated that their own status and relation to a childcarer also impacted on their choice of childcare. Some commented that nannies were for higher-class people, or that class becomes more unmanageable when both parties are British:

To be honest I would feel funny asking a young girl to do the cleaning and ironing ... I hate asking them to do that anyway. I feel very happy, it may sound silly, but she has come here to earn money, and I just feel happier asking her because that is what she has come here to do. I would feel embarrassed asking somebody who by an accident of birth, you know, is in a position where she had to be subservient to me.

Long hours, anti-social hours and unpredictable hours were further factors identified as contributing to recruitment difficulties. Almost 50 per cent of hospitality employers surveyed felt that unpredictable shift patterns affected recruitment. A lower proportion of agricultural employers regarded this as an issue. However, in qualitative interviews, agricultural employers noted that, for crops such as salad produce, harvesting routines varied day to day according to supermarket orders. Thus workers needed to be willing to extend shifts at no prior notice, and to work weekends and anti-social hours. They felt that UK workers were not willing to tie working hours to fluctuating orders in this way whereas migrant labour 'actually find non-working Sundays exceedingly boring' (A8).

In a similar vein, 85 per cent of host families surveyed saw having 'childcare available when I need it' as a key reason for hosting au pairs and 81 per cent felt it was a 'flexible' form of childcare. 'Flexibility' as explored in the interviews seems to apply to both the type of work done and the hours worked. One of our interviewees whose au pair left her following EU enlargement contrasted having a childminder with having an au pair: 
I have to be home by a certain time now and worry about the time. I'm paying somebody on an hourly rate now ... and you cannot ask a daily childminder to do the jobs that an au pair does. They're not really responsible for the ironing and the cleaning, just general cleaning up. Um, so I, I really feel I'm spending probably double what I was spending with an au pair.

Work patterns in the sectors often fluctuate across the year as well as immediately impacting on daily shifts. Eighty-six per cent of agricultural and food processing sector respondents to the employer postal survey, and 53 per cent of hospitality sector respondents, reported seasonal fluctuations in their employment of workers. The qualitative interviews in the construction sector suggested that employment was seasonal (with more work taking place in the summer), temporary (when a site was complete the contract ended) and cyclical (the extent of demand for construction work reflected the state of the economy). Construction interviewees also claimed that UK workers wanted 'fixed patterns' and were unwilling to work evenings and weekends.

Forty-seven per cent of host families, 58 per cent of hospitality employers and 34 per cent of agricultural and food processing employers gave retention concerns as a factor determining whom they chose to employ. This suggests that the root causes of retention difficulties as well as those of recruitment need to frame our understanding of demand for migrant labour. 'Retention' must of course be broadly understood: in some instances it may mean a worker who is prepared to stay for weeks, in others it may mean someone who is prepared to stay for years. Concerns about hours, shifts, reliability and availability suggest an arena of possible tensions between flexibility and availability on the one hand, and retention on the other.

\section{Recruitment solutions: high-quality migrants for 'low-skilled' jobs}

In general employers were extremely positive about migrant workers. It was not simply that they offer a 'good enough' solution to otherwise unmanageable recruitment difficulties, or that migrants are simply providers of labour for basic jobs, but that they are perceived to be 'good workers'. They are high-quality workers for 'low-skilled' jobs. In practice, such 'low-skilled' jobs typically involve low-waged work. Thus an advantage of 'low-skilled' migrant labour for one farmer was that:

They pick things up very quickly, because they're already university students.

(A3) 
'High quality' may also indicate that workers are English speaking. Even for work considered low skilled, English language can sometimes be a considerable advantage. Survey data indicate that English language skills were a determinant of nationality employed for 51.6 per cent of hospitality employers and 37.4 per cent of agricultural employers (see Figure 10 later in this chapter). Construction employers were also concerned with English levels, largely because of safety considerations:

It's a prerequisite that people that come and register with us have a command of the English language ... You can't stick them on a building site not knowing what 'duck', 'fire', 'live electricity cable' means you know. (2C4)

Employers also discussed more generic 'soft' skills - having a pleasing manner for example, being motivated, being able to work in a team or having a flexible attitude (qualities that of course may also make workers more retainable). This employer was talking about the 'low-skilled' work of cauliflower harvesting:

One of the reasons why the Eastern Europeans have come and work so well is because they do have somewhat higher intellect and their understanding ... unless the job is done well, there really isn't any point in doing it ... we find them lovely people we really do. I mean you know that once you've got over any initial misunderstandings about what the job's about they are consistently capable of producing high quality.

(A1)

It is not only agricultural employers who value migrants as high-quality workers in low-waged occupations:

They are so friendly they never stop smiling and they work damned hard. They are really polite people. There really are differences in races and different countries and they really work hard. (H10)

Demeanour - want pleasant sociable person for sharing our family (not moody or impatient, etc.).

(Host family survey respondent)

A recurring theme in the employers' in-depth interviews is that the willingness of migrants to do particular kinds of work ('motivation') is related to conditions back in migrants' home countries. Comparisons are commonly made with what similar workers or professionals earn in their countries of origin: 
I've had doctors ... bit of a sad waste really, doing laddering work because it paid better than being a doctor back home.

(2C6)

High unemployment and generalised poverty are often held to explain why migrants are prepared to work hard for relatively low wages:

They come from a Polish small village where they spend 100 euros a month if they were lucky. They still live with their parents, with their animals, they come here seeing the wealth of England. (2P6)

Some remarked that such poverty means that they are appreciative and respectful as well as hard-working. They are financially motivated workers, working hard to support a family back home, 'smart, tidy, no piercings, no noses and no eyebrows', as one hospitality placement agency described Polish workers.

All this suggests that employers are acutely aware of - and base some of their recruitment and employment decisions on - migrants' employment prospects and earnings in their countries of origin. Employers clearly recognise that the discrepancies between wages in Britain and migrants' countries of origin mean that migrants often 'accept' a trade-off between working in Britain with employment conditions that are poor by British standards but high - at least in terms of the wages received - when compared to employment in migrants' countries of origin.

\section{Accessing migrant labour}

In order for migrants to offer a solution to recruitment difficulties it is not sufficient for them to be willing to work in low-status, poorly paid and insecure jobs. Employers must be able to access this labour in order for it to offer them a satisfactory solution to their recruitment difficulties. There are many ways of accessing (migrant) labour, such as the internet, chance calls or advertisements. At first sight the most obvious way is through immigration schemes, but it is important to remember that employers may also recruit from migrants who are already in the UK, and in this case the fact that workers are migrants may only be incidental to their employment. Employers we interviewed accessed migrant labour principally through immigration schemes, through personal networks or through agencies, so we limit our discussion to these routes. 
The State actively facilitates access to migrant labour from abroad in certain sectors through immigration schemes. Interview data suggest that employers and host families clearly value the SAWS and au pair schemes. SAWS permits are held by workers, and theoretically they may change to another employer within the sector as long as that employer has permission to host SAWS workers and has not exceeded their quota. As will be discussed in more detail later in this chapter, some of the advantages of these schemes from the point of view of the employers/host families included: for employers of SAWS workers, ease of retention due to the difficulty for workers to move to another employer because of the sectoral employment requirement; and, for host families, the provision of low-cost, flexible, live in childcare. Neither SAWS employers nor host families have to pay national insurance.

Of our respondents in the postal survey of employers (accessed through Work Permits UK, so with a high likelihood of applying for permits), 72 per cent had applied for permission to employ SAWS permit holders. Forty-four per cent said that all of their non-EU workers were employed on such permits. The Seasonal Agricultural Workers Scheme was commented on by almost all of the agricultural labour providers and employers in the in-depth interviews. Employers were expressive about why they valued the scheme:

SAWS is, is a brilliant scheme ... They've got a bit of comeback if they have trouble, they can go and ask to be relocated if they've got trouble with the farmer or anything like that ... in principle I really like the idea of getting people who are young and fun and marginally um educated, if they're educated people ... I feel you know you can explain to them ... and it's really good ... to show people what actually is a little bit of what England is like at this level.

(2A7)

The generally positive views of agricultural employers contrasted strongly with those of two of the three agricultural labour-providing agencies interviewed. These agencies were both members of the Association of Labour Providers, which has expressed scepticism about the SAWS scheme. These views may be explained in part by the competition that private labour providers faced from SAWS operators. There are only nine operators in the UK and several labour providers tried unsuccessfully to join their ranks in the last tendering exercise.

In contrast with the tightly run SAWS scheme where there are only a handful of operators, the au pair system is mediated by hundreds of au pair agencies, largely 
unregulated. Personal contacts, advertisements and the internet are all important in this regard. UK-based agencies typically have links with au pairs' countries of origin, which may be other recruitment agencies, colleges and schools, or personal contacts. They may run reference checks, advise on immigration requirements, assist with visa applications, offer ongoing support to au pairs and host families, or they may do none of these, and au pair agencies are often extremely scathing about the level of service offered by some of their competitors. While there are immigration rules governing the au pair scheme, its implementation is highly deregulated. Host families were generally enthusiastic about the au pair 'ideal' but critical of its implementation, and concerned at the vulnerability to exploitation on both sides resulting from the lack of regulation and protection.

Accessing host families via au pair agencies necessarily meant that our sample was heavily biased towards agency users (and agencies that were members of the selfregulating British Association of Au Pair Agencies), though it was clear from some of our in-depth interviews that host families who use agencies also use other recruitment methods. While, for agricultural employers, issues regarding the actual SAWS operators (agencies) did not figure very much in interviews, for host families, agencies were a major cause of concern. They were felt to be advantageous because they offer reference checks (69 per cent) and host families had greater confidence in the reliability of the au pair (60 per cent). There were, however, considerable criticisms of agencies, both from the point of view of cost and of service. Bad agencies were represented as simply collecting money without providing more than a minimum service and, for some, the profit motive of agencies made them intrinsically problematic:

It's my kids and these are, these are businesses, they are interested in the profit they make, they are not interested in being nice to you. I mean, on the whole there are people that are very nice because that's how they got the kind of jobs they got into. But in the end it would be like saying, 'Well don't you trust the supermarket?' Well of course not, it's just the place I buy food.

(P10)

Some host families interviewed expressed concern that self-regulation by the agencies was not sufficient and suggested that they should be more closely monitored. Agencies were also cited as a problem for the au pair system by our survey respondents. Host families were also concerned that agencies did not properly represent the interests of au pairs, and those that attracted the most praise were those that offered follow-up, put au pairs in touch with others in their areas and demonstrated 'pastoral care'. 


\section{Agency labour}

A major disadvantage of accessing migrant labour through schemes is its lack of flexibility. For example, while SAWS workers are useful when there is a need for labour for a concentrated period of at least five weeks, they may be too expensive for the purposes of harvesting consumer and weather-related crops, where demand is unpredictable, intense but short-lived. In this case casual labour may be cheaper and more suitable:

With SAWS for the period they're there you're having to provide them with work all the way through their period of time. With casual labour, obviously if the weather is unsuitable, you're not having to pay them for that day, and so economically it's quite advantageous to utilise the gangmaster system ... you are very definitely involved in housing and entertainment and all the other aspects of SAWS and ... it's quite demanding.

(A1)

Many of the advantages perceived by employers to attach to migrant workers flexibility, availability, short-term with limited commitments - might in theory apply to any agency worker, migrant or not. Regarding questions of seasonality and temporary employment, for example, migrants may be more receptive to offers of highly temporary work but are also more likely to be 'agency workers', i.e. formally employed by an employment business, but working temporarily for a 'labour user' who is not, technically, their employer. ${ }^{4}$ Among our survey respondents, agricultural and food-processing employers were more likely than hospitality employers to use labour provided by agencies (employment businesses) as of May 2005. Twenty-two per cent of their total workforce is provided by agencies, as opposed to 4 per cent of the hospitality workforce (see Table 22). One-hundred-and-fifty-one of our employers reported never using an agency, and 126 of these were in the hospitality sector.

Table 22 Employers' use of agencies

\begin{tabular}{lcc}
\hline & Hospitality & $\begin{array}{c}\text { Agriculture and food } \\
\text { processing }\end{array}$ \\
\hline Share of workforce provided by agency & 4.1 & 21.7 \\
Mean \% & 177 & 89 \\
$N$ & 1.4 & 1.4 \\
Share of British workers provided by agency in total workforce & 86 \\
Mean \% & 178 & \\
$N$ & &
\end{tabular}

Source: postal survey of employers, May-July 2005. 
Workers who are provided by agencies to labour users do not have to be migrants, but in practice migrants do represent a high proportion of such workers. Data from our employers' survey suggest that migrant workers in agriculture/food processing and hospitality were more likely than UK workers to be formally employed by agencies. As indicated in Table 22, in hospitality a mean of 4.1 per cent of businesses' total workforce work for employment businesses, of which 1.4 per cent would be UK workers and the remaining 2.7 per cent would be migrants. That is, for every three workers provided by an agency, it is most likely that one will be British and two will be migrants (though of course this could include EU nationals). The proportions are more stark for the agricultural/food-processing respondents. A mean of 21.7 per cent of the total workforce are employed by agencies, of which 1.4 per cent are UK workers and the remaining 20.3 per cent are migrants. For every 22 workers provided by an agency, it is likely that 20 will be migrants.

As shown in Figure 9, the main reasons given by both hospitality and agricultural employers for using agency workers is the provision of short-term labour. Very few respondents felt that it was cheaper, and this was confirmed by in-depth interviews, where employers frequently complained about the expense of workers provided by agencies.

Figure 9 Reasons given by employers for using agency workers

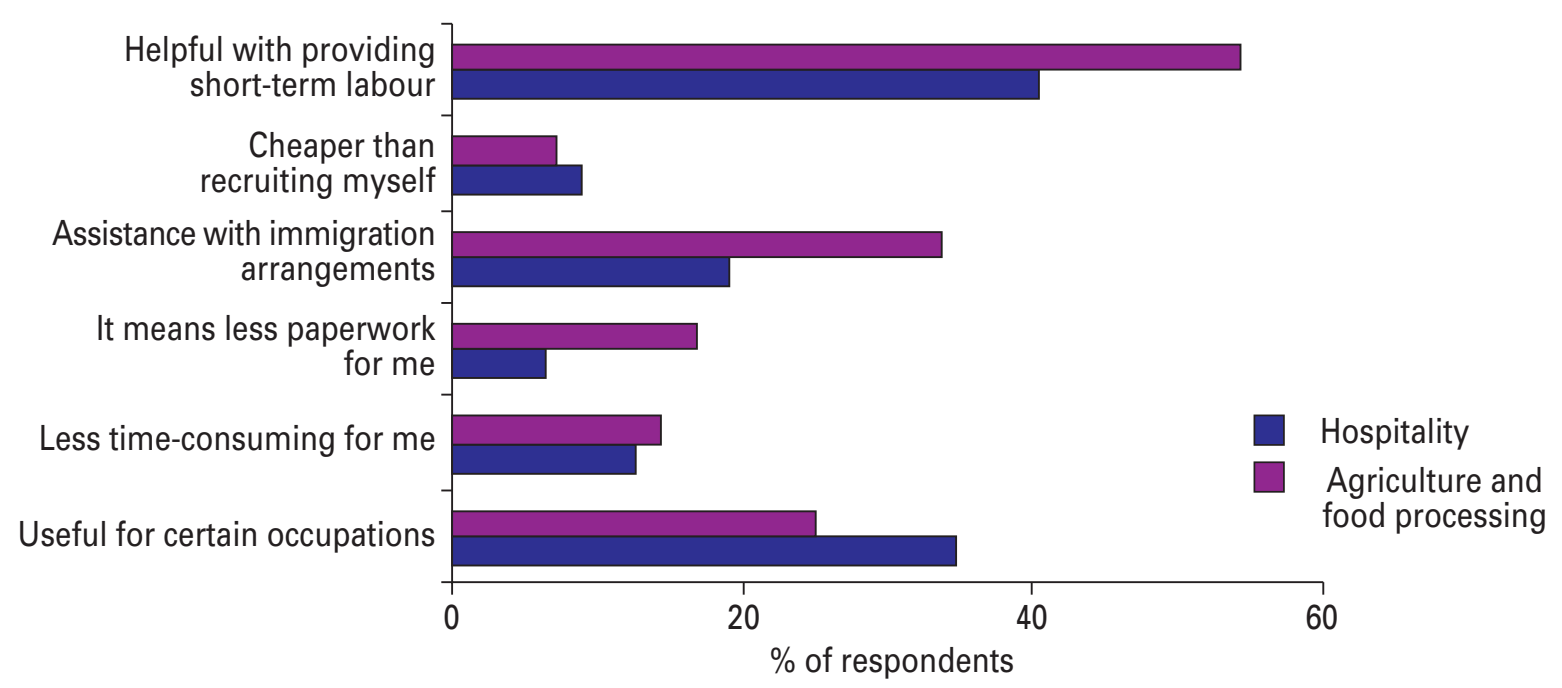

Source: postal survey of employers, May-July 2005. 


\section{Personal networks}

Networks are generally thought to be highly important in terms of migrants accessing employment, but little is known of how employers engage with these networks. There are indications from the survey that employers do actively use migrant networks to access labour. In order to access more workers, 21.7 per cent of hospitality employers and 30.4 per cent of agricultural/food-processing employers report using contacts of migrants already employed by their business. ${ }^{5}$ The sampling method may well have influenced this, since a large proportion of these employers have applied to Work Permits UK (WPUK) and therefore are more likely to use government schemes - such as SAWS or SBS - than employers in the sector in general. These indications are confirmed by some of our in-depth interviews, particularly in hospitality. Word of mouth is 'cheap' - 'they are all talking to each other' $(\mathrm{H} 8)$ - and agencies are costly:

I don't have to go out and actively recruit you know. l'll say I need someone and they'll have ten people for me tomorrow if I need it. $(\mathrm{H} 2)$

Wave 1 qualitative data suggest that networks, particularly those pertaining to host families and in construction, can extend into countries of origin:

You get a certain amount of people come over from one country like the Polish. They get contacts in the UK, and then they give the phone numbers to those who are back home. And so the people come over. (C5)

While we have presented them separately, these means of accessing labour are not mutually exclusive in practice. Information about immigration schemes may be passed between individual employers and individual migrants. Agencies also work with schemes, as we have seen, and personal networks may inform and assist with access to both agencies and schemes.

\section{Nationality, immigration status and demand}

One of the issues we set out to explore is the role of immigration status as a potential determinant of employer demand for migrant labour. However, in qualitative interviews, employers talk about migrants/foreigners/the 'not English' and rarely in terms of immigration status per se. In fact employers often use nationality rather than 
immigration status as a means of expressing preferences for particular types of labour. While there are ways in which the two concepts can and do map on to one another, the relationship between nationality and immigration status is complex. If we are to understand the nature of the demand for migrant labour from the point of view of employers, we must therefore consider what they mean when they express preferences for particular nationalities, as well as straightforwardly for certain types of visa holder.

\section{The nationality 'code'}

In line with the remarks above, employers rarely used the term 'A8 national'. They often talked about 'Eastern Europeans' in general including, for example, Russians, Romanians, A8 nationals and others in the term. They are not always spoken of as a homogeneous group, however, and indeed some employers remarked that conflict between different Eastern European nationalities was a management concern. Others, as will be seen below, expressed preference for particular nationalities.

'Nationality' can be used as shorthand to refer to different aspects of workers' personal characteristics, both objective and subjective. In some instances employers use the term literally and are referring to how their impressions of conditions in countries of origin affect workers' trade-offs. At other times, more subjective characteristics are attributed to 'nationality', such as being hard-working or pleasant. Survey responses are revealing in this regard (see Figure 10). When employers were asked what was important in determining the nationalities of workers they employed, some respondents clearly indicated factors where nationality has a direct and objective impact. Immigration regulations, for instance, clearly have an objective impact, as nationals of certain states may be able to apply under different schemes, or may find it easier to get entry clearance. However, the relationship between retention ('likely to stay with my company for a while') and nationality, if there is one at all, is surely most likely to be mediated by immigration status. There is no ostensible reason why, for example, Polish people are, by virtue of their nationality alone, more or less likely to remain in the same job than Ukrainians (leaving aside for a moment the question of employers' perceptions of the impact of conditions in countries of origin). ${ }^{6}$ 
Figure 10 Determinants of nationalities of non-British workers recruited, as reported by employer postal survey respondents

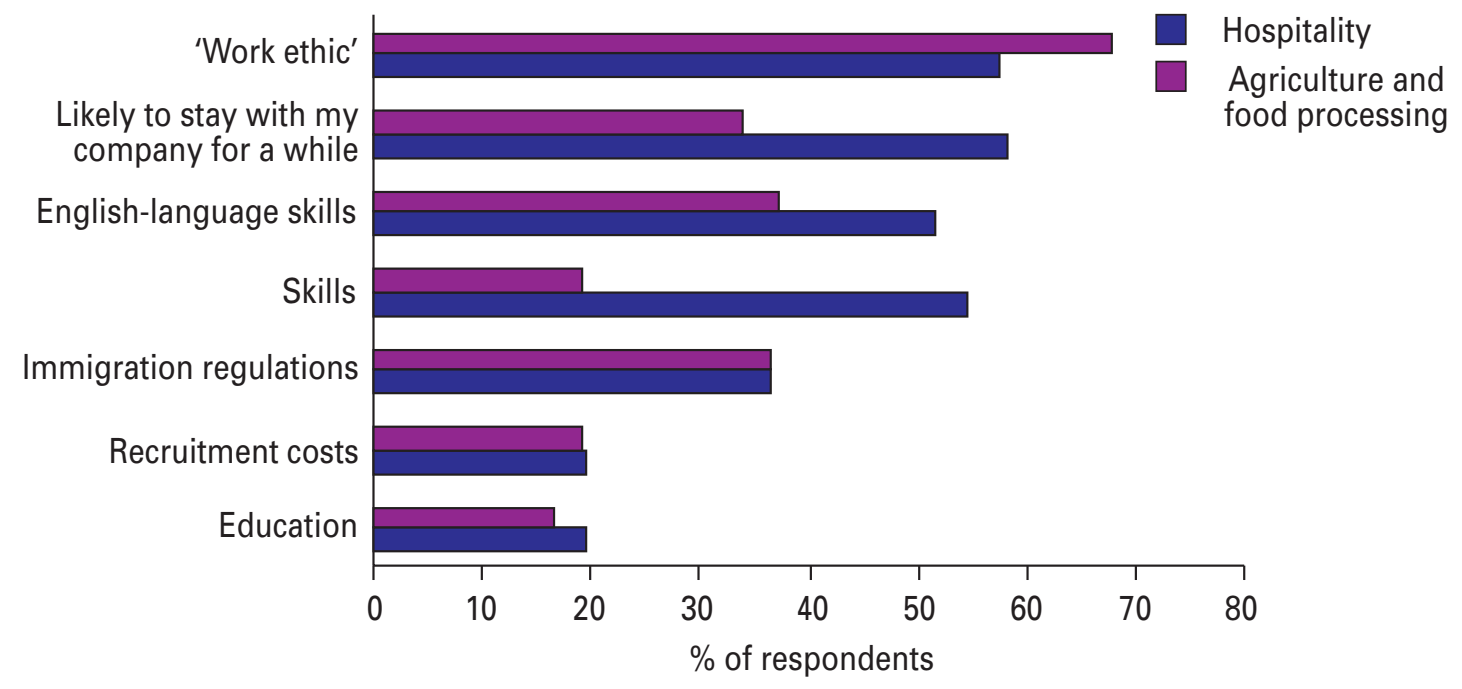

Source: postal survey of employers, May-July 2005.

The most prominent key determinant of nationalities of non-British workers recruited for those agricultural and hospitality employers surveyed was the highly subjective notion of 'work ethic' (see Figure 10).

Survey respondents commented that non-British workers are 'grateful for the job', 'polite, always turn up and do what they are asked' are 'loyal, hard-working and "nonclock-watching"'. Some in-depth interviewees went further and this association of being hard-working with being 'foreign' was expressed as a quality that was particularly associated with certain nationalities. Three construction interviewees, for example, overtly discussed contractors' preferences for particular nationalities. As one put it, 'we negotiate conversationally, it depends what we have had in' (C4). This was explained as being in part because of language skills, but also because of stereotyped ideas about particular nationalities:

The Poles have a strong work ethic, they are northern Europeans, they are Christians, their whole ethos - not to be racist - it's a hard-working culture that they come from. It's also a hard-drinking culture.

(C1)

Such stereotyped ideas were particularly marked in some of the in-depth interviews with hospitality employers. The situation was described by one employer whose housekeeping staff are Polish, with EU15 nationals serving in the restaurant and 'our kitchen washing-uppers tend to be more African nationals'. This suggests that the job 
and pay hierarchy map on to nationality and ethnicity. Many employers were keen to explain that they did not discriminate or actively go out to recruit certain nationalities, but there was a marked difference here between the small and large employers. The three smaller hospitality businesses overtly expressed certain preferences, such as that Bangladeshis were 'more reliable than Italians' $(\mathrm{H} 3)$, 'the occasional advantage given to a Scandinavian person' (H8), Polish being preferable to the 'old ... leisurely laid-back attitude of some of the black nations who we have over here' (H12).

Stereotypes were also marked in host family data:

Colder more Northern European climates seem a more successful match for us.

(Host family survey respondent)

I would never have a Czech or Slovakian now again because I have learned that they are here through prostitution ... Slovakian ... I haven't met an honest one yet.

(P5)

Host family interviewees and survey respondents often drew on particular experiences, good or bad, that they had had with an individual au pair to make generalisations, positive or negative, about the au pair's nationality. One interviewee commented on the racism of certain host families of her acquaintance against Turkish au pairs (12 per cent of our respondents specified a preference for Turkish au pairs, 43 per cent for EU15 nationals), and another remarked:

The thing that would really worry me about having them is the, where's the nearest synagogue, where's the nearest you know, nearest um, brown or black or yellow au pair? You know they're all white around here. So that's the only thing that would put me off.

(2P9)

It is apparent from some of our interviews with host families and with employers that 'East Europeans' are assumed to be white. One agricultural labour provider, many of whose workers were British Asian, certainly believed that he had experienced a considerable downturn in business because employers were actively choosing to employ newly available Polish workers 'because it's the colour of their skin'. Few employers made any statements to support this, though there were some suggestions of disreputable employment practices for 'the African side of things' (2C4), and one employer overtly stated: 
I think if I'm honest, I would say, if I had two application forms on my desk and they both had the same qualifications and they were both interviewed and they were strong interviewees, and I had to make a decision, whether it was someone from the Eastern bloc or someone from the black side ... I would tend to go for the Eastern bloc because they seem to be such hard workers ... we now have a new culture coming which is a white Eastern European culture and they're hungry for work.

$(2 \mathrm{H} 11)$

At the same time as being generally positive about migrant workers, the employers interviewed often expressed a surprising negativity about British nationals, with migrants in general being favourably compared with them. This was particularly noticeable in the hospitality sector - UK nationals 'don't want to work', 'are up themselves', 'don't want to get on', etc. One farmer contrasted Eastern European workers with Yorkshire and Nottinghamshire workers, because the former 'just seem[ed] quite happy to sort of buckle down' (A1). 'English blokes were always taking days off' (A7). According to another agricultural employer:

... [foreign nationals] just want to work to earn money ... you can actually rely on them to get up in the morning ... a British person will wake up in the morning and draw the curtain and you know if it looked like it was going to rain they would just pull the curtains and go back to sleep. (A8)

In construction, one employer described English workers as 'lazy', while another commented that non-UK nationals are:

Willing to do what the English workers are not willing to do, which is the lower end of the scale labouring work. They are here to work; they will work Saturday, Sunday. If you tell them to work till 8 o'clock at night they will.

Similar comments were written on the survey - all posts are hard to fill with UK workers, according to one respondent, because 'most British workers have low ability and poor motivation'. 


\section{Immigration status and demand: schemes}

For workers of a particular immigration status to be considered more or less employable than others, the employer must at least think they know what the immigration status of those workers is. Of course this is less straightforward than it sounds, particularly given the conflation of immigration status and nationality: an employer might assume that a Ukrainian's permit is fake and that a Polish passport is genuine, for instance. Nevertheless, what the employer knows, chooses to know, or thinks they know is key to appreciating the relation between immigration status and demand, as is the specific immigration status that the worker has.

One of the key advantages that employers and host families attached to the SAWS and au pair schemes was retention. This is at first sight somewhat surprising as, unlike many work permit holders, both au pairs and SAWS workers are in theory free to change employer/host family as long as they continue in the same sector and, for SAWS workers, as long as they change to an employer who is permitted to employ SAWS workers. However, agricultural employers themselves acknowledge that there are practical difficulties with finding new employers in rural areas and often describe SAWS workers as 'tied' by their permit. Non-SAWS workers in contrast can 'easily move between jobs' or 'simply move on to other work'. The advantage of SAWS workers as opposed to EU nationals is that they cannot leave the employer:

SAWS students must remain with us. EU member students may leave at any time, which is potentially disastrous for the harvesting of crops. (Employer postal survey respondent)

Labour agency critics of SAWS claimed this was unethical:

SAWS should not exist. I don't think there's a reason for SAWS to be in existence now ... I can't see the ethics of SAWS because, knowing what they've done in the past ... still think it's a form of bonded labour ... I have to say it's another form of state labour. (2A8)

In practice, au pairs are more likely than SAWS workers to change families. However, pre-enlargement host families and agencies identified a clear difference between au pairs who were EU15 nationals and au pairs who were visa holders. The former were considered far more likely to use au pairing as a 'stepping stone' to other forms of work, staying with a family a few months until they found their feet, and then moving on to another type of employment. Those on au pair visas were more likely to stay and provide the kind of stability required for childcare: 
Families are quite aware of the fact that they've had experiences that their au pair wants to get another job, etc., that they, they're going for girls who have to get a visa and can't do something else. (2P4)

\section{Immigration status and demand: managing legality}

As we have seen, employers do not only access migrant labour through schemes, and may employ migrants who are already in the UK. In this case workers may have a wide variety of statuses, they may be students and other visa holders working within or in breach of conditions, and they may also be overstayers or illegal entrants. Employers are liable to fines and imprisonment should they be found to be knowingly employing 'illegal' workers. Those who are concerned about the possibility of employer sanctions may therefore prefer to use labour provided by employment agencies rather than directly employ migrants themselves, as it is the employment agency in this case that must take responsibility for checking workers' documentation. Several in-depth interviewees in both the agricultural/food processing and hospitality sectors were clear that this was a distinct advantage, and even a motivating factor in using workers provided by employment agencies. They would claim that certain segments of work tend to be dominated by people with no permission to work, but that they do not themselves directly employ such workers. This hotelier for example:

Lots of housekeeping agencies employ illegally ... Luckily I'm exempt from the law on that ... I wouldn't be in trouble, but the agency would. (H8)

This is particularly an issue for short-term temporary work, where checking documents for large numbers of workers who are likely to be employed for only a few days is logistically extremely difficult:

The reality is that it's not practical. So, what we do, and to a certain extent it is an element of buck-passing from our end, is we have this written contract which actually makes it quite clear, not only that we're not employing these people, they're employed by the gangmaster, but also that it is his onus or responsibility to make sure that the labour is legal. (A1)

In-depth interviews with employers suggest that some of them are concerned that unscrupulous employers seek out 'illegal migrants' specifically because they can 
exploit them with no redress. However, they used the term 'illegal' colloquially, and made no explicit distinction between what we term 'illegally resident' workers (i.e. those without leave to remain in the UK) and those working in breach of their conditions (e.g. students working for more than 20 hours during term-time). Of course, none of the employers we surveyed or interviewed admitted any illegal practices, but the advantages of having access to illegal labour were acknowledged:

A guy who doesn't have permission to work is gonna ... you know, perform ... You've got no worries about him suddenly saying 'ooo, hurt me back'.

(A7)

Moreover, some of our employers knew that they were 'bending the rules' in their employment of migrants:

There's times when you do twist it a bit ... will you work an extra couple of hours, you know, nudge, nudge and so on.

$(\mathrm{H} 12)$

Or this host mother who encouraged her au pair to take on extra work in a bar:

... if they've got the ability to earn a bit of extra cash then they are going to be happier so I think that would be quite helpful to be looked at because I don't know what the rules are. I don't think anybody really knows the rules on that. I don't think it's a big deal to do it.

(P6)

Employers and host families may bend the rules, not only by claiming ignorance, but also by omitting to uncover relevant information. Assessing knowledge is not straightforward, and there are ways in which employers may choose not to know:

They come with their letter and their student visa in their passport and their letter of acceptance for their course. And you think 'l've never heard of that university' ... they're just an excuse to give people letters ... so fine, let's give them two or three days' work. Make use. $(2 \mathrm{H} 6)$

Construction employers described using the Construction Industry Scheme (CIS) registration card when checking migrants' documentation. As explained in Chapter 2, possession of a CIS card does not serve as proof that the migrant has the lega/as opposed to taxation status of self-employed. Neither does it prove that he or she has 
that immigration status. Several of the construction employers who were interviewed nevertheless used the CIS card as proof that a person has a right to work under immigration laws:

They have all the relevant paperwork. How they get it, I do not know. You ask them for the CIS tax card, they have all those tax cards. From my point of view, as long as they have got one of those tax cards, it is not a problem.

(C5)

Exploring what it is to 'knowingly' employ illegally resident workers is also of relevance in considering the issues around employer sanctions, and it should be noted that several of our employer interviewees expressed reluctance to check documents - because of time, complexity and a sense that 'it is not really our job' (C5). Despite employer sanctions and stated concerns to work within the law, in practice the employers we interviewed were not enthusiastic in their efforts to comply consistently with immigration rules.

In conclusion, employers identify skills shortages, labour shortages, requirement for flexibility and retention issues as reasons for employing migrant labour. Of these, retention was associated particularly with migrant labour provided by schemes (i.e. of a particular immigration status). However, the demand is often not simply for a worker to do a job, but for a particular type of person. Soft skills, including demeanour, enthusiasm and teamworking, were sometimes regarded as necessary to do the job, and sometimes simply value added - but much appreciated. Migrants were regarded as more likely to have these skills than UK nationals available to do similar work. Employers often used 'nationality' as an indicator of whether or not people had these skills (and indeed other 'harder' skills such as English language), and also as an explanation for migrants' perceived greater motivation.

\section{EU enlargement perceptions and impacts}

EU enlargement had two effects on the supply of A8 workers in the UK: first, it increased the number of workers from the new EU member states migrating to the UK and taking up employment with all the rights of an EU national; and, second, it changed the legal status of all A8 workers already employed in the UK before 1 May 2004. This section first explores how employers perceived these two effects and then discusses how employers responded to EU enlargement in terms of their recruitment and employment decisions in practice. 


\section{Increased labour supply}

As mentioned in the introduction, according to the Government's latest registration figures for A8 workers, about 345,000 workers from the new EU member states registered for employment during the period between May 2004 and December 2005. Up to 30 per cent of A8 workers who registered between May 2004 and September 2005 may have already been in the UK before 1 May 2004.

The second wave of in-depth interviews carried out at the end of 2004 showed the extent to which employers perceived labour market conditions to have changed. In agriculture, construction and hospitality, employers noted a significant increase in the number of workers making themselves available, and a consequent loosening of the labour market. The emphasis was very much on the increase in the available labour pool in the UK both because of a change in the immigration status of those already in the UK and because of numbers of new people entering the UK to work:

... we've been bombarded by it ... we were just deluged by Eastern Europeans in particular. $(2 \mathrm{C} 4)$

... it [EU enlargement] made it so much easier for us at the moment. We're being inundated with people actually looking for work. $(2 \mathrm{~A} 10)$

... we're getting a lot more European people that are coming in off the streets for jobs - literally every day without fail.

$(2 \mathrm{H} 10)$

Three-quarters of the agricultural, food processing and hospitality employers felt that EU enlargement had been good for business, with no significant sectoral difference, and the reason given for this by over 90 per cent of relevant respondents (i.e. those who said that it was good for business) was that there was a larger pool of labour available. Of those who said that it was not good for business, 96 per cent indicated that it had no effect, or that it was not possible to say, rather than it had a negative effect. While the predominance of self-employment in much of the construction sector means that workers are not technically 'employed' by employers, in-depth interviews with construction agencies similarly suggest that enlargement has 'dramatically increased the supply of people available', and that this is for both labouring and skilled trades, though skilled people may be working below their qualifications: 
That's partly because we're probably downgrading their status a bit because they haven't got the tools, or they haven't got British registered qualifications.

(2C4)

Employers characterised the increased labour supply very broadly: young, both male and female, and prepared to do 'entry-level jobs' as well as those bringing skills. Indeed, some employers observed that skilled workers were available at lower pay, either because their qualifications are not recognised, or because they want to work abroad - 'they're willing to drop back a position to take a position in London' (2H9). Low- and high-skilled, experienced workers and students, seasonal, temporary and permanent - A8 nationals are perceived as offering a wide variety of possible labourmarket contributions.

The notable exception to this abundance of labour is in the au pair sector. Au pair agencies were all reporting that the numbers of au pairs applicants were down sharply, particularly male au pairs:

The Eastern bloc countries that have moved into the European Union have got other reasons for coming. So they come and get a proper job if their English is good. The ones that haven't got good English come and be au pairs, until they've got good English, then they can move on ... I'm 50 per cent down, my list is half the size it used to be. And I'm also struggling to find good boys actually because of course they can come labouring. (2P4)

This may in part reflect simply that host families and au pairs are not using agencies but getting in touch direct. However, 84 per cent of the respondents to the host family survey said that EU enlargement had made no difference to the way they found their au pair. ${ }^{7}$ Host families in general did not comment on the lack of A8 nationals available as au pairs, though, as will be seen in the following section, there were some questions over their continuing suitability as au pairs. Host families have very much a 'micro' perception of the market, extrapolating from their personal observations, so it is perhaps not surprising that they did not report perceiving any significant shift, though many anticipated that things might change:

Maybe in time young people will feel able to come to the country to work without feeling the need to come via the au pair route. So I guess the availability of au pairs will reduce, 'pocket money' will increase and my kind of family will either use local childcare or change our working lives! Who knows!

(HF53) 


\section{Migrants' changing status}

While the labour supply was perceived as increasing, one of the key characteristics of the migrant labour supply, its immigration status, had changed. A8 nationals who had formerly been employed on permits or who had limitations on labour market access as a result of their immigration status were now unrestricted in the hours and type of employment they could take up.

EU enlargement was recognised by employers as offering the opportunity for some A8 nationals to regularise their status and, through this, to escape exploitative conditions 'a pittance wage ... stupid hours and squalid conditions' (2H11). However, it was speculated by one interviewee that companies continued to seek illegally resident workers 'because they [the workers] were desperate' $(2 \mathrm{H} 2)$ and some employers were sanguine about the limitations of enlargement as a strategy for cracking down on the employment of illegally resident migrants:

Because they brought them into the country illegally, set them up in their houses, and the whole chain has not yet been broken.

(2A8)

Given that retention was clearly important to employers and host families who previously accessed migrant labour through schemes, it is scarcely surprising that was a concern following enlargement, when A8 nationals would no longer have to use schemes and would be free, not just to change employers, but also to move to other sectors of the labour market:

Anybody now who has an au pair from any of the ten accession states are in a vulnerable situation, because they know their au pair can leave at any time. Their immigration status was changed, they can find another job with more money and they will be off.

I worry that an au pair will come and use us as a base to find a job and accommodation and then leave us in the lurch. This is now possible for Eastern European au pairs, which was not possible before enlargement. (Host family survey respondent)

Au pair agencies reported host families as specifying that they wanted Romanian, Bulgarian or Turkish au pairs because they can't legally 'run off', and indeed the agencies in turn were recommending visa nationals: 
My Romanian is going up. I have to say, because Romanians can't get other jobs.

(2P4)

There was considerable concern among agricultural employers that the SAWS scheme would be phased out following EU enlargement. ${ }^{8}$ Forty-seven per cent of respondents in hospitality and 43 per cent in agriculture suggested that it would not be possible to fill all current and future vacancies in respondents' businesses with workers from within the enlarged EU. ${ }^{9} \mathrm{~A}$ third of respondents in hospitality, and twothirds in agriculture, further claimed that the phasing out of low-skill work permit schemes would adversely affect their businesses, primarily because it will be difficult to find 'appropriate' workers. Box 2 contains a selection of employers' responses, many of which indicate that employers are concerned about how to retain workers if they are not on work permits.

\section{Box 2 'Specify how the Government's plan to phase out low-skill migration schemes will affect business policies'}

A poor chance. SAWS students are pioneers. EU workers will lose their edge.

Catastrophically. It will add 11-12 per cent to my costs. If this happens, soft fruit growing in the UK will be brought to a standstill.

... considerably as EU countries don't want farm work and can easily move between jobs if they choose.

The loss of SAWS would be devastating. It would be almost impossible at present for us to rely on a workforce from the EU as they simply move on to the other work to meet their long-term needs.

We will have to close the business.

... drastically. SAWS students must remain with us. EU member students may leave at any time, which is potentially disastrous for the harvesting of crops.

EU workers do not want hard physical work, which horticulture is. UK horticulture cannot survive without non-EU workers.

(Continued) 
It will make it extremely difficult to source enough seasonal labour to harvest field vegetables.

Most of our workers are SAWS. This is a bad and ill-thought policy. SAWS had worked well for many years. Seasonal staff from accession countries are more likely to immigrate to the UK. SAWS workers always return home after their work period.

SAWS is perfect for our business using seasonally hired harvesting staff.

Not sure yet. With SAWS you are guaranteed workforce.

We will continue to employ SAWS to avoid National Insurance Contribution (NIC) costs to our business.

This would be a disaster for UK horticulture and agriculture. It would reduce most of the production to overseas or accession countries.

Source: employer postal survey, March-July 2005.

While immigration status changed, nationality did not, and particular nationalities, as before EU enlargement, continue to be given particular attributes by some employers after EU enlargement - for example, 'occasional attitude problem - only with Latvians' (employer postal survey), 'Czech au pairs always cheerful, where I have found Lithuanian/Slovak girls more morose in outlook' (host family survey respondent).

\section{Reported changes in workers' expectations and mobility}

There is a significant sectoral difference in survey respondents' answers to whether or not A8 nationals' expectations of wages and employment conditions increased. Hospitality employers were far less likely than agricultural/food-processing employers to report this to be the case (20.5 per cent and 50 per cent respectively). This was also reflected in the in-depth interviews:

The people that came from the countries that became members of the European community started to get just a little bit more stroppy because they knew what their rights were ... the relationship did change ... they all 
use mobile phones. They're very, they're very streetwise ... we're likely to swing more towards non-EU members for the simple reason that they're more flexible. It's not about treating them unfairly, I'm not saying that at all, and I wouldn't even allude to it. But someone might get that feeling from you know, what I'm saying.

(2A3)

In some instances, employers suggested that EU enlargement accounted for changes in the approach and even personal characteristics of migrant workers, some of whom have become less loyal and more mercenary:

The greed kicks in after a few months ... because the visa does not restrict them.

(2P7)

I think they've become more money-driven. They know that, they hear that they can earn some more tips in another place, so they tend to go there. Given freedom of movement anywhere, there's no visa regulation now. So they tend to follow that, a lot more than they used to. $(2 \mathrm{H} 11)$

While some interviewees suggested that they might prefer to employ non-EU nationals following EU enlargement, others claimed to have used the change to reassess their employment relations or conditions. Several survey respondents hosting A8 au pairs commented that enlargement had affected their relationship with their au pair - 'I am inclined to watch my Ps and Qs with her a bit more' (HF20), 'we feel more pressure to make the job attractive to her' (HF80). This agricultural employer also reviewed his employment conditions as a direct result of retention concerns:

Everyone has the entitlement to freedom, everyone should have the entitlement to have choice of where they want to work so, it's, it's made us sit back and look at what we offer. It's made us sit back and say, okay, is this the right way of doing things? We may need to change our practices, we've looked more at training our supervisors, to make sure they can deal with people in a better way, um, and it's not a bad thing.' (2A10) 


\section{Likelihood of employment}

Employers were also asked to assess any potential changes, following EU enlargement, in the likelihood of their employing A8 workers, workers from outside the enlarged EU, and British workers (see Figure 11).

Sixty-four per cent of employers in hospitality and 54 per cent of employers in agriculture claimed to be more likely to employ A8 workers, largely because of ease of recruitment (availability and less bureaucracy). For those employers who said that they were not more likely to employ A8 workers, the reasons given included that they did not use A8 national workers (mainly in hospitality) ${ }^{10}$ and that they would need to pay national insurance (in agriculture). This was confirmed by in-depth interviews, where agricultural employers cited having to pay national insurance as incurring them additional extra cost when employing A8 nationals, as opposed to SAWS permit holders who are exempt from NI.

About a third of all respondents also suggested that they had become less likely to employ non-EU25 workers and also UK workers. There were, however, significant sectoral differences among our respondents. Only 23 per cent of respondents in hospitality, but over 50 per cent of respondents in agriculture/food processing, said that they had become less likely to employ workers from within the UK.

Figure 11 Employers' reported post-enlargement likelihoods of employing A8 nationals, non-EU25 nationals and British workers

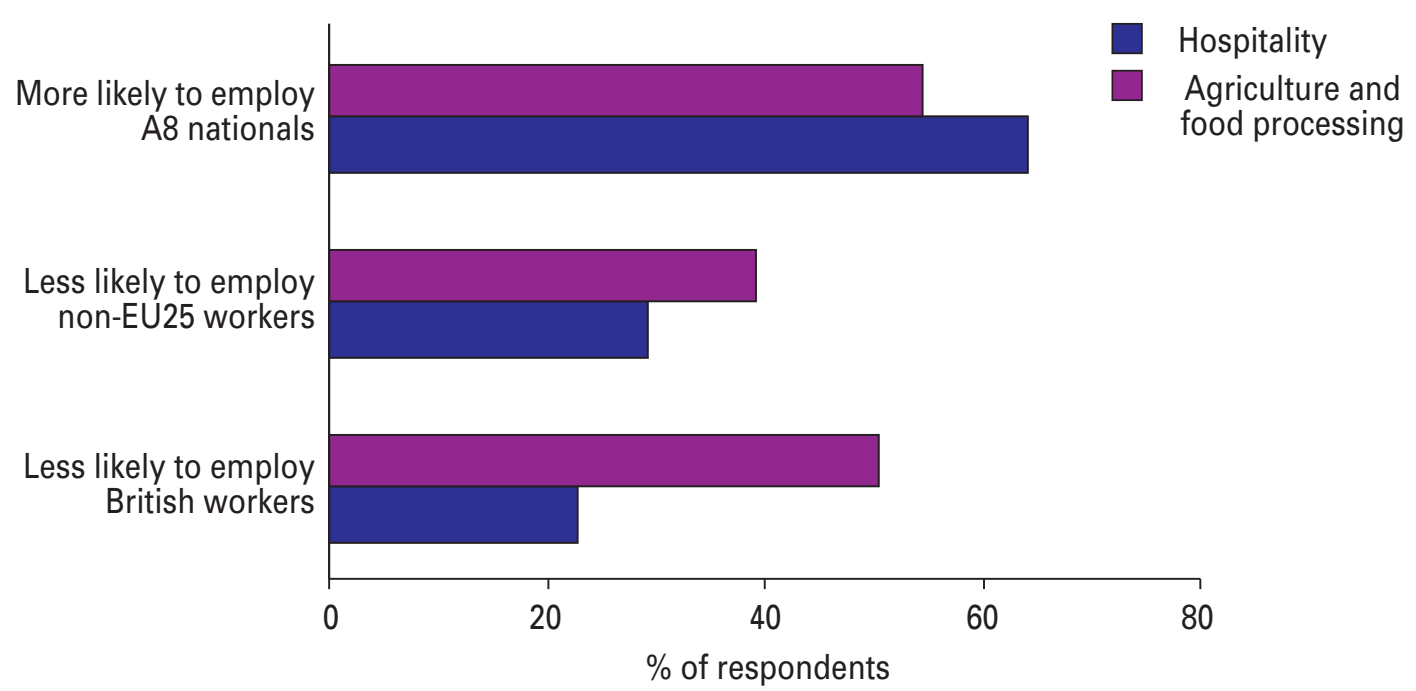

Source: postal survey of employers, May-July 2005. 
One-third of host families surveyed said that they would be less like/y to host an A8 national, largely because of their access to the labour market, which meant that they feared the family would be used as a 'stepping stone'. A minority of families and agencies interviewed felt that au pairs from A8 states were more likely to have chosen to be an au pair post-enlargement when they also had other options and were therefore likely to be more committed. Of our survey respondents, 22 per cent said that they were more likely to host an A8 national, often because of the loosening of immigration requirements.

\section{Workforce remodelling}

The discussion above pertained to employer perceptions of the effects of newcomers and migrants changing status in the UK. This section explores whether and how employers responded to EU enlargement in terms of their employment and recruitment decisions in practice.

\section{Changes in the composition of the workforce employed}

The postal survey data paint a somewhat ambiguous picture about employers' remodelling of their workforce following EU enlargement in practice. Just over 50 per cent of total respondents said that the share of A8 nationals in their workforce had not changed (see Table 23). ${ }^{11}$ At the same time, 44 per cent of all employers surveyed in agriculture and hospitality reported an increase in the share of A8 nationals in their workforce. In hospitality, almost half of employers reporting an increase in the share of A8 nationals employed suggested that the share of workers from outside the enlarged EU had not changed. A quarter said that it had fallen. In agriculture, more than half of respondents suggested that their increases in A8 nationals employed were accompanied by falls in the share of non-EU25 workers employed. 
Table 23 Changes in shares of A8 workers and non-EU25 workers in total workforce, as reported by employer respondents

\begin{tabular}{|c|c|c|c|c|c|}
\hline \multicolumn{4}{|c|}{ Share of workers from outside the enlarged EU } & \multicolumn{2}{|c|}{ Total } \\
\hline & Has risen & Has fallen & Has not changed & $N$ & $\%$ \\
\hline \multicolumn{6}{|l|}{ Hospitality } \\
\hline \multicolumn{6}{|c|}{ Share of $A 8$ workers } \\
\hline Has risen & 23 & 16 & 35 & 74 & 43.3 \\
\hline Has fallen & 1 & - & 2 & 3 & 1.8 \\
\hline Has not changed & 12 & 5 & 77 & 94 & 55.0 \\
\hline Total & 36 & 21 & 114 & 171 & 100.0 \\
\hline$\%$ & 21.1 & 12.3 & 66.7 & 100.0 & \\
\hline \multicolumn{6}{|c|}{ Agriculture and food processing } \\
\hline \multicolumn{6}{|c|}{ Share of $\mathrm{A} 8$ workers } \\
\hline Has risen & 9 & 23 & 11 & 43 & 43.4 \\
\hline Has fallen & 9 & - & 1 & 10 & 10.1 \\
\hline Has not changed & 5 & 4 & 37 & 46 & 46.5 \\
\hline Total & 23 & 27 & 49 & 99 & 100.0 \\
\hline$\%$ & 23.2 & 27.3 & 49.5 & 100.0 & \\
\hline
\end{tabular}

Source: postal survey of employers, May-July 2005.

While some of the increase in the share of A8 nationals employed following EU enlargement might be accounted for by 'normal' seasonal shifts, the size of the proportion suggests that this change is not simply a temporary blip.

Some employers surveyed experienced losses of A8 national staff. Fifteen per cent of employers (13 per cent hospitality, 18.8 per cent agriculture) reported that some A8 workers had left their business, as one respondent wrote 'because they can work anywhere legally now'.

The host family survey is not directly comparable, and host families generally only host one au pair at a time, but the data gathered on all cases do not suggest an overall increase in proportions of families hosting A8 nationals as au pairs. Of the 185 families who had an au pair in April 2004 and an au pair at the time of completing the survey in January 2005, 87 per cent had an A8 national as an au pair in April 2004 and 80 per cent by early 2005. This is not a significant difference, but it is worth noting that, of the 15 families that had either stopped hosting an au pair or had changed, almost all had been hosting A8 nationals. There is also some evidence from comments written on the survey, and from in-depth interviews with host families, that those who were currently hosting A8 nationals were not confident that they continued to be suitable as au pairs. For example: 
It seems that before the 'open market' you would come across people who would pretend to want to be an au pair and get a visa for a couple of years - then they would leave the family to earn 'black' money. Now they seem to have more of a swagger about them and a 'couldn't care less' attitude.

(Host family survey respondent, currently has a Hungarian au pair)

Some host families felt that EU enlargement meant that au pairs were less likely to stay as au pairs, while others were more concerned about 'extra jobs'. Au pairs from accession states now have the opportunity to supplement their pocket money with wages from legal work. While this had been generally tolerated before enlargement when the employment was informal, post-enlargement there seemed more concern among host families about the practice:

If she did want to take a 'proper job' on the side we would lose our flexible help (e.g. to cover when kids are ill) and so she would be less useful to us. We told au pair up front that we would not be keen for her to seek out additional employment other than occasional cleaning jobs.

(Host family survey respondent)

Employers in both agricultural and construction sectors, and indeed host families, felt that A8 nationals preferred to work in hospitality, and were not committed to their sector. ${ }^{12}$ In contrast, hospitality employers did have some concerns about 'poaching', by other employers in hospitality, but none expressed any worries about staff moving into construction, agriculture or au pairing. This suggests that employers' concerns regarding retention were confirmed for agriculture and au pairs (both visa-holding sectors) but not for hospitality. Both agricultural employers and host families felt that those who moved into hospitality often looked solely at the salary. In particular, they thought migrants did not take into account the extra cost of accommodation and were likely to find themselves disappointed and exploited.

\section{Reported changes in the employment of visa holders}

Employers were asked about any changes in their use of work permit schemes following EU enlargement. The answers obtained from the survey are ambivalent. More agricultural employers report an increase in use of work permits post May 2004 than report a decrease. However, it cannot be assumed that those who report a decrease in their use of SAWS permits are choosing not to use SAWS. The quota was significantly reduced in this period (it went from 25,000 in 2004 to 16,250 for 2005), and the decrease might be explained partly by the fact that, as one employer 
remarked, permits are 'harder to obtain', rather than because employers no longer wanted to apply for permits. Indeed, two agricultural employers interviewed, who used the SAWS scheme both before and after enlargement, were explicit that A8 nationals would not be replacing SAWS visa holders.

... [we will employ fewer A8 nationals this year] because the majority of our workers are through SAWS.

(2A6)

... with the change, we are going to be employing less of [A8 nationals] and using more people from non-member states.

(2A3)

Several employers remarked on the consequences of EU enlargement for A8 students. Some claimed to now be employing them full-time, whereas previously they had employed them for only 20 hours a week - 'trimming down from parttimers', as one employer put it (2H10). Naturally, no employers said that they had ever employed illegally, but they said that they had come under pressure from students to employ them for longer hours:

In fact, when we had some on the 20 hours, legal basis ... quite often they'd be asking us for work over the hours, and quite obviously we couldn't, so now that they've got that opportunity they're grabbing it really. $(2 \mathrm{H} 10)$

There is the suggestion of a shift from student employment in excess of the legally allowed 20 hours per week:

I think that they were hidden away a bit because they were only working 20 hours a week there, well supposedly 20 hours a week ... they're just coming out of the woodwork a bit you know, because they're allowed to now.

$(2 \mathrm{H} 9)$

It was not only that former student visa holders could work for longer hours, but also that they could commit for longer, and be re-employed had their visa expired, or they returned to their country of origin. 


\section{Reported changes in accessing labour}

Concerns about illegal employment naturally diminished as a result of EU enlargement, potentially removing one of the reasons employers claimed made them turn to agencies. Au pair agencies in particular said that business fell following enlargement, not just because A8 nationals were less likely to be au pairs, but also because host families used personal networks and no longer needed agencies to facilitate paperwork:

I'm getting a lot of families getting a friend of a friend ... when they needed to get a visa they didn't like to do it themselves because they weren't sure they'd get the paperwork right ... so there's that, plus the ones that can stay longer. I haven't had the roll-over of business from the existing families I had before. They can go elsewhere and they have done.

Some agencies in all three sectors actively took advantage of the change in order to recruit from abroad, partnering up with agencies or setting up agencies themselves in Lithuania, Estonia, or Poland:

So a client can come to us and say 'Look I need four people for Monday, ongoing contract, can you get them?' And, if they're not on our books, we'll then turn round and say 'OK well we've got a partnership in Estonia, we'll give them a call' and normally Saturday night they're on the plane and in they come.

$(2 \mathrm{H} 6)$

The qualitative data suggest a significant growth in recruitment by word of mouth and personal networks, including especially transnational networks, which seem to have been strengthened after EU enlargement:

We're able to source new EU students, workers, without going through [name of SAWS operator]. Word-of-mouth and personal contacts are important. People ask 'Can I bring my brother? Can I bring my sisters?' .... we're oversubscribed by more than ten times.

(2A6)

A8 nationals themselves were sharing information about possible vacancies, not only with current employers, but also with people who had employed them in the past: 
... a lot of Eastern and Polish students who have been here, who have done, done well, they rung us up or sent us emails saying 'can I come and work?'

(2A2)

Hospitality employers also reported an increase in the number of A8 national 'drop ins', people passing by and asking for work. Interestingly, employers were also more likely to mention the internet as a means of accessing labour than they were before EU enlargement. Several employers reported an increase in contacts from unsolicited work seekers making use of the internet.

Agencies were very conscious of employers' increasing use of direct recruitment. While word-of-mouth recruitment was a method that they themselves used to access workers, and some reported their numbers of workers increasing, the problem was accessing labour users: 'if the market's flooded, then people will go direct to sites and we get cut out' (2C4). Two agencies supplying workers to agriculture and food processing reported losing business to other agencies, which were perceived as having cut their rates, in addition to losing business because of an increase in direct recruitment by labour users themselves. A hospitality agency reported their business had begun to hit difficulties because of expanded labour supply: 'the margins are getting lower' $(2 \mathrm{H} 6)$.

In conclusion, the consequences of EU enlargement on employer use of migrant labour are somewhat ambiguous and close attention needs to be paid to sectoral differences. Employers generally clearly welcomed the increased number of workers available, and the decrease in bureaucracy attached to employing them (though, as will be seen below, there were complaints about the Worker Registration Scheme in this regard). Conditions in countries of origin continued to be referred to. Some employers gave 'poor backgrounds' as an explanation for retention difficulties, as it meant that 'money is such a huge issue to these people' (2P5) that, when free to do so, they will take any opportunity that is coming to them. On the other hand, poverty was identified by employers as a reason for workers being prepared to do low-paid work for which they were often over-qualified, and this was recognised as being something that did not change overnight. This broader perceived context meant that employers often mentioned fluidity and change, and this was confirmed by other stakeholder interviews. It is not just that changes in recruitment and employment practices in response to workers' change in status will take time to bed down, but also that, as the economic situation in the countries of origin changes - and it seems generally accepted that it will change for the better - so different nationalities will have to be found: 
I think probably there will not be so many people from these countries [EU15] who are going to want to be au pairs, because they are that little bit more sophisticated ... And I think very soon, well maybe in a year or two, they'll [A8 nationals] be the same And so then it will be the next lot, I would assume, and they may not be white any more. And that will be very interesting seeing how all that works out.

(2P9)

\section{Summary}

This chapter has drawn on postal surveys conducted after EU enlargement, and indepth interviews conducted before and after enlargement, to explore how employers and host families understand the demand for migrant workers, what the determinants of this demand are, and how migrants have been and are being recruited. We distinguish between the demand for a certain type of worker, who in practice is a migrant, but who in theory could equally be a UK citizen, and the demand for people of a particular immigration status.

Employers claimed to be experiencing both labour and skills shortages. The reasons for these shortages and for using au pairs were identified as including low wages, the physical nature and/or status of the work and anti-social, long or erratic hours. However, retention as well as recruitment difficulties were identified as a problem by employers. For certain types of work, it was crucial for employers that they had labour they could rely on, and this was given primacy over flexibility. For more erratic types of work, flexibility was the key characteristic, but nevertheless 'reliability' continued to be important. Understanding the recruitment-retention balance throws light on the nature of the demand for (migrant) labour.

Employers did not only use immigration schemes such as SAWS or the au pair scheme to facilitate access to migrant labour however, but also took on migrant labour already in the UK. This could be accessed in a variety of ways, including through employers' active engagement with migrant networks and use of agencies. These workers, in contrast with those on schemes, have a range of possible immigration statuses, including student visa holders and illegal residence. Employment of workers whose status precludes them from undertaking the work they are doing is a criminal offence. Concerns about illegal employment led some employers to use agencies ('agency labour'), not just because they are highly flexible, but also because the agency is the direct employer and therefore has responsibility for checking documentation. However, employers and host families 
often preferred to turn a blind eye to possible breaches, or claimed ignorance. They were not enthusiastic in their efforts to comply consistently with immigration rules.

Migrant labour was not viewed as making the best of a bad job but in general was spoken of very positively by employers. Migrants were recognised as bringing experience, education and motivation to jobs that were 'low-skilled' and this was often contrasted with British workers. Migrants are high-quality workers, for work that is often designated low-skilled, but which is perhaps better characterised as lowwaged. They are cheaper than UK workers even when their skills are recognised. UK workers were often very negatively stereotyped in contrast.

While we were focused on the role of immigration status as a determinant of demand for migrant labour, employers tended to express their preference for certain types of labour in terms of nationality, either generally ('Eastern European') or for specific nationalities with specific attributes. 'Nationality' may be used as a shorthand for both objective and subjective characteristics. It is sometimes used literally to refer to employers' perceptions of conditions in countries of origin (which are typically described as poor and offering few opportunities), which they believe explain workers' motivation. Employers recognised that migrants might be prepared to make trade-offs partly as a response to the conditions in their countries of origin. A key determinant of nationalities recruited by employers was the highly subjective notion of 'work ethic'. In in-depth interviews some employers and host families expressed straightforwardly negative or positive stereotypes about particular nationalities, including negative stereotypes of British working people.

The main advantage of migrant workers legally recruited under schemes was ease of retention. While both these visas, unlike many other forms of permit, are 'portable' (technically at least), and workers are not tied to a specific employer, they nevertheless were felt to provide a more reliable type of worker/au pair, who at times was contrasted explicitly with 'EU nationals'. There was, therefore, considerable concern expressed about the fate of both of these schemes post-enlargement. For those migrants recruited under these schemes, employers knew what their status was, but, for those recruited in the UK, the situation was often unclear - and whether or not an employer knows the rights and limitations attached to a worker's immigration status is crucial to unpacking the relation between immigration status and employment relations. It is clear from our in-depth interviews that there is a spectrum between employers 'knowing' and 'not knowing' a worker's immigration status. For example, an employer can suspect and choose not to know where workers have sufficiently good documents, or can suspect but choose not to know through the use of employment agencies that act as the employer. In cases where employers know about the conditions attached to their migrant's immigration status, 
they frequently talked about 'bending the rules', which was also one of the dominant themes coming out of our interviews with migrants.

EU enlargement was generally deemed to have been good for business because it increased the number of workers available, both low- and highly skilled, including experienced workers, students, people available for work temporarily and those available for longer periods. Nevertheless, there were concerns expressed by scheme users (i.e. agricultural employers and host families) that A8 nationals would no longer be available for specific kinds of work. This seems to have been borne out for the au pair sector, as agencies reported a sharp decline in applicants from A8 countries. Fifty per cent of agricultural/food processing employers felt that A8 nationals' expectations of wages and employment conditions had increased. Both they and host families felt that A8 workers would gravitate towards the hospitality sector. Construction employers also expressed this, but it was less of a concern.

Over half of employers in agriculture/food processing and hospitality reported an increased share of A8 nationals in their workforces after enlargement, citing availability and reduced bureaucracy. Data on use of work permit schemes are ambivalent. EU enlargement does seem to have initiated a change of emphasis in recruitment methods, with a greater engagement in personal networks, including transnational networks. Direct recruitment, word of mouth and the internet have all had important roles in reducing dependence on employment agencies. 


\section{The Worker Registration Scheme}

This chapter discusses employers and migrants' perceptions of - and experience with - the Worker Registration Scheme (WRS). After a brief overview of the scheme's rationale and mechanisms, we discuss the incentives for - and incidence of - registration among our survey respondents. This is followed by a discussion of migrants', employers' and agencies' views on the WRS.

\section{The scheme's rationale and mechanisms}

Only two of the ten EU accession states, Cyprus and Malta, were fully assimilated into existing EU free movement and establishment law after May 2004. Nationals of the remaining eight accession states (A8 nationals) were subject to transitional arrangements. The Worker Registration Scheme was put into place in February 2004. It was not intended to limit A8 nationals' access to the UK labour market, but to limit access to certain welfare benefits and services. It was also intended to encourage participation in the formal economy and to provide empirical data to facilitate evidence-based policy.

Under the Worker Registration Scheme, A8 nationals must register with Work Permits UK (WPUK) as soon as they start a new job. If they do not apply within one month of acquiring this job the employment is considered illegal. To obtain a registration card they must complete an application form and send it together with their passport/ID card, photographs and a letter from their employer confirming employment to WPUK. An employer is defined as 'the person who directly pays your wages or salary'. Workers must also pay a one-off fee, which in May 2004 was $£ 50 .{ }^{1}$ This is in order to make the scheme 'self-financing'. For each job that they have, a worker must obtain a registration certificate in the form of a letter authorising them to work for a named employer. Thus an A8 national will have one registration card, but potentially several registration certificates. After having been registered for 12 months without interruption, the registration requirement no longer applies, and the worker has the same full rights of free movement and access to benefits as any other EEA national.

Not all A8 nationals have to register. There are several exceptions and the following are key for our analysis:

- self-employed people 
- those working legally in the UK for 12 months or more in the job they held on 1 May $2004^{2}$

- those working legally and remaining in the same job after 1 May 2004

- those working and intending to work for under one month with a particular employer

au pairs.

\section{The numbers registering and incentives to register}

The Government publishes quarterly Accession Monitoring Reports with data obtained from the registration of $A 8$ nationals. ${ }^{3}$ According to the latest report, there were 345,000 applications for registration between May 2004 and December 2005. The Home Office estimates that up to 30 per cent of $A 8$ workers who registered between May 2004 and September 2005 were from applicants who had already been in the UK before 1 May 2004. ${ }^{4}$ There has been some discussion about the extent to which the registration data reflect the number of A8 nationals working in the UK following EU enlargement. It is clear, for example, that the various exemptions from registration explained above mean that the registration data underestimate the number of A8 nationals working in the UK. The exemption of self-employed A8 nationals is significant in this regard. Self-employment is known to be particularly important in the construction sector where a large number of A8 nationals are known to be working. Moreover, it should not be assumed that A8 nationals were informed about the registration requirement. There were also some concerns as the scheme was introduced that the fee might act as a disincentive for workers to register, and some stakeholders continue to hold that this is the case. ${ }^{5}$ Even for those who have registered, the question remains whether they continue to inform WPUK of second and subsequent jobs. The number of multiple registrations - as of December 2005, 6 per cent of all applications for registration ${ }^{6}$ - appears to be rather low.

It is worth considering what the incentives to register for A8 nationals are. While working for longer than one month without registration does constitute 'illegal work', the sanctions on workers are extremely limited and complex to enforce. It may well be that certain groups of A8 workers, most particularly those who are not intending to stay for very long in the UK and who are not concerned with claiming benefits at any time in the future, are not motivated to register. Similarly, although it is theoretically possible to fine employers up to $£ 5,000$ for employing A8 workers who are not 
registered and not exempt from doing so, 7 in practice employers may perceive little risk of 'illegally' employing unregistered $A 8$ workers. As mentioned in the introduction to this report, there continues to be a very low level of prosecution of employers found guilty of violating immigration laws.

We interviewed a total of 217 A8 workers after EU enlargement. For each of these survey respondents we used the interview data to assess whether they needed to register or not. This yielded the following results.

- At least 75 workers (i.e. about a third of the total) needed to register.

- At least 69 workers (i.e. slightly less than a third of the total) did not need to register, as they fell within one of the various categories exempted from the registration requirements.

- Seventy-three workers (i.e. another third of the total) did not provide sufficient information for us to assess whether registration was required or not. Of those, we speculate, based on the interview data, that 24 workers could have potentially been self-employed (and therefore exempt from registration). The remaining 49 workers were, in our assessment, unlikely to be self-employed.

It may thus be concluded that the share of our A8 respondents who needed to register for employment following EU enlargement was between 35 and 68 per cent. It should be noted that this proportion is relatively low because of the impact of selfemployment in construction and because au pairs do not have to register.

Table 24 compares our assessments of the number of respondents who should have registered with the number of respondents who said that they had actually applied for registration. Slightly less than a third of respondents registered. Of the 139 respondents who did not register, about half did not need to do so. At least six respondents failed to register when we know they needed to do so. The number of A8 respondents who did not register when they should have done so is likely to be greater, however, as all the 73 respondents for whom we do not know if they had to register either did not register or did not provide any information about registration. 
Table 24 Registration of A8 respondents after EU enlargement

\begin{tabular}{lcccc}
\hline Should register?** & \multicolumn{4}{c}{ Applied for registration?* } \\
& Yes & No & No answer & Total \\
\hline Yes & 69 & 6 & 0 & 75 \\
No & 0 & 67 & 2 & 69 \\
Don't know - potentially self-employed & 0 & 19 & 5 & 24 \\
Don't know - but unlikely to be self-employed & 0 & 47 & 2 & 49 \\
Total & 69 & 139 & 9 & 217 \\
\hline
\end{tabular}

Source: survey of migrants, six to eight months after EU enlargement.

* Answer to survey question about whether respondent had registered or not.

** Authors' assessment based on a number of relevant survey questions.

\section{Migrant workers' perspectives on the Worker Registration Scheme}

Of the 72 A8 respondents who failed to register when they needed - or potentially needed - to do so, 21 workers said that they had 'never heard' about the Worker Registration Scheme ${ }^{8}$ and this was also frequently given as a reason for nonregistration. Several of our in-depth interviewees who should have registered claimed not to have heard of registration. Moreover, their responses suggested that they were not alone, but that information about the requirement to register had not permeated their social/employment networks:

I never came across it, nobody told me anything about it ... None of my friends knows it either. I also have friends working in hotels, [we know about] wages, taxes, but nothing like this. My sister works in a hotel and has nothing like that.

(Polish male construction worker aged 27 [W2reint])

One person clearly had registered (had paid $£ 50$ and received a document from the Home Office with her photograph and details on it) but did not realise that was what it was. Indeed, among those who knew about registration, there seemed to be some confusion about what it actually is.

Ten respondents suggested the cost of registration as the primary reason for why they failed to register. In-depth interviewees expressed some cynicism over the registration fee, and indeed some felt that it was the fee that was the sole reason for imposing the system in the first place. Registration is:

Perfect way for Great Britain to make some extra money.

(Polish female hospitality worker, age unknown [W2reint]) 
... to collect £50 from every new person.

(Lithuanian female former au pair, aged 28 [W2reint])

This reflects a general misunderstanding and confusion about registration, why it was imposed and what its relation to immigration control is. It was perceived by some interviewees as a means of restricting access to the labour market - indeed this was cited more commonly than restrictions to welfare benefits. Self-employed people were more likely to describe themselves as 'already registered' or 'automatically registered' through their previous visa, rather than as being exempt from registration. The confusion between registration and immigration status means that it can be perceived as unimportant for EU citizens:

They [foreigners] could be working without a registration now that we became EU citizens.

(Lithuanian male construction worker aged 39 [W2reint])

While misunderstanding and lack of information about registration explained some of our respondents not registering, there were also instances of interviewees simply not seeing the point. It was felt to be worth it if you were planning to remain in the UK (which of course many of them did not see themselves doing), or were in a 'proper' legal job, but otherwise it seemed to offer few benefits:

If you want to stay longer, of course it's a good idea. It is important to do everything legally, which brings peace of mind. But, if somebody comes only to earn some money for a house or a car and then to leave, then it's probably not worth wasting time.

(Lithuanian male construction worker aged 27 [W2ret])

Peace of mind, feeling legal, might be a motivating factor, but not for everyone. In fact it does seem that employer or agency pressure to register was a key factor in encouraging registration, and workers report some employers and agencies as being more concerned than others about this. One interviewee specifically mentioned his restauranteur employer's concern about the $£ 5,000$ fine for illegal working, while others contrasted employers who 'demand' registration with others who are unaware or simply do not care. A few survey respondents also said that their 'employers did not insist on registration'.

Of those in-depth interviewees who had registered, some suggested that significant numbers of people whom they knew were not registered: 
I am one of, I don't want to say one of a million, but definitely one of the very few that have registered. Other people, even when they have work here, they say, 'Registration? Pch.'

(Czech female former au pair, now shop assistant, aged 28 [W2ret])

The Czechs working here who I know, most of them are not registered, but there are some registered ones as well.

(Czech female au pair aged 30 [W2ret])

While two of our interviewees who had registered reported bad experiences of the process (one had not had her ID card returned and the other had not received all the appropriate documentation), these were relatively unusual. Most of those who had registered did not complain about the system itself. One, who was extremely cynical about the purpose of registration, felt that it was very positive because of the dissemination of a TUC leaflet providing information on employment rights, which they received as part of the process:

On the one side I think it is so they can make money, but also it has such positive consequences that at the same time we are informed about our rights ... If we pay for something we should at least receive something in exchange like information where to turn in case we need help.

(Polish female hospitality worker [W2reint])

Although they were not specifically questioned about it, some of our interviewees volunteered that they had not registered for second or subsequent jobs.

\section{Employers' and agencies' perspectives on the Worker Registration Scheme}

The employer postal survey asked employers if they had written a letter in support of the registration of an A8 national - a legal requirement of registration. Forty per cent of respondents had written such a letter (28 per cent of hospitality respondents and 62 per cent of agricultural respondents), but we have no way of estimating what proportion of those who did not write such a letter ought to have written one. However, it does seem that some employers had not assisted workers with registration despite a legal obligation to do so. Some employers, for example, had not written a letter because their workers did not want to register (this would not constitute a defence should they be accused of employing illegally). Other comments suggested that it was simply too burdensome - 'too busy with my business already', 'waste of time', 'indifference', 'haven't got round it'. 
There were employers who had not heard of registration, commenting that: 'Never been asked', 'Wasn't aware I had to', 'Wasn't aware that businesses were either invited to do so or should be doing so', or 'Never got a letter from them'. There was also some confusion about what the registration scheme entailed and who is required to register and who is not. This agricultural employer had looked up the Worker Registration Scheme on the internet following an interview for the COMPAS project. He claimed not to know about it until then, but still professed confusion:

And found that actually if you employ people, I think you, you have to, it's up to a month, so you've got 30 days. Now, I don't know about this 30 days because does that mean that you actually have them for 30 days' work, so, if they work, they work three days one week and then they come to you the next day, the next week, for four days ... and then 30 days can string out quite conveniently less ... and of course they're all students these people that have, you know they're not actually obliged to pay tax anyway.

(2A7)

About two-thirds of respondents who had written a letter in support of their A8 workers' registration described the registration system as 'efficient' or 'acceptable'. The remaining third $(N=45)$ described it as 'inefficient'. A minority of postal survey respondents recorded specific problems that they had encountered with receiving copies of registration certificates. These emphasised the slow turnaround, sometimes meaning that people were unable to return to their country of origin because their passport had not been returned in time, or even, in a few cases, loss of applications together with passports by the Home Office. There was some sympathy expressed with workers' concerns about handing over passports, and with them having to pay the registration fee:

Telling people to do something, you can't force them. This is temporary labour work. If they don't want to do something, they won't do it ... they just get up and leave ... I think the $£ 50$ a bit ridiculous.

(2C3)

One hospitality employer said some workers 'disappear' rather than register and, just as migrant workers had questioned the Government's motives in introducing the scheme, so most of the employers interviewed face to face questioned the rationale for the Worker' Registration Scheme. Several felt that it was just a way to make some money ('a stealth tax' [2C3]) and complained on both their and their workers' behalf about the administrative and financial implications for people already overwhelmed by bureaucratic requirements: 
... if the Government really wants $£ 50$ why don't they just say, look, we want $£ 50$ for every person that's worked for you for over 30 ? ... and l'll just give them $£ 50$ and then just shut up about it you know, l've got my book and I'll write down their names and everything else. I don't want to have to go traipsing off to Redditch with a passport and get it photocopied and, you know, get national insurance numbers and all that stuff. (2A7)

At least one agency regarded it as hypocritical of the Government to have one process whereby they could charge for registration and at the same time make it illegal for any recruitment agency to charge workers for their services.

In spite of these criticisms, employers and agencies noted that there had been an improvement in the performance of the scheme over its first seven or eight months and that, over time, the turnaround in the system became faster. This was reflected in comments by WPUK officials, who acknowledged initial difficulties with the system but felt that they had been ironed out.

Echoing the views expressed by some migrant workers that there were advantages to workers in registering, one employer said they found it useful because it was in the end the worker's responsibility rather than the employer's and, by going through it successfully, workers proved their suitability for employment, including that they had legal status:

... it's a jump they have to get over; they've got to have confidence in their application and they've got to have confidence that they've got the right information. It makes me have a warm glow because I believe that person is suitable to stay here and has got the right documentation. $(2 \mathrm{H} 4)$

\section{Summary}

Taken together, our data suggest a mismatch between the Government's intentions in the design and introduction of the Worker Registration Scheme, and the experience and perspectives of workers and employers. Significant numbers of workers who fell within the rubric of the scheme did not register when they needed to, in some cases because they had not received information about it. Some workers considered registration as unnecessary or unfair given their plans for a temporary stay in the UK. Several employers and agencies reported experiencing major delays 
in the processing of documentation, and believed that this caused disadvantage to workers. However, there is also evidence that the working of the scheme improved over time. There were fewer delays and a small minority of respondents believed that the WRS was good for workers, both because it gave them documentation of the right to employment inherent in their immigration status, and because it enabled them to gain confidence in dealing with UK immigration officials. Attitudes of workers and employers to the WRS suggest that 'bending the rules' is not a phenomenon that disappeared after May 2004. Employers may again turn a blind eye to legal requirements - in this case, the WRS - thereby avoiding bureaucracy and 'paperwork', while workers avoid paying the fee. 


\section{Conclusion}

The 'Changing status, changing lives?' research project provides an unprecedented evidence base for the study of Central and East European low-waged migrants in the UK before and after EU enlargement. This first report from this major research project comes at a time of intense and polarised public debate on immigration. We set out to address two sets of research questions of both policy and theoretical interest:

1 What are migrants' experiences and perceptions of working in low-wage jobs in the UK?

2 What is the nature of employers' demand for migrant labour and how are employers recruiting migrants to meet this demand in practice?

We have been particularly interested in the role of immigration status with reference to both these questions.

Our findings reveal a wide diversity in Central and East European migrants' experiences and backgrounds, and a complexity of factors explaining employer demand for their labour. A key finding has been that many of our migrant respondents, although working in low-wage, low-status occupations, are in fact well educated and/or experienced. They can be described as high-quality migrants in low-wage jobs. We have identified this as being important in understanding both migrants' experiences and perceptions of working in the UK, and employer demand. Our respondents recognised that the jobs they were working in were often arduous and relatively poorly paid, and did not reflect their potential or their qualifications. However, many of them consciously, if reluctantly, made trade-offs. Sometimes these were economic trade-offs (jobs may pay little in the UK, but are relatively well paid in comparison with countries of origin), but this was not the only form. Speaking English, living abroad, gaining different kinds of experience were other reasons that interviewees gave for choosing to work in the UK. Of course, just because there is a trade-off does not mean that there are not people who are frustrated, bored, isolated and - in some cases - vulnerable to 'exploitation' because of the nature of their work. It is not necessarily the best of all possible worlds for them, but chosen from the limited options available.

The temporariness of doing a certain job is an important aspect of such trade-offs. Work may be unstimulating, but it is not necessarily for ever, and people often imagine moving on to better jobs in or outside the UK, having gained contacts and 
experience or repaid debt. For migrants, poor work, low pay and uncertain or illegal status can be rendered more tolerable if their situation is perceived as temporary. This does not mean that stay in the UK is necessarily regarded as temporary. Neither does it mean that people actually do move on to 'better' jobs. The question remains, then, how our sample will view the trade-offs they made with hindsight. How temporary will migrants' perceived temporariness of their situation turn out to be? For some, tolerating conditions because they are only temporary may mean they are prepared to tolerate a situation for a matter of days. For others, 'temporary' may be understood as meaning years. This is likely to be related to other characteristics and goals. It may also be related to life cycle. Most of our respondents were young with no dependants and it may be that they are more likely than people at other stages in their lives to feel that certain jobs and situations are temporary phases rather than permanent patterns.

All this suggests that the impact of immigration status on employment relations and conditions is more complex than the straightforward and individualised 'illegal migrant'/'exploitative employer' model allows. In order to understand migrants' choices and agency one must then consider the options that are available, and how these constrain and/or facilitate choice. In understanding experiences and labour market outcomes the particular circumstances and personal characteristics of individuals are important - age, gender, education, whether they have dependants or debts, for instance. These interrelate to shape the range of options open to people. Immigration status is one such factor, but it cannot be understood in isolation. While some interviewees with no leave to remain 'chose' to stay in the UK, others presented themselves as having no other options. This points to the importance of emphasising that the conclusions deriving from this research can at most indicate trends for this particular group of East and Central European migrants. Other groups may have more or less agency in the labour market depending on how broader economic and social structures interact with their personal characteristics.

Immigration status is, moreover, directly related to nationality. Certain nationals have opportunities for legal entry or stay presented to them, while others do not. So, in the case of our research, au pairs and self-employed status were not in practice available for Ukrainians. Other nationalities sometimes used these statuses as opportunities to legally reside and to work in the UK. This does not mean that people necessarily want to be au pairs, or indeed to be self-employed, and given other options they might well choose otherwise. They do not necessarily think it is 'fair' that they are au pairs rather than secretaries or receptionists (or students).

Employers recognised that migrants were often making trade-offs, and tended to emphathise their economic nature. Host families were more likely to emphasise 
cultural exchange, accommodation and living as part of the family. Both employers and host families were more likely than migrants to present the situation as 'win-win' on both sides. Interviewees recognised that they were getting high-quality workers for low-wage work. It was not just that migrant workers solved recruitment difficulties, but also that they are 'good workers'. Their 'motivation' was often related by employers to trade-offs, in particular conditions in countries of origin. It was contrasted with that of British workers and held to account for better retention as well as recruitment. High-quality workers for low-waged work is not the only story however. In some circumstances, employers want a worker with particular skills for instance, or a highly 'flexible' worker, available at short notice for an uncertain period. It might be more likely that these workers will be migrants - so, for example, a migrant with no dependants in the UK might be more likely to be prepared to work anti-social shifts - but this does not per se constitute a demand for migrant labour.

Issues around temporariness are important for employers and host families as well as migrants. Whether it is driven by the pressures of production, the requirements of the season, or the conflicting rhythms of work and home, we have seen that there may be tensions between flexibility and retention. Certain types of work require a reliable and stable workforce (though of course this may mean weeks in some cases and years in others). This may be facilitated through restrictions attached to immigration status, and employers and host families using the SAWS and au pair schemes certainly appreciated this. But the relation between migration and labour markets is also much more subtle and complex. Nearly one-fifth of our migrant worker respondents were working for agencies (specifically 'employment businesses', which employ workers directly) rather than directly for an employer. Two-thirds of au pairs were doing additional work (often cleaning in private houses) and student visa holders seem to be an important labour pool for many of our employer interviewees. This indicates that the factors influencing demand for migrant labour and outcomes for migrants must be understood within the context of the UK's labour market being one of the most flexible in Europe. ${ }^{1}$ Flexibility and 'light-touch' regulation is promoted in the name of economic competitiveness, and data from both employers and migrants suggest that a proportion of flexible labour is, for various reasons, provided by migrants. But how does this flexibility work with considerations of immigration control, in particular the monitoring and enforcing of the conditions and limitations placed on migrants' access to the labour market?

In terms of compliance with immigration status and regulations, our research reveals many 'shades of grey' in the migrant labour market. For example, it is simplistic to describe employers as either definitely knowing or definitely not knowing the immigration status of their worker. Employers may suspect, choose not to know, choose not to investigate, not know the rules, etc. We have observed very many 
instances of 'bending the rules' on the part of both employers and workers - the employment of student visa holders for over 20 hours for instance, the encouragement by host families of au pairs to take on extra work outside their home, or people on self-employed visas who have 'employers'. In enforcement terms, a bent rule is a broken rule but, for many of our respondents and interviewees, workers and employers, working in breach of conditions is not perceived to be the same as working or employing 'illegally' or 'being illegal'. This suggests that the dichotomous distinction, common in policy and public discourse, between 'legal' and 'illegal' migrants, or even legal and illegal working, does not adequately capture migrants' or employers' perceptions of what is happening. Host families do not feel that they are facilitating illegal immigration when they find their au pair a job in a local bar. Many of our respondents and interviewees' responses suggest that, in certain immigration circumstances, there are shades of grey, which might technically be illegal, but in practice are tolerated. Crucially, migrants may be legally resident, but working in breach of the conditions of entry that attach to their immigration status.

To allow a more nuanced analysis of the relation between immigration status and employment, we propose developing the notion of compliance with laws and rules governing rights to reside and work in the UK. This would make more transparent the distinction between illegal residence and illegal working, which are too often confused. This is not to propose categorising people simply for the sake of it. It could be usefully developed as a tool to distinguish between:

- those who are legally resident and working exclusively under and in full compliance with the conditions attached to their immigration status, whom we describe as compliant

- those people who do not have valid leave to remain in the UK, whom we describe as non-compliant

- the situation where migrants have valid leave to remain but are working in breach of some or all of the conditions attached to their immigration status, whom we describe as semi-compliant.

This concept of semi-compliance is extremely broad and could capture a range of violations with varying degrees of severity. The discussion of where and how the line should be drawn between semi-compliance and non-compliance is highly politicised and may rest on personal judgement. Different actors may draw the line in different places. However, as a research and analysis tool, it has the advantage of at least rendering such distinctions transparent. ${ }^{2}$ 
Understanding how and why employers and workers bend the rules, and what the consequences are for both, requires going beyond the legal/illegal, knowing/not knowing dichotomies. We need to develop more refined tools to analyse how immigration status 'works' in labour markets and, in particular, how workers can be both a source of flexible labour and subject to immigration controls. This study begins to explore where migrants' and employers' interests seem to coincide and where they conflict, and how both understand immigration restrictions. It provides empirical data and analysis on an under-researched group of migrants at a time when their role in the British labour market is coming to the fore. 


\section{Notes}

\section{Chapter 1}

1 We use 'illegal residence' as a shorthand to describe all migrants without valid 'leave to remain' in the UK.

2 For overviews see, for example, Salt (2005) and ippr (2005).

3 Dudley et al. (2005, Table 1.2).

4 If one broadens one's definition to consider all those who were foreign-born, i.e. including foreign-born people who now have UK citizenship, the numbers are significantly higher. According to the Labour Force Survey 2004, 10 per cent of the working-age population in Britain were foreign-born (see Dustmann and Fabbri, 2005).

5 Salt (2005).

6 Woodbridge (2005) discusses issues to do with estimating the number of 'unauthorised' migrants in the UK. For an overview of 'irregular' migration in the UK, see ippr (2006).

7 The ten EU accession states include the 'A8' countries - comprising the Czech Republic, Estonia, Hungary, Latvia, Lithuania, Poland, Slovakia and Slovenia plus Cyprus and Malta.

8 See Home Office (2004a).

9 Home Office et al. (2006).

10 Gilpin et al. (2006), see Figure 4.1.

11 A study commissioned by the Home Office predicted that EU enlargement would lead to an average annual netmigration (i.e. inflows minus outflows) of 5,00013,000 accession state nationals for the period up to 2010 (Dustmann et al., 2003).

12 See Gilpin et al. (2006, Table 4.1). 
13 The European Economic Area (EEA) includes the EU plus Norway, Iceland and Liechtenstein.

14 See Home Office (2006).

15 See Home Office (2005b).

16 See Home Office (2005c).

17 See Home Office (2006).

18 See Home Office (1998).

19 In 2001, the Home Office published Migration: An Economic and Social Analysis, an attempt to begin to develop a new analytical framework for migration policy. It highlighted the importance of improving the assessment of labour market impacts and outcomes of migration (see Glover et al., 2001).

20 See, for example, Gilpin et al. (2006) and Dustmann et al. (2005).

21 See, for example, Gott and Johnston (2002); Coleman and Rowthorn (2004); Sriskandarajah et al. (2005).

22 See Haque (2002); Dustmann and Fabbri (2005); Spence (2005).

23 It needs to be recognised that the relation of such research to policy can raise potential conflicts of interest for researchers, participants and policy makers.

24 These exceptions include Jordan and Düvell (2002); Evans et al. (2005); Ryan (2005); TUC (2003).

25 See Home Office (2006).

26 But see Samers (2005) and Anderson and Rogaly (2005).

27 A recent study commissioned by the Home Office has begun to research some of these issues. See Dench et al. (2006).

28 In practice, the study of the impacts of EU enlargement on A8 workers already in the UK before EU enlargement has been complicated by the larger than expected inflow of A8 workers since 1 May 2004. Of course, any analysis of the impacts of 
the change in legal status of A8 workers in the UK before and after EU enlargement would need to control for any other changes in the UK labour market during the period of analysis, including the impacts that may result from the inflow of newcomers.

29 For ease of reference, we use the term 'respondents' to refer to migrants and employers who answered survey questionnaires. 'Interviewees' refer to migrants and employers who participated in semi-structured, in-depth interviews.

30 Funding from ESRC was derived partly from COMPAS core funds and partly through a special grant. ESRC also funded the employer and host family postal survey conducted in early 2005.

31 Note that we set out to interview only those migrants who were employed in agriculture, construction, hospitality or the au pair sector in April 2004. We anticipated that some of our respondents/interviewees would leave those sectors after EU enlargement.

32 To be eligible to enter the UK under the SAWS scheme, migrants need to be registered as students in their home countries.

33 These figures exclude au pairs.

34 Of course, these are self-assessments and we have no 'objective' measurement

35 Although we set out to interview migrants employed in April 2004 in four sectors only (hospitality, construction, agriculture and the au pair sector), some of our interviews were with people in other sectors. Migrants employed in these other sectors will be excluded from most of the analysis of employment issues in this paper. They will, however, be included to a greater extent in the subsequent report on migrants' experiences of life (i.e. outside the workplace) in the UK.

36 See Home Office (2005a).

37 It should be noted that some of the immigration rules relating to au pairs were deemed unlawful in a judgement published 20 July 2005. Justice Stanley Burnton found that whether or not the principle purpose of a Turkish national who sought to enter the UK as an au pair was to learn English was irrelevant to the question whether she qualified as a worker under article 6.1 of the Council Decision 1/80 on the conclusion of the agreement establishing an association between the European Economic Community and Turkey (OJ 1964 L217/3685). 
38 The low response rate in our postal survey of employers contrasts the response rate obtained in our postal survey of host families (33 per cent).

39 The majority of hotels were individual hotels rather than part of chains of hotels.

40 For linguistic convenience, we use 'businesses surveyed' to refer to the 365 businesses that completed and returned questionnaires, rather than to all 5,500 businesses that were included in the survey.

41 For ease of reference, we have used the term 'agricultural employer' to apply to all those who use agricultural migrant labour, even though some of them are technically labour users rather than employers, i.e. using labour provided and formally employed by other businesses, rather than directly employing themselves.

42 Again for ease of reference, we have used the term 'construction employer', even though, in fact, they may be using self-employed labour contractors or agency labour.

43 For an overview of migrant workers in construction, hospitality and agriculture in the UK, see, for example, RSA Migration Commission (2005, especially Web Annex A Introduction and four sectoral reports). The role of migrants in the UK's au pair sector is discussed in Cox (2006).

44 RSA Migration Commission (2005, Web Annex A).

45 See for example, Collins (1976).

46 Precision Prospecting (2005).

47 Precision Prospecting (2005).

48 Lindsay and Macaulay (2004).

49 RSA Migration Commission (2005).

50 Matthews (2005).

51 TUC (2003).

52 See CSCI (2005).

53 See Cox (2006). 


\section{Chapter 2}

1 The term 'au pairs' refers to all respondents whose primary job was that of an au pair in April 2004. Except for one respondent, all au pairs in April 2004 were working on an au pair visa (see Table 5). Au pairs are legally allowed to work for a maximum of 25 hours per week. In other words, the two-thirds of au pairs we have designated as working 'part-time' are those who are working within the legally specified limits. Respondents who were in the UK on an au pair visa, but working in other sectors have been classified by the sector within which they were working.

2 Gender is obviously an important determinant of workers' outcomes in the labour market. It is not explored in any depth in this report, which focuses on the role of immigration status. Further analyses will include a more explicit and in-depth discussion of gender.

3 Wherever possible and reasonable, self-employed respondents are analysed separately. The analysis is not restricted strictly to employees, as we think that respondents' descriptions of their employment status are among the less reliable data obtained from our survey interviews with migrants.

4 Our classification of respondents' occupations is based on the Standard Occupational Classification 2000 (SOC 2000).

5 Compared to their average share of 67 per cent of our survey respondents working in hospitality in April 2004, women were 'over-represented' in elementary occupations (75 per cent female) and 'under-represented' in skilled trades occupations (33 per cent female).

6 Where only monthly gross pay was given, hourly rates were computed as follows: gross pay per hour = gross pay per month/(weekly working hours *4.33).

7 Note the interviewee is working on a visitor's visa, but is nevertheless paying taxes.

8 'W1' indicates the interview was obtained in Wave 1 of the research. 'W2ret' indicates the interview was obtained in Wave 2 of the research and was retrospective. 'W2reint' indicates it was obtained in Wave 2 of the research and was a reinterview.

9 In hospitality, 20 of our respondents were under the age of 22. In construction, three respondents were under the age of 22 . 
10 It should be noted that SAWS employers are obliged to provide accommodation for workers but that SAWS workers may have to pay for the accommodation they receive either from their employer or from the SAWS operator.

11 Respondents who worked as au pairs in April 2004 but were interviewed only in Wave 2 were not asked about how they spent their time working as an au pair in April 2004.

12 The free-time activities of the au pairs and migrant workers in our study will be covered more fully in a subsequent report.

13 Standard Occupational Classification 2000, Vol. 1, p. 12.

14 Harvey (2001, p. 16).

15 The concept was significantly extended in the National Minimum Wage Act 1998, Working Time Regulations Act 1998 and Employment Relations Act 1999 (see Harvey, 2001).

16 See Harvey (2001).

17 See Immigration Directorate Instructions, Chapter 1, Section 4, Annex A.

18 Home Office $(2002,5.5)$.

19 It should be noted that, unlike employer interviews, in-depth migrant interviews were conducted in and translated from the interviewee's mother tongue, and there might be an interviewer/translator effect here.

20 In addition to having to control for other factors that may impact on migrants' earnings, the analysis of the role of 'illegal residence' as a potential determinant of migrants' earnings is complicated by the problem that employers may not always be aware of the immigration status of their workers.

21 Table 16 includes respondents who describe their employment relation as selfemployed.

22 The other main type of agency that we do not discuss in this report is 'employment agencies'. In contrast to employment businesses that employ workers directly, employment agencies place people who are then in the employ of someone other than the employment agency (this includes the placement of self-employed people). 
23 Note that, as discussed in the section on 'Self-employment as an immigration status' earlier in this chapter, those on self-employed visas are required to be self-employed and not in an employee relationship with either an employer or an employment business.

24 Grabiner $(2000,1.4)$.

25 Grabiner (2000, 1.19).

26 Agriculture and the au pair sector are excluded from this analysis, as migrants working under these schemes are exempt from making national insurance payments.

27 This should not be interpreted as indicating that A8 nationals intended to exercise these rights immediately.

28 Of course, not all of those plans are necessarily the direct results of EU enlargement.

29 Data for this section comprise that obtained from (a) a proportion of respondents to the Wave 1 survey who were reinterviewed in Wave 2; and (b) respondents to our retrospective survey in Wave 2. See section on 'Research methods and overview of data collected' in Chapter 1 of this report.

30 It is well known, for example, that a key determinant of migrants' performance in the host country labour market is length of stay.

31 In this section, all references to self-employment refer to respondents' description of their employment status/relation rather than to respondents' self-reported immigration status.

32 Respondents who have been self-employed in only one wave (i.e. Wave 1 or Wave 2) are included in the figures reported in Table 19.

33 Among the 145 respondents, 34 reported earnings figures that were inconsistent with the answers provided in response to questions about perceived changes in earnings since EU enlargement. 


\section{Chapter 3}

1 This figure may be somewhat skewed for the hospitality sector. All employers who participated in our postal survey had been recipients of work permits for employing non-EEA workers in low-skill jobs (i.e. SBS permits in the case of hospitality or SAWS permits in the case of agriculture). SBS permits are issued only after the employer has demonstrated that no local workers (i.e. no workers from within the EEA) are available to fill the vacancies ('resident labour market test'). There is no resident labour market test for prospective SAWS employers.

2 See, for example, Anderson (2000); Harvey (2001); Matthews (2005).

3 In depth interview references: $P=$ host family/au pair agency; $A=$ agricultural employer/agency; $\mathrm{C}=$ construction employer/agency; $\mathrm{H}=$ hospitality employer/ agency; 2 = Wave 2 interview

4 As mentioned before, it is important to distinguish between employment businesses and employment agencies. Employment businesses act as an employer, whereas employment agencies place people who are then in the employ of someone other than the employment agency (including placing selfemployed people). In both cases, such arrangements are often associated with temporary placements. Unless indicated otherwise, in this report, the term 'agencies' refers specifically to employment businesses rather than to all types of agencies.

5 It should be noted that the postal survey was conducted post-EU enlargement, when the pool of available A8 labour in the UK had increased. This might well have influenced employers' use of personal networks.

6 In our postal survey, employers chose from options presented to them; this was not an open question.

7 This should, however, be treated with some caution, as the postal survey was distributed by agencies, and they might well have chosen to send it to particularly reliable clients.

8 In its consultation document $A$ Points-based System: Making Migration Work for Britain (Home Office, 2006), the Government stated that it is not convinced that there is a need for low skill migration schemes for non-EEA nationals following EU enlargement' and promised detailed discussions with the agricultural sector about the future of SAWS. 
9 This resonates with the Home Office description of the 'strong response' from the agriculture and hospitality sectors that low-skilled migration is essential for business (Home Office, 2006).

$10 \mathrm{It}$ is important to remember that over 60 per cent of our hospitality respondents had applied for SBS permits. By far the largest group applying for SBS permits in 2003-04 were for Bangladeshis working in 'ethnic cuisine'. Thus, a significant proportion of our survey respondents are likely to have been restauranteurs from the 'ethnic cuisine' sector, who may be more unlikely than most to employ A8 nationals.

11 Forty-five per cent of respondents in hospitality and 37 per cent in agriculture/ food processing said that both the share of A8 nationals and that of non-EU25 workers had remained the same (see Table 23).

12 One au pair agency was experimenting with switching to placements in the hospitality sector.

\section{Chapter 4}

1 It has since risen to $£ 70$, but not in the period covered by this report.

2 Since au pairs do not count as workers, any period with a host family served before May 2004 would not exempt them from registration. Neither would an A8 national working as an au pair have to register post May 2004.

3 The reports are available at http://www.ind.homeoffice.gov.uk/ind/en/home/0/ reports/accession_monitoring.html.

4 Gilpin et al. (2006, see Figure 4.1).

5 See, for example, Association of Labour Providers (2005).

6 This was calculated as follows (number of multiple registrations + multiple reregistration)/total number of registrations. Registration figures taken from Home Office et al. (2006).

7 See Home Office (2004b).

8 In total, 42 workers said that they had never heard about the WRS. 


\section{Chapter 5}

1 This flexibility has several dimensions: flexible employment patterns, for instance with regard to working hours; easier hiring and firing of workers; widespread use of short-term contracts; greater flexibility in pay arrangements linked to performance; high geographic mobility of the workforce.

2 For a more detailed discussion of the concept of compliance and how it can be operationalised using the data generated in this research project, see Ruhs and Anderson (2006). 


\section{References}

Anderson, B. (2000) Doing the Dirty Work? The Global Politics of Domestic Labour. London: Zed Books

Anderson, B. and Rogaly, B. (2005) Forced Labour and Migration. London: Trade Union Congress (TUC)

Association of Labour Providers (2005) 'Request by the Association of Labour Providers to the Statistics Commission to investigate the Accession States Workers Registration Scheme', available at http://www.labourproviders.org.uk/policypapers/ statistics.html

Coleman, D. and Rowthorn, R. (2004) 'The economic effects of immigration into the United Kingdom', Population and Development Review, Vol. 30, No. 4, pp. 579-624

Collins, E. (1976) 'Migrant labour in British agriculture in the nineteenth century', The Economic History Review, Vol. 29, pp. 38-59

Cox, R. (2006) The Servant Problem: Domestic Employment in a Global Economy. London: I.B. Tauris

$\mathrm{CSCl}$ (Commission for Social Care Inspection) (2005) The State of Social Care in England 2004-2005. London: CSCl

Dench, S., Hurstfield, J., Hill, D. and Akroyd, K. (2006) Employers' Use of Migrant Labour. Summary Report. Home Office Online Report 03/06. London: Home Office

Dudley, J., Roughton, M., Fidler, J. and Woollacott, S. (2005) Control of Immigration; Statistics 2004. London: Home Office

Dustmann, C. and Fabbri, F. (2005) 'Immigrants in the British labour market', Fiscal Studies, Vol. 26, No. 4, pp. 423-70

Dustmann, C., Fabbri, F. and Preston, I. (2005) 'The impact of immigration on the British labour market', The Economic Journal, Vol. 115, November, pp. F324-41

Dustmann, C., Casanova, M., Preston, I., Fertig, M. and Schmidt, C. (2003) The Impact of EU Enlargement on Migration Flows. Home Office Online Report 25/03. London: Home Office 
Evans, Y., Herbert, J., Datta, K., May, J., Mcllwaine, C. and Wills, J. (2005) Making the City World: Low Paid Employment in London. London: Department of Geography, Queen Mary, University of London

Gilpin, N., Henty, M., Lemos, S., Portes, J. and Bullen, C. (2006) The Impact of Free Movement of Workers from Central and Eastern Europe on the UK Labour Market. Department of Work and Pensions Working Paper No. 29. London: Department of Work and Pensions

Glover, S., Gott, C., Loizillon, A., Portes, J., Price, R., Spencer, S., Srinivasan, V. and Willis, C. (2001) Migration: an Economic and Social Analysis. RDS Occasional Papers No. 67. London: Home Office

Gott, C. and Johnston, K. (2002) The Migrant Population in the UK: Fiscal Effects. Home Office Occasional Paper 77. London: Home Office

(Lord) Grabiner QC (2000) The Informal Economy. London: HM Treasury (available at http://www.hm-treasury.gov.uk)

Haque, R. (2002) Migrants in the UK: A Descriptive Analysis of their Characteristics and Labour Market Performance. Department of Work and Pensions Working Paper. London: Department of Work and Pensions

Harvey, M. (2001) Undermining Construction. London: Institute for Employment Rights

Home Office (1998) Fairer, Faster, and Firmer - A Modern Approach to Immigration and Asylum. London: Home Office

Home Office (2002) Secure Borders, Safe Haven: Integration with Diversity in Modern Britain. London: Home Office

Home Office (2004a) Living and Working in the UK: Rights and Responsibilities of Nationals from the New Member States from 1 May 2004. WRS 10/05. London: Home Office

Home Office (2004b) Changes to the Law on Preventing Illegal Working: Short Guidance for United Kingdom Employers. London: Home Office (available at http:// www.ind.homeoffice.gov.uk/ind/en/home/0/ preventing_illegal.Maincontent.0004.file.tmp/changes_to_law.pdf) 
Home Office (2005a) Sector-based Scheme Review. London: Home Office (available at www.ind.homeoffice.gov.uk)

Home Office (2005b) Illegal Working Taskforce Regulatory Impact Assessment from Immigration, Asylum and Nationality Bill. London: Home Office

Home Office (2005c) Selective Admission: Making Migration Work for Britain. London: Home Office

Home Office (2006) A Points-based System: Making Migration Work for Britain. Cm. 6741. London: Home Office

Home Office and Department of Work and Pensions et al. (2006) Accession Monitoring Report, May04-Dec05. London: Home Office (available at http:// www.ind.homeoffice.gov.uk/ind/en/)

ippr (Institute for Public Policy Research) (2005) Selecting Wisely: Making Managed Migration Work for Britain. ippr submission to the Home Office consultation on 'Selective admission: making migration work for Britain'. London: ippr

ippr (Institute for Public Policy Research) (2006) Irregular Migration in the UK, an ippr FactFile. London: ippr

JCWI (Joint Council for the Welfare of Immigrants) (2002) Immigration, Nationality and Refugee Law Handbook. JCWI: London

Jordan, B. and Düvell, F. (2002) Irregular Migration, The Dilemmas of Transnational Mobility. Cheltenham: Edward Elgar

Lindsay, C. and Macaulay, C. (2004) 'Growth in self-employment in the UK', Labour Market Trends, October, Office for National Statistics

Matthews, G. (2005) 'Migrants and employment relations in the UK's hospitality sector', mimeo, September

ONS (Office for National Statistics) (2004) Annual Survey of Hours and Earnings 2004. London: ONS (available at http://www.statistics.gov.uk/STATBASE/

Product.asp?vInk=13291) 
Precision Prospecting (2005) Temporary Workers in UK Agriculture and Horticulture: A Study of Employment Practices in the Agriculture and Horticulture Industry and Colocated Packhouse and Primary Food Sectors. London: DEFRA

RSA Migration Commission (2005) Migration: A Welcome Opportunity. London: Royal Society of Arts (RSA)

Ruhs, M. and Anderson, B. (2006) 'Semi-compliance in the migrant labour market', paper prepared for the British Journal of Industrial Relations (BJIR) conference on 'The political economy of immigration and migrant labour', London, February

Ryan, B. (ed.) 2005 Labour Migration and Employment Rights. London: Institute of Employment Rights

Salt, J. (2005) 'Migration matters', Prospect Magazine, No. 110

Samers, M. (2005) 'The "underground economy", immigration and economic development in the European Union: an agnostic-skeptic perspective', International Journal of Economic Development, Vol. 6, No. 2, pp. 199-272

Spence, L. (2005) Country of Birth and Labour Market Outcomes in London, an Analysis of Labour Force Survey and Census Data. London: Data Management and Analysis Group, Greater London Authority

Sriskandarajah, D., Cooley, L. and Reed, H. (2005) Paying their Way. The Fiscal Contribution of Immigrants in the UK. London: Institute for Public Policy Research (ippr)

TUC (Trade Union Congress) (2003) Overworked, Underpaid and Over Here. London: TUC

Woodbridge, J. (2005) Sizing the Unauthorised (Illegal) Migrant Population in the United Kingdom in 2001. Home Office Online Report 29/05. London: Home Office 


\section{Appendix: Exploratory wage analysis}

This appendix carries out preliminary and exploratory analysis of the determinants of migrant respondents' wages in April 2004. A key variable of interest in this exercise is immigration status and, more specifically, the impact of 'illegal residence' on respondents' wages.

We focus the analysis on the determinants of gross hourly wages of respondents working as employees in hospitality, construction and agriculture in April 2004. After excluding outliers and individuals for whom there are missing data for either the dependent and/or some of the explanatory variables, we are left with a sample of 268 respondents of whom 95 (35 per cent) are illegally resident.

Table A.1 reports the mean values of the dependent and explanatory variables employed in our preliminary wage regression. In addition to immigration status, the explanatory variables include schooling, work experience, gender, proficiency in speaking English, citizenship, sector of employment, occupational category and type of employment contract (written or not).

Table A.1 contains purely descriptive statistics and, therefore, cannot be used to make any statements about the impact of immigration status on respondents' gross hourly wages. What we can see, however, is that, in addition to differences in immigration status, there are also significant differences between the personal characteristics of illegally resident and other respondents. For example, compared to other respondents, illegally resident respondents have: more work experience (both in and outside the UK); a lower share of women; a lower share of respondents speaking only basic or no English; and a higher share of people working in skilled-trades occupations (and a lower share working in elementary occupations). We may expect these differences in the personal characteristics between illegally resident and other respondents to counteract - and potentially offset - any negative impact that illegal residence may have on respondents' earnings. This theoretical conjecture would be in line with the fact that the average gross hourly wages of illegally resident respondents (£6.15) are higher than those of other respondents (£5.70) in our sample.

In order to begin an analysis that isolates the impact of immigration status on wages, Table A.2 reports the results of a preliminary estimation of a simple earnings equation, with a dummy variable indicating illegal residence. Among other things, this assumes that the process of wage determination is the same for illegally resident and other workers. This important assumption will be tested at a later stage of the analysis. The dependent variable in the model below is (the natural logarithm of) gross hourly pay. 
Table A.1 Mean values (and standard deviations) of variables employed in preliminary wage regressions

\begin{tabular}{|c|c|c|c|}
\hline & All & Illegally resident & Other \\
\hline \multirow[t]{2}{*}{ Ln gross hourly wage } & 1.72 & 1.77 & 1.69 \\
\hline & (0.32) & $(0.31)$ & (0.33) \\
\hline \multirow[t]{2}{*}{ Schooling (years) } & 13.29 & 13.42 & 13.23 \\
\hline & (3.32) & (2.97) & (3.51) \\
\hline \multirow[t]{2}{*}{ Work experience in the UK (months) } & 18.10 & 18.91 & 17.65 \\
\hline & $(17.32)$ & $(15.46)$ & (18.29) \\
\hline \multirow[t]{2}{*}{ Work experience outside the UK (months) } & 44.44 & 51.08 & 40.79 \\
\hline & $(64.11)$ & (64.97) & (63.53) \\
\hline Female (\%) & 0.44 & 0.34 & 0.49 \\
\hline Speaks only basic or no English (\%) & 0.28 & 0.26 & 0.30 \\
\hline Czech Republic (\%) & 0.12 & 0.16 & 0.10 \\
\hline Lithuania (\%) & 0.22 & 0.19 & 0.24 \\
\hline Poland (\%) & 0.18 & 0.19 & 0.18 \\
\hline Slovakia (\%) & 0.14 & 0.25 & 0.08 \\
\hline Bulgaria (\%) & 0.08 & 0.01 & 0.11 \\
\hline Ukraine (\%) & 0.26 & 0.20 & 0.29 \\
\hline Hospitality (\%) & 0.54 & 0.52 & 0.55 \\
\hline Construction (\%) & 0.25 & 0.39 & 0.18 \\
\hline Agriculture (\%) & 0.20 & 0.09 & 0.27 \\
\hline Occupation category $1^{\text {a }}(\%)$ & 0.09 & 0.08 & 0.09 \\
\hline Occupation category $2^{\mathrm{b}}(\%)$ & 0.24 & 0.32 & 0.20 \\
\hline Occupation category $3^{c}(\%)$ & 0.67 & 0.60 & 0.71 \\
\hline Written employment contract (\%) & 0.58 & 0.52 & 0.62 \\
\hline Illegally resident (\%) & 0.35 & na & na \\
\hline Number of observations & 268 & 95 & 173 \\
\hline
\end{tabular}

Source: survey interviews with migrants.

a Includes managers and senior officials; professional occupations; associate professional and technical occupations; and administrative and secretarial occupations.

$b$ Includes skilled-trades occupations.

$c$ Includes personal service occupations; sales and customer service occupations; process, plant and machinery operatives; and elementary occupations. 
Table A.2 Preliminary results of estimating a simple earnings equation for all respondents who are employees in hospitality, construction and agriculture in April 2004

\begin{tabular}{|c|c|c|c|c|c|}
\hline \multirow[t]{2}{*}{$\begin{array}{l}\text { Model } \\
\text { Dependent variable }\end{array}$} & \multicolumn{5}{|c|}{$\begin{array}{l}\text { All respondents who describe themselves as 'employees' } \\
\text { Ln gross pay per hour }\end{array}$} \\
\hline & Coefficient & Standard error & $t$ & $P>t$ & Beta \\
\hline \multicolumn{6}{|l|}{ Personal characteristics } \\
\hline Years of schooling & 0.0011 & 0.0054 & 0.21 & 0.837 & 0.1136 \\
\hline $\begin{array}{l}\text { Months of work experience in } \\
\text { the UK }\end{array}$ & 0.0033 & 0.0029 & 1.12 & 0.265 & 0.1748 \\
\hline Squared & -0.0000 & 0.0000 & -0.24 & 0.810 & -0.0353 \\
\hline $\begin{array}{l}\text { Months of work experience } \\
\text { outside the UK }\end{array}$ & 0.0003 & 0.0007 & 0.47 & 0.638 & 0.0665 \\
\hline Squared & -0.0000 & 0.0000 & -0.61 & 0.542 & -0.0853 \\
\hline Female (d) & -0.1331 & 0.0424 & -3.14 & 0.002 & -0.2042 \\
\hline $\begin{array}{l}\text { Speaks only basic or no } \\
\text { English (d) }\end{array}$ & -0.0776 & 0.0409 & -1.90 & 0.059 & -0.1086 \\
\hline $\begin{array}{l}\text { Czech Republic (d; ref. } \\
\text { Ukraine) }\end{array}$ & -0.0384 & 0.0588 & -0.65 & 0.515 & -0.0390 \\
\hline Lithuania (d) & 0.0202 & 0.0494 & 0.41 & 0.682 & 0.0260 \\
\hline Poland (d) & -0.0617 & 0.0538 & -1.15 & 0.253 & -0.0737 \\
\hline Slovakia (d) & 0.0773 & 0.0576 & 1.34 & 0.181 & 0.0834 \\
\hline Bulgaria (d) & 0.0100 & 0.0724 & 0.14 & 0.890 & 0.0081 \\
\hline \multicolumn{6}{|c|}{ Sector of employment (ref. hospitality) } \\
\hline Construction (d) & 0.1894 & 0.0542 & 3.50 & 0.001 & 0.2549 \\
\hline Agriculture $(d)$ & -0.0134 & 0.0515 & -0.26 & 0.795 & -0.0168 \\
\hline \multicolumn{6}{|c|}{ Occupation (ref. occupation category 3$)^{c}$} \\
\hline Occupation category $1^{\mathrm{a}}$ & 0.2122 & 0.0620 & 3.42 & 0.001 & 0.1838 \\
\hline Occupation category $2^{\mathrm{b}}$ & 0.1613 & 0.0460 & 3.51 & 0.001 & 0.2139 \\
\hline $\begin{array}{l}\text { Written employment contract } \\
\text { (d) }\end{array}$ & 0.1421 & 0.0372 & 3.82 & 0.000 & 0.2168 \\
\hline Illegally resident (d) & -0.0062 & 0.0368 & -0.17 & 0.866 & -0.0092 \\
\hline Constant & 1.5422 & 0.0931 & 16.56 & 0.000 & \\
\hline Adjusted $\mathrm{R}^{2}$ : & & & 0.3592 & & \\
\hline Number of observations: & & & 268 & & \\
\hline
\end{tabular}

a Includes managers and senior officials; professional occupations; associate professional and technical occupations; and administrative and secretarial occupations.

$b$ Includes skilled-trades occupations.

$c$ Includes personal service occupations; sales and customer service occupations; process, plant and machinery operatives; and elementary occupations.

d Indicates 'dummy variable'.

The figures in bold indicate significant coefficients. 
As expected, no or low level of English-speaking proficiency and being female are both found to have significant and negative impacts on respondents' wages. The results also suggest that working in construction positively impacts on wage compared to working in hospitality. The estimated coefficients of the two occupation categories are also both significant and the magnitudes of the coefficients are as expected (i.e. respondents in occupations requiring higher skill levels receive higher wages). As could be expected, having a written employment contract also exerts a positive and significant impact on gross hourly wages.

The estimated coefficients of schooling, work experience and work experience squared (in and outside the UK) are all insignificant. Although this needs to be investigated further, one potential explanation for this could be the mismatch between respondents' qualifications and jobs held in the UK (as discussed in this report).

Finally, at this preliminary stage of the analysis, illegal residence - the key variable of interest in this study - is not found to have any significant impact on respondents' gross hourly wages.

\section{Caveats}

As mentioned before, all these estimates are exploratory and preliminary, and should not be interpreted as robust 'findings' of our research. One big caveat is that the sample is small for this type of analysis given the usual variability due to interpersonal heterogeneity and inadequacy of measurement, e.g. of education, skills and features of the job. Furthermore, the model used in this preliminary analysis is based on a number of methodological assumptions, some of which will need to be tested and relaxed in further analysis. For example, there is clearly scope for analysis that explores (among other things):

- the potential interaction of illegal residence with some of the other explanatory variables

- whether or not the process of wage determination is the same for illegally resident and other workers

- the results of analysis that includes data from Wave 2 of the research (i.e. panel data analysis). 
In addition to caveats pertaining to methodology, there are two more fundamental issues that are likely to complicate and potentially distort the analysis of the impact of illegal residence on respondents' wages. First, the usefulness of the discussion of respondents' earnings by immigration status obviously depends on the correct assessment of whether respondents are legally or illegally resident in the UK. Second, the idea that illegal residence may have an impact on migrants' wages rests largely on the assumption that employers know about their workers' immigration status. This may not always be the case in practice (especially when employers are using agency workers). These issues will need to be addressed in more detail in further work. 